\title{
ESP - Data from Restarted Life Tests of Various Silicone Materials - 2011
}

Federal Manufacturing \& Technologies

J. W. Schneider

KCP-613-9016

Distributed December 2011

Approved for public release; distribution is unlimited.

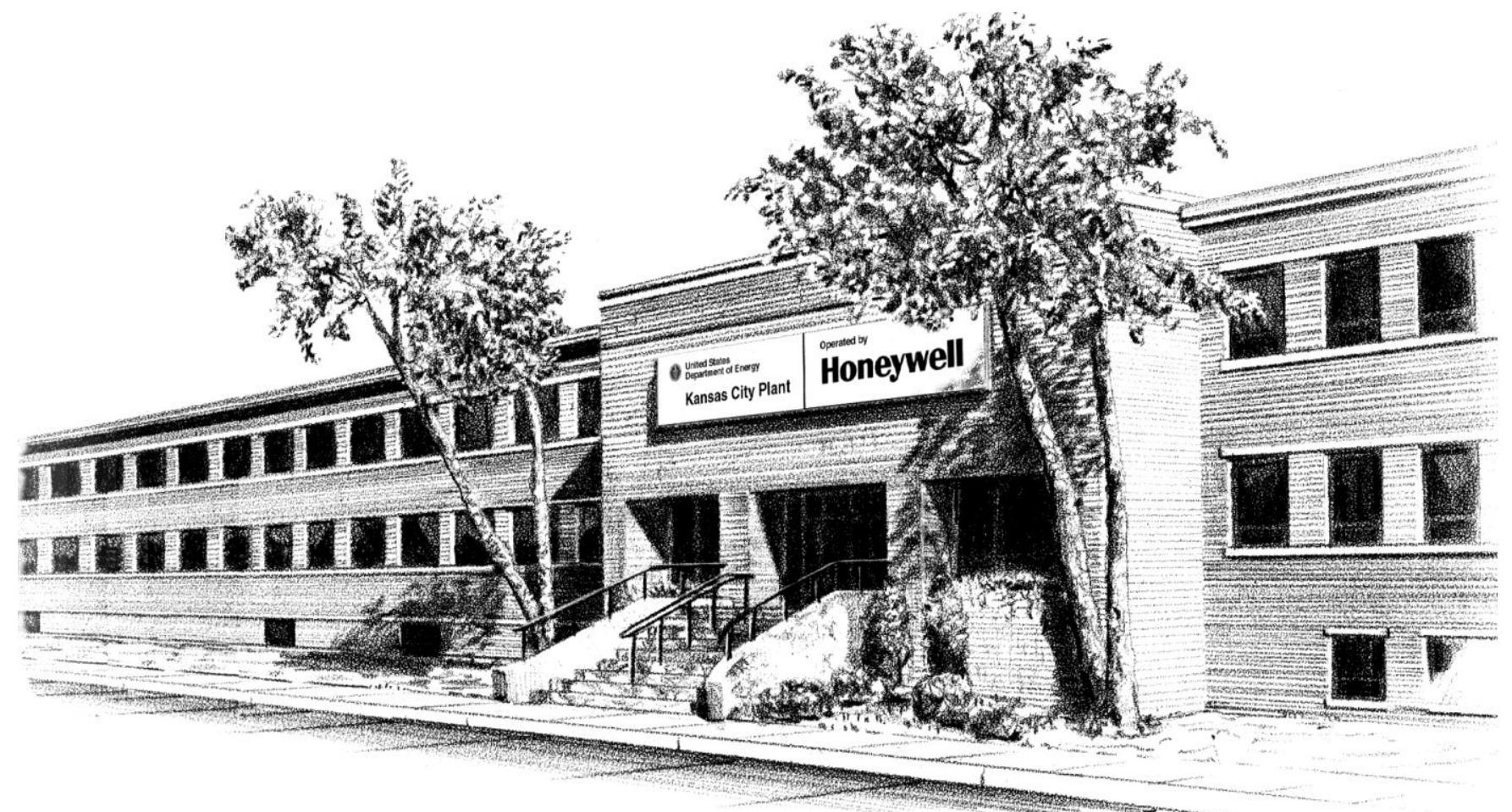

Prepared under prime contract DE-ACO4-01AL66850 for the United States Department of Energy 


\section{DISCLAIMER}

This report was prepared as an account of work sponsored by an agency of the United States Government. Neither the United States Government nor any agency thereof, nor any of their employees, makes any warranty, express or implied, or assumes any legal liability or responsibility for the accuracy, completeness, or usefulness of any information, apparatus, product, or process disclosed, or represents that its use would not infringe privately owned rights. Reference herein to any specific commercial product, process or service by trade names, trademark, manufacturer, or otherwise, does not necessarily constitute or imply its endorsement, recommendation or favoring by the United States Government or any agency thereof. The views and opinions of authors expressed herein do not necessarily state or reflect those of the United States Government or any agency thereof.

All data prepared, analyzed, and presented has been developed in a specific context of work and was prepared for internal evaluation and use pursuant to that work authorized under the reference contract. Reference herein to any specific commercial product, process, or service by trade name, trademark, manufacturer, or otherwise, does not necessarily constitute or imply its endorsement, recommendation, or favoring by the United States Government, any agency thereof, or Honeywell Federal Manufacturing \& Technologies, LLC.

Printed in the United States of America.

This report has been reproduced from the best available copy.

Available to DOE and DOE contractors from the Office of Scientific and Technical Information, P.O. Box 62, Oak Ridge, Tennessee 37831; prices available from (865) 576-8401, FTS 626-8401.

Available to the public from the National Technical Information Service, U.S. Department of Commerce, 5285 Port Royal, Rd., Springfield, Virginia 22161, (703) 487-4650.

A prime contractor with the United States Department of Energy under Contract Number DE-AC04-O1AL66850
Honeywell Federal Manufacturing \& Technologies

P.O. Box 419159

Kansas City, Missouri, 64141-6159 
KCP-613-9016

Distribution Category UC-42

Approved for public release; distribution is unlimited.

ESP - DATA FROM RESTARTED LIFE TESTS OF VARIOUS SILICON MATERIALS - 2011

J. W. Schneider

Published December 2011

Topical Report

J. W. Schneider, Project Leader 



\section{Contents}

Section Page

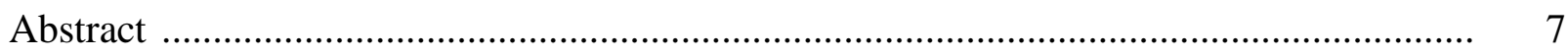

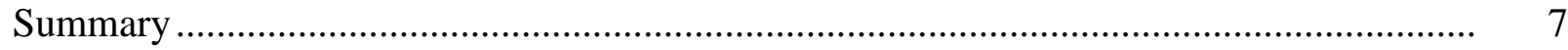

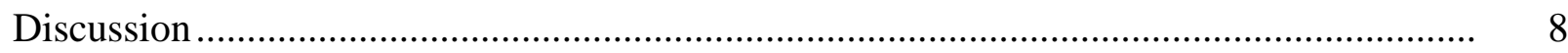

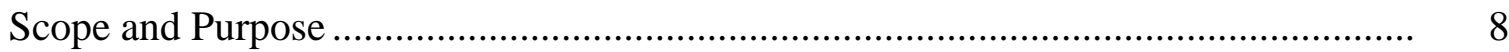

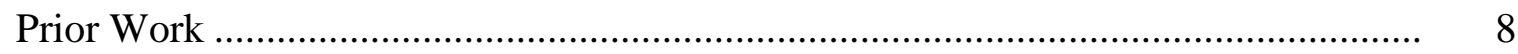

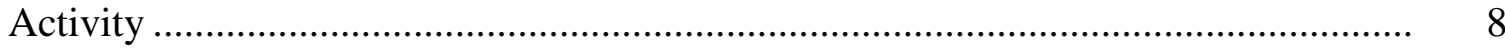

M-9750 at 0.31 Weight Percent Vinyl ....................................................... 10

M-97 at 0.7 Weight Percent Vinyl ....................................................... 11

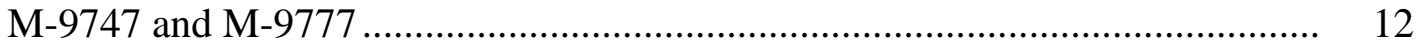

M-9760 and M-9763 ................................................................... 13

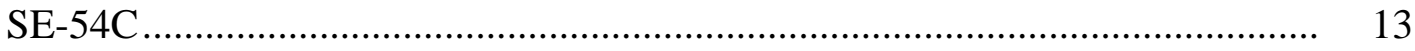

SE-54R (Reload Samples) .............................................................. 13

S-5445 Compounded With "Fine Urea" ................................................ 14

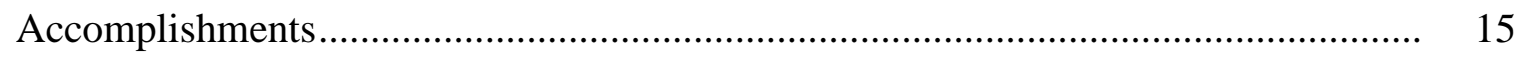

Future Work ......................................................................................... 15

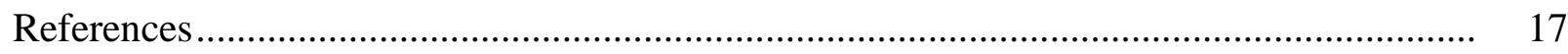

Appendices

A. M-97 at 0.31 Weight Percent Vinyl Charts ................................................ 19

B. M-97 at 0.7 Weight Percent Vinyl Charts .................................................. 27

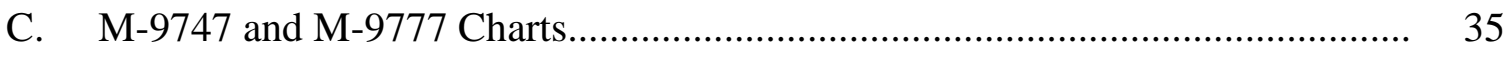

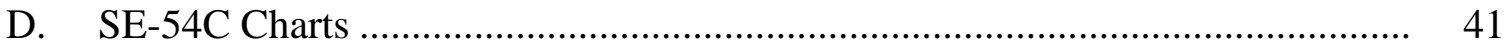


E. SE-54 Reload Charts.................................................................................. 55

F. S-5445 Compounded with "Fine Urea" Charts ……………………………....... 69

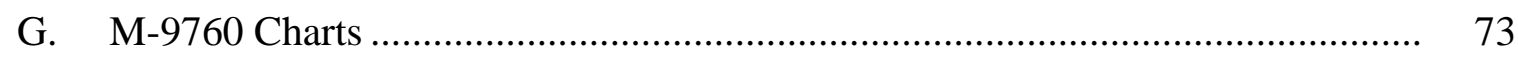

H. M-9763 Charts ........................................................................................ $\quad 79$

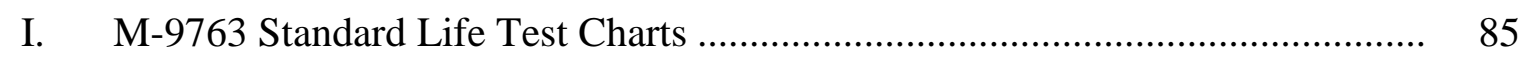

\section{Illustrations}

Number Page

1 Cross Section of Compression Fixture with Specimen Compressed

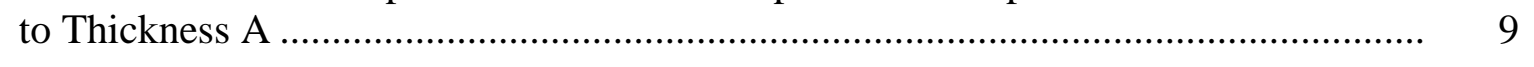

2 Compression Fix ture for Aging of Material ............................................................ 9

\section{Tables}

Number Page

1 Standard Test Slab Results for 0.7 Weight Percent Vinyl M-9755

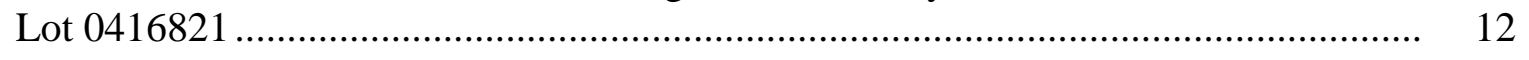

2 Material Formulation Information for M-9760 and M-9763 Samples

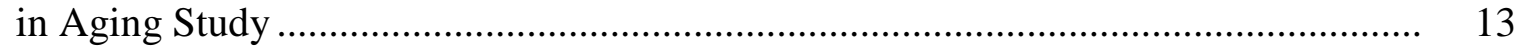




\begin{abstract}
Current funding has allowed the restart of testing of various silicone materials placed in Life Tests or Aging Studies from past efforts. Some of these materials have been in test since 1982, with no testing for approximately 10 years, until funding allowed the restart in FY97. This report will provide data on materials used in production and on experimental materials not used in production. Charts for the various materials at different thickness, compression, and temperature combinations illustrate trends for the load-bearing properties of the materials.
\end{abstract}

\title{
Summary
}

In the past, reimbursable orders initiated Life Testing or Aging Studies of silicone cushion materials to be used on new programs. These orders also provided for subsequent testing for some time period. At the end of this funding period, the samples were left in their test conditions. The Life Test of cellular silicone cushion materials has standard conditions of three thicknesses: $0.045,0.100$, and $0.160 \mathrm{inch}$; three temperatures: room temperature, $50^{\circ} \mathrm{C}$, and $70^{\circ} \mathrm{C}$; and two compressions: $20 \%$ and $35 \%$ for each density/porosity. Funding has been provided for the restart of testing. Some of these samples have not been tested for approximately 10 years. The cellular silicone materials being tested now are based on the M-97 and SE-54 silicone polymers.

Samples of SE-54 silicone polymer, compounded with regular and densified CAB-O-SIL, are included in these tests. Samples of cellular silicone material based on SE-54 silicone polymer using "fine urea" [smaller prill size than used for existing reserve] are also in test. In addition, M-97 silicone polymer at two different methylvinylsiloxane (vinyl) contents, 0.7 and 0.31 weight percent, and compounded into cellular silicone, are in test. The SE-54 based cellular silicone was used in one program, while the M-97 at 0.31 weight percent vinyl was initially used in another program and later as a replacement in a third program. Cellular silicone material based on the 0.7 weight percent vinyl was not used in production. These samples were kept in test for comparison with the 0.31 weight percent samples. Development activities involving "fine urea" were based on the SE-54 silicone polymer with currently no production application. Also in test are high porosity materials based on the M-97 silicone polymer, M-9760 and M-9763. These two materials have been incorporated into production.

The M-9777 samples at elevated temperatures continue to exhibit less and less load bearing properties. The M-9777 samples at 0.160 inch at $35 \%$ compression and stored at $50^{\circ} \mathrm{C}$ had only one sample with a Percent Load Retention (PLR) value. The remaining samples, as well as the M-9747 samples, will continue to be tested at a minimum of once a year. 


\section{Discussion}

\section{Scope and Purpose}

Life Test or Aging Study is a Honeywell Federal Manufacturing \& Technologies (FM\&T) project requested by Lawrence Livermore National Laboratory (LLNL) using reimbursable orders for the collection of data on the testing of silicone materials. Silicone cushions fill gaps, compensate for manufacturing tolerances, and allow for thermal expansion of components. At the end of the test periods covered by the reimbursable orders, the samples were left in their test conditions. The purpose of this project is to fund additional collection of information about the long-term stress relaxation of the silicone cushion material under load.

\section{Prior Work}

The following silicone materials were reported on at various times as part of the original reimbursable orders:

- M-9750 at 0.31 weight percent vinyl ${ }^{1}$

- $\quad$ M-97 at 0.7 weight percent vinyl ${ }^{2}$

- $\quad \mathrm{SE}-54 \mathrm{C}^{3}$

- $\quad \mathrm{SE}-54 \mathrm{R}^{4}$

\section{Activity}

The Life Test of cellular silicone cushion materials has standard conditions of three thicknesses: $0.045,0.100$, and $0.160 \mathrm{inch}$; three temperatures: room temperature $(\mathrm{RT}), 50^{\circ} \mathrm{C}$, and $70^{\circ} \mathrm{C}$; and two compressions: $20 \%$ and $35 \%$, for each density/porosity.

The testing of cushion samples over long periods of time has evolved into each sample being stored in an individual fixture. This allows the tester to be calibrated over time and does not tie up the tester. The fixture is capable of applying specific compressions for a given thickness. The top and bottom (cup) of the fixtures are all the same, but a removable plug detail is special for each thickness/compression combination (see Figure 1).

Initially the sample is placed in the cup of the fixture, and the top is assembled (see Figure 2). At that time, there is a gap between the top and the cup rim, because the cushion is not compressed. The tester applies force to the fixture, compressing the cushion until the fixture is closed. At that time, there is a change in the direction for the load deflection curve due to the change from loading on the cushion to loading on the compression fixture. This point of change is determined manually. 


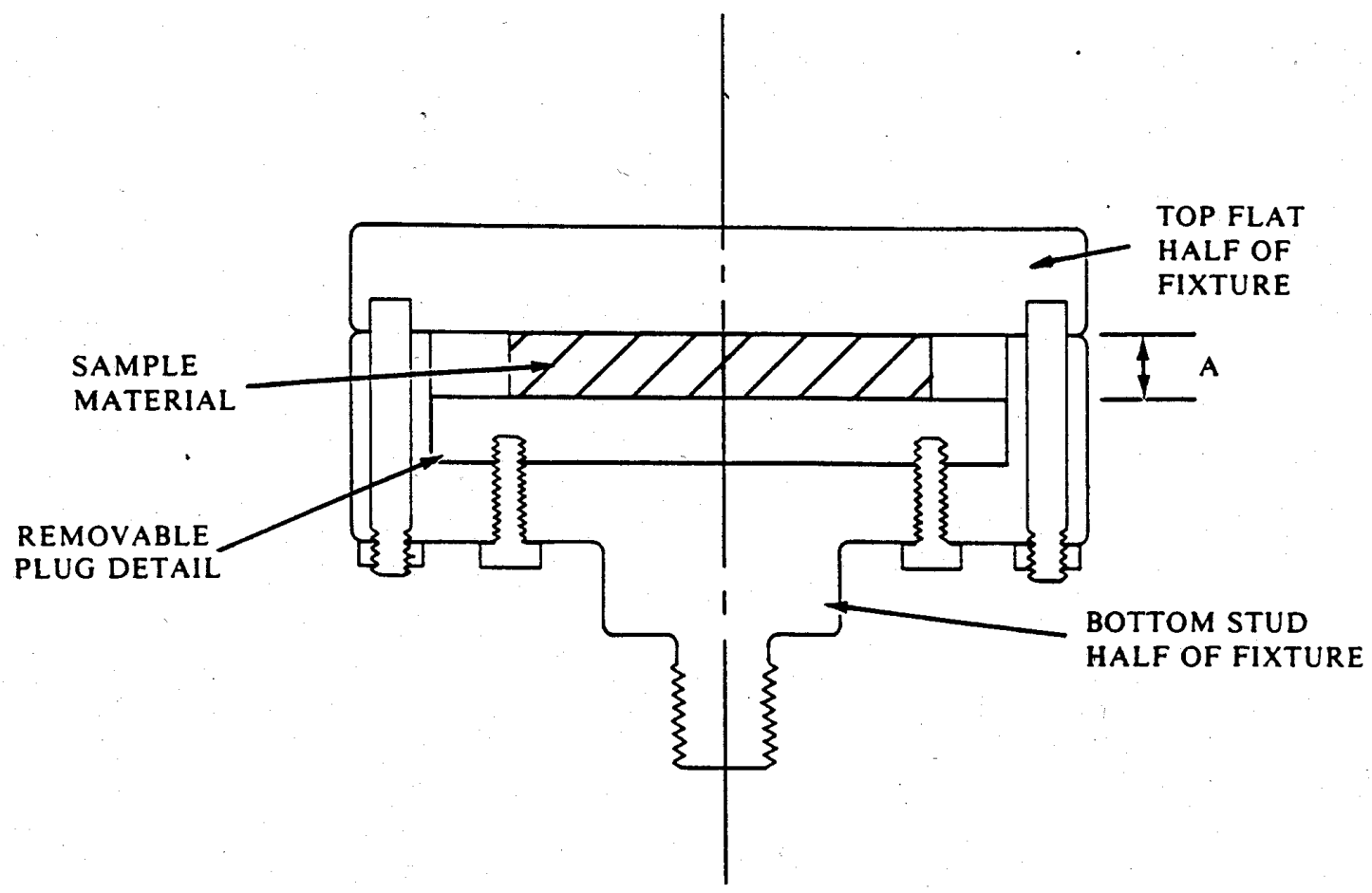

Figure 1. Cross Section of Compression Fixture with Specimen Compressed to Thickness A

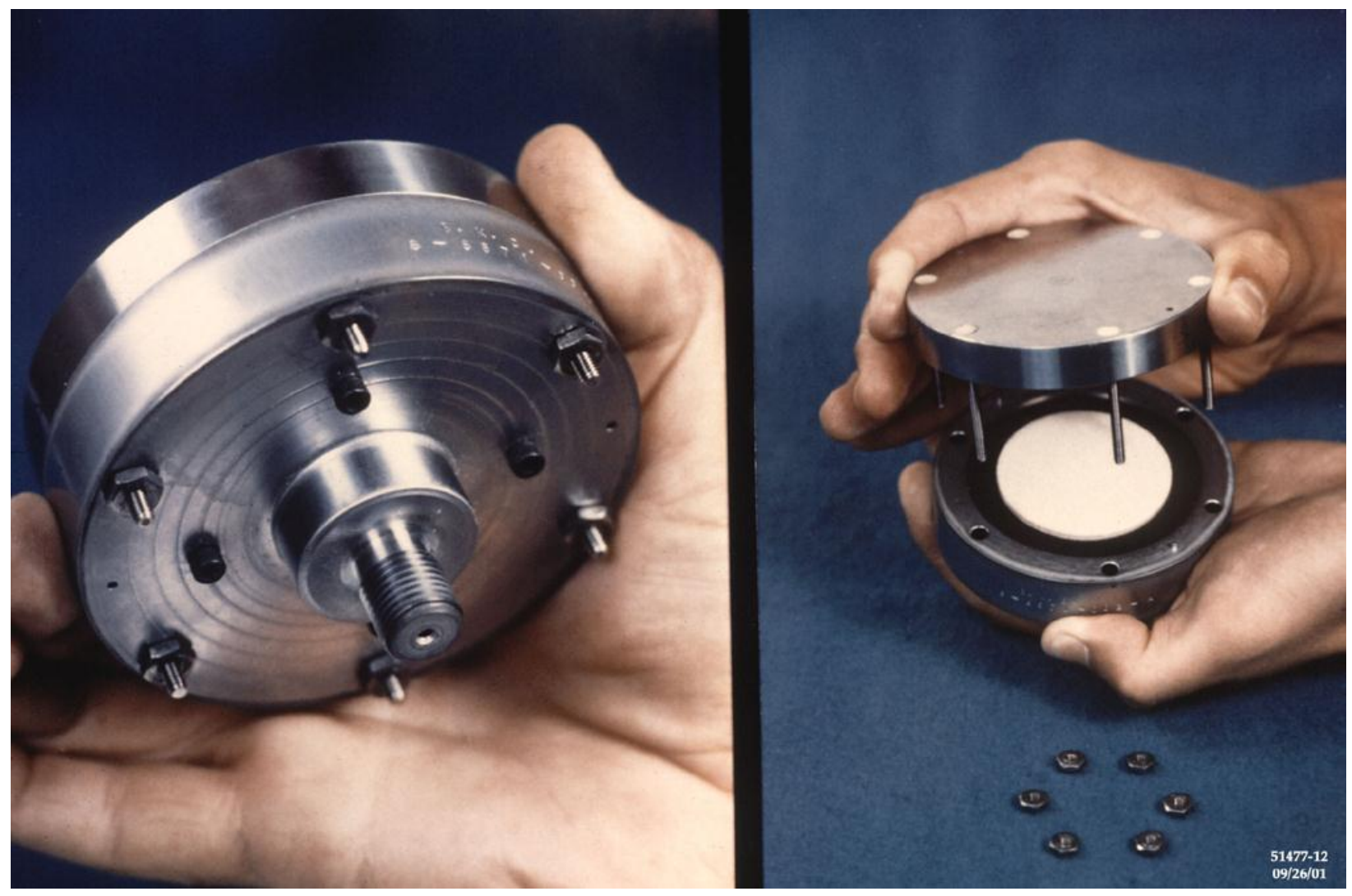

Figure 2. Compression Fixture for Aging of Material 
Later testing determines a new point of change, which is less than the original, from cushion loading to fixture loading; again determined manually. This new closure force divided by the initial closure force yields a PLR value. The average PLR for the thickness and compression combinations and the three temperature conditions are plotted against time in assembly. This illustrates the trend of the load-bearing properties of the cushion material over time, with respect to the effect of temperature.

The procedure used to obtain these data is to take the elevated temperature aging fixtures out of the ovens in the morning and allow them to cool. The fixtures are tested and, at the end of the day, placed back into their respective ovens. If for some reason all of the fixtures are not tested, they are returned to the ovens and removed again the next morning.

\section{M-9750 at 0.31 Weight Percent Vinyl}

The M-97 silicone polymer is synthesized using " $N$ " catalyst, tetramethylammonium silanolate, and a vinyl end-blocker VB, thus "M-97 NVB." The resulting 0.31 weight percent methylvinylsiloxane, or vinyl polymer, is a blend of low and high vinyl materials synthesized by McGhan-NuSil for this study. McGhan-NuSil is now referred to as NuSil Technology. The low vinyl polymer, LVM-97, is targeted for 0.2 weight percent vinyl, and was Lot 0322841 . The LVM-97 is a random polymer using 90.8 weight percent dimethylsiloxane, 9.0 weight percent diphenylsiloxane (manufactured by Rhone-Poulenc), and 0.2 weight percent methylvinylsiloxane. The high vinyl polymer, HVM-97, is targeted for 0.7 weight percent vinyl and was Lot 0319841 . The HVM-97 is also a random polymer using 90.3 weight percent dimethylsiloxane, 9.0 weight percent diphenylsiloxane (manufactured by Rhone-Poulenc), and 0.7 weight percent methylvinylsiloxane. These polymers were checked at LLNL, and the low and high vinyl polymers were determined to be 0.198 and 0.698 weight percent vinyl, respectively. These two lots of M-97 NVB were the first two batches heat-stripped by the vendor in the reactor.

The actual vinyl content being known, the polymers were blended and compounded to yield M-9787 silica reinforced base (Lot 0426841) targeted for 0.31 weight percent vinyl. The compounding consisted of the addition of CAB-O-SIL, Hi-Sil, and Y-1587 processing aid. The material was bin aged for a minimum of 28 days followed by a heat strip of 18 hours at $350^{\circ} \mathrm{F}$. The average weight loss for the heat strip was 2.5 percent. After the heat strip, a sample of reinforced base was tested and determined to have a vinyl content of 0.313 weight percent. The name "M-9787" refers to silica reinforced material using M-97 polymer blended to 0.31 weight percent vinyl and initially used in production. 
The name "M-9750" refers to cellular silicone material based on M-97 silicone polymer and a porosity of $50 \%$. The M-9750 at 0.31 weight percent vinyl cellular silicone material (Lot 0627841) was compounded using 497-M catalyst (t-butyl per 2-methyl benzoate in mineral spirits, Lot 0509-069A, Bottle 4) and urea as the leachable filler. The amount of 497-M catalyst used was determined by the equation

$$
\mathrm{pph}=\frac{(\mathrm{Vi})(\text { Catalyst Constant })}{0.7}
$$

where: Vi - weight percent vinyl of the base,

and Catalyst Constant -1.0658 for 497-M catalyst,

so the amount of $497-\mathrm{M}$ required for a base of 0.31 weight percent vinyl $=0.47 \mathrm{pph}$.

The final compounding ratio was 46.0 pounds of catalyzed base to 58.0 pounds of urea.

Standard 12-inch x 12-inch by 0.160 -inch thick test slabs were molded from this material. The material exhibited the following:

- Loads of approximately 21.9 psi at $30 \%$ compression

- Compression set of approximately $9.5 \%$

- Apparent density of $0.579 \mathrm{~g} / \mathrm{cm}^{3}$ yielding a porosity of $50.7 \%$

- A linear shrinkage of $3.1 \%$

The test slabs were molded for 120 minutes at $250^{\circ} \mathrm{F}$, leached, and oven cured for 24 hours at $400^{\circ} \mathrm{F}$.

The test for the M-9750 material at 0.31 weight percent vinyl was started in February 1985.

\section{M-97 at 0.7 Weight Percent Vinyl}

The M-97 0.7 weight percent vinyl material is NuSil's random terpolymer synthesized using 90.3 weight percent dimethylsiloxane, 9.0 weight percent diphenylsiloxane, and 0.7 weight percent methylvinylsiloxane. The full name of the polymer is M-97 KVB. The catalyst used for the polymerization reaction for this lot was " $\mathrm{K}$ " catalyst, potassium silanolate. The "VB" refers to the polymer chain being vinyl end blocked. The vendor did not heat strip this polymer.

The polymer was compounded to silica reinforced base (Lot 1208811) using CAB-O-SIL, Hi-SIL, and Y-1587 processing aid. Following a 28-day minimum bin age, the reinforced base was heat stripped for 18 hours at $350^{\circ} \mathrm{F}$. The average weight loss was 7.9 percent. The M-9755 (Lot 0416821) cellular compound was formulated using 497 XL catalyst, a t-butyl per-2methylbenzoate on calcium carbonate (Lot 509-001Z) at 2 pph, and urea as the leachable filler. 
The final compounding ratio for the cellular silicone material was 40.0 pounds of catalyzed base to 60.0 pounds of urea. The name "M-9755" refers to cellular silicone material based on M-97 silicone polymer and a porosity of $55 \%$.

Standard 12-inch x 12-inch by 0.160 -inch thick test slabs were molded from this material and tested. Results are shown in Table 1 . The test slabs were molded for 120 minutes at $250^{\circ} \mathrm{F}$ with a 24-hour leaching operation followed by a 16-hour minimum air cure. The slabs were oven cured for 4 hours at $300^{\circ} \mathrm{F}$, followed by an additional 24 hours at $480^{\circ} \mathrm{F}$.

Table 1. Standard Test Slab Results for 0.7 Weight Percent Vinyl M-9755 Lot 0416821

\begin{tabular}{ll}
\hline Test & Result__ \\
\hline Load at 30\% Deflection & $27.0 \mathrm{psi}$ \\
Compression Set & $4.7 \%$ \\
Apparent Density & $0.53 \mathrm{~g} / \mathrm{cm}^{3}$ \\
Linear Shrinkage & $3.9 \%$
\end{tabular}

The test for the M-97 cellular silicone material at 0.7 weight percent vinyl was started in November 1982.

\section{$\underline{M-9747 \text { and M-9777 }}$}

As previously defined, the names "M-9747" and "M-9777" indicate the cellular silicone material is based on the NuSil Technology M-97 silicone polymers, and 47 and 77 refer to the porosity. The M-9747, M-9777, and M-9757 cellular silicone materials were developed as replacement materials for B-3223, B-3233, and B-3260, respectively, which were based on the RG-97 silicone polymer produced by Rhone Poulenc. ${ }^{5}$

This test is a reduced version of the normal Life Test used to evaluate materials, because so much data was already available at the $50 \%$ porosity level for the M-97 silicone polymer. This reduced test scheme consists of two thicknesses, 0.045 and $0.160 \mathrm{inch}$; three temperatures, RT, $50^{\circ} \mathrm{C}$, and $70^{\circ} \mathrm{C}$; and only $35 \%$ compression for each material. Three replicas are still used at each condition for a total of 36 fixtures. Only the M-9747 (Lot 0118932) and M-9777 (Lot 0202931) were placed in test. Testing of these two types of material was started in April 1993.

As previously reported ${ }^{6}$, the M-9777 samples at both thicknesses, 0.045 and 0.160 inch, and at test conditions of $35 \%$ compression and $70^{\circ} \mathrm{C}$, have no PLR values. The M-9777 samples at 0.160 inch at $35 \%$ compression and stored at $50^{\circ} \mathrm{C}$ had only one sample with a PLR value. The room temperature samples of the M-9777 continue to perform well. The remaining samples as well as the M-9747 samples will continue to be tested at a minimum of once a year. 


\section{M-9760 and M-9763}

As previously defined, the names "M-9760" and "M-9763" indicate the material is based on the NuSil Technology M-97 silicone polymers, with 60 and 63 referring to the porosity of the cellular silicone. The M-9760 and M-9763 cellular silicone materials were developed to meet the needs of a new application. Compounding information for these two materials is in Table 2.

LLNL wanted a different test scheme for evaluating the aging of the M-9760 and M-9763 materials. For each porosity, there are still the three temperatures and three replicas, but there are three compressions $(20 \%, 35 \%$, and $50 \%)$ and only one thickness $(0.040$ inch). This results in a test scheme of 27 fixtures each for the two materials. Testing of these two materials was started in approximately October 1998.

To ensure comparability of these porosities with other materials already in test, samples of M-9763 were also placed in a reduced version of the Standard Life Test. This slightly reduced test scheme consists of only two thicknesses, 0.045 and 0.160 inch; the standard three temperatures, $\mathrm{RT}, 50^{\circ} \mathrm{C}$, and $70^{\circ} \mathrm{C}$; and standard two compressions, $20 \%$ and $35 \%$. Three replicas are still used at each condition for a total of 36 fixtures. Testing of the M-9763 material in this format was started in November 1998.

Table 2. Material Formulation Information for M-9760 and M-9763 Samples in Aging Study

\begin{tabular}{|l|l|l|l|l|l|l|l|l|}
\hline Material & Lot \# & $\begin{array}{l}\text { Catalyst } \\
\text { Trigonox 97-C75 }\end{array}$ & $\begin{array}{l}\text { Silica } \\
\text { Reinforced } \\
\text { Base Lot \# }\end{array}$ & $\begin{array}{l}\text { LVM-97 } \\
\text { Lot \# }\end{array}$ & $\begin{array}{l}\text { HVM-97 } \\
\text { Lot \# }\end{array}$ & $\begin{array}{l}\text { CAB-O-SIL } \\
\text { Lot \# }\end{array}$ & $\begin{array}{l}\text { Hi-Sil } \\
\text { Lot \# }\end{array}$ & $\begin{array}{l}\text { Y-1587 } \\
\text { Process Aid } \\
\text { Lot \# }\end{array}$ \\
\hline M-9760 & 0901981 & $1420692 A 06$ & 0619982 & 0610971 & 0908931 & IA-268 & D-10-7 & 2155 SX081791 \\
\hline & & & & & & & & \\
\hline M-9763 & 0805981 & 1406894 A06 & 0618981 & 0610971 & 0908931 & IA-268 & D-10-7 & $2155 S X 081791$ \\
\hline
\end{tabular}

\section{$\underline{\text { SE-54C }}$}

A total of 108 SE-54C specimens are in test. The SE-54C material consists of General Electric (GE) SE-54 silicone polymer compounded with densified CAB-O-SIL and SE 4210U processing aid. After bin aging ( 7 days minimum), the cellular compound was made by the addition of the catalyst (497XL) and urea. The material compounded was 4003040 (S-5445) and 4003042 (S-5455) having lot numbers 0131831 and 0131832, respectively. The name "S-5445" referring to the cellular silicone material is based on SE-54 silicone polymer and $45 \%$ porosity. The name "S-5455" is similar, but refers to 55\% porosity. The S-5445 and S-5455 cellular silicone materials were compounded to yield $45.0 \%$ minimum and $55.0 \pm 1.5 \%$ porosity, respectively.

Samples of the S-5445 and S-5455 were placed in test July 1983.

\section{$\underline{\text { SE-54R (Reload Samples) }}$}

The SE-54R material is defined as the original SE-54 Life Test samples of GE's silicone polymer compounded with $\mathrm{CAB}-\mathrm{O}-\mathrm{SIL}$ and processing aid. After bin aging, the cellular silicone 
materials, S-5445 and S-5455, were compounded using catalyst (497XL) and urea. Again, the name refers to the polymer on which the material is based and the resulting target porosity.

The samples were originally tested for 719 days, then removed from the aging fixtures on approximately March 26, 1984. The samples were reloaded into their original fixtures starting September 11, 1984. The concept of "time" for these fixtures is the sum of the initial test days plus the number of days of reload. The calculation for the PLR is the current force to close the fixture divided by the initial force from April 1982 to close the fixture.

\section{$\underline{\text { S-5445 Compounded with "Fine Urea" }}$}

As previously defined, the name "S-5445" indicates the cellular silicone material is based on the GE SE-54 silicone polymer, and the 45 refers to the porosity percentage. The urea used in this batch of material (Lot 0216901) was finer or smaller than the normal reserve production size. Normal urea size is 25 to 40 mesh, 0.0278- to 0.0165-inch diameter. Sherritt Gordon, the Canadian supplier of the urea at that time, was willing and able to provide urea at a smaller prill size. The urea used for this lot was in the range of 40 to 60 mesh, 0.0165- to 0.0098-inch diameter. This fine urea was used as a direct substitution into the reserve formulation of S-5445 material. The only change needed was for the mixer ram float time, which was increased from 1 to 2 minutes. This change was the result of the initial lot of material, with the fine urea, which had unmixed areas present.

The interest in finer urea is that it allows the molding of thinner cushions. The thinnest the reserve-size urea will allow is approximately $0.040 \mathrm{inch}$. Theoretically, this thickness would result in approximately 0.005 -inch of gum on either side of the cell. Parts that taper thinner than 0.040 inch are molded by design to be thicker past the waist or trim height. This allows the part to have a better chance not to tear.

Attempting to mold thinner than 0.040-inch thickness with current reserve urea results in crushing the urea; this could damage the molding surfaces and parts that have very large cell size due to the crushed urea. Flat slabs of the S-5445 with fine urea were molded at 0.020 and 0.030inch thickness with acceptable appearance and stayed together. A contoured part in the 0.040-inch range was also molded with the finer urea, and the part was acceptable for load and visually looked thicker because of the smaller cells and appearance of more gum.

The testing of this material was also a reduced version of the normal Life Test used to evaluate materials, because so much data was already available at the $45 \%$ porosity level for SE-54 polymer. This reduced test scheme consists of two thicknesses: 0.045 and 0.160 inch; three temperatures: RT, $50^{\circ} \mathrm{C}$, and $70^{\circ} \mathrm{C}$; and only $35 \%$ compression. Three replicas are still used at each condition for a total of 18 fixtures.

Testing of this material was started in April 1990. 


\section{Accomplishments}

Renewed testing of existing silicone samples representative of materials employed in production and development has been provided by program funding. This report contains updated charts of the PLR trends for the M-97 and SE-54 based materials.

\section{Future Work}

The materials will continue to be tested a minimum of once a year, with associated reports. 


\section{References}

${ }^{1}$ J. W. Schneider, M-97 0.31 Weight Percent Vinyl, Life Test Results for 272 Days (Topical Report). UNCLASSIFIED. Honeywell Federal Manufacturing \& Technologies (FM\&T): BDX-613-3466, April 1986.

${ }^{2}$ J. W. Schneider, M-97 0.7 Weight Percent Vinyl, Life Test Results for 1,092 Days (Topical Report). UNCLASSIFIED. Honeywell FM\&T: BDX-613-3460, April 1986.

${ }^{3}$ J. W. Schneider, SE-54C Life Test Results for 912 Days (Topical Report). UNCLASSIFIED. Honeywell FM\&T: BDX-613-3495, May 1986.

${ }^{4}$ Internal Memorandum, "2,180 Days of Aging.” J. W. Schneider to Distribution, Honeywell FM\&T, August 3, 1989.

5J. W. Schneider, Replacement of RG-97 with M-97 and the Subsequent Characterization of the New Cellular Silicone Materials (Topical Report). UNCLASSIFIED. Honeywell FM\&T: BDX-613-5225, June 1993.

${ }^{6}$ J. W. Schneider, ESP - Data from Restarted Life Tests of Various Silicone Materials - 2010 (Topical Report). UNCLASSIFIED. Honeywell FM\&T: KCP-613-804, September 2010. 


\section{Appendix A}

\section{M-97 at 0.31 Weight Percent Vinyl Charts}




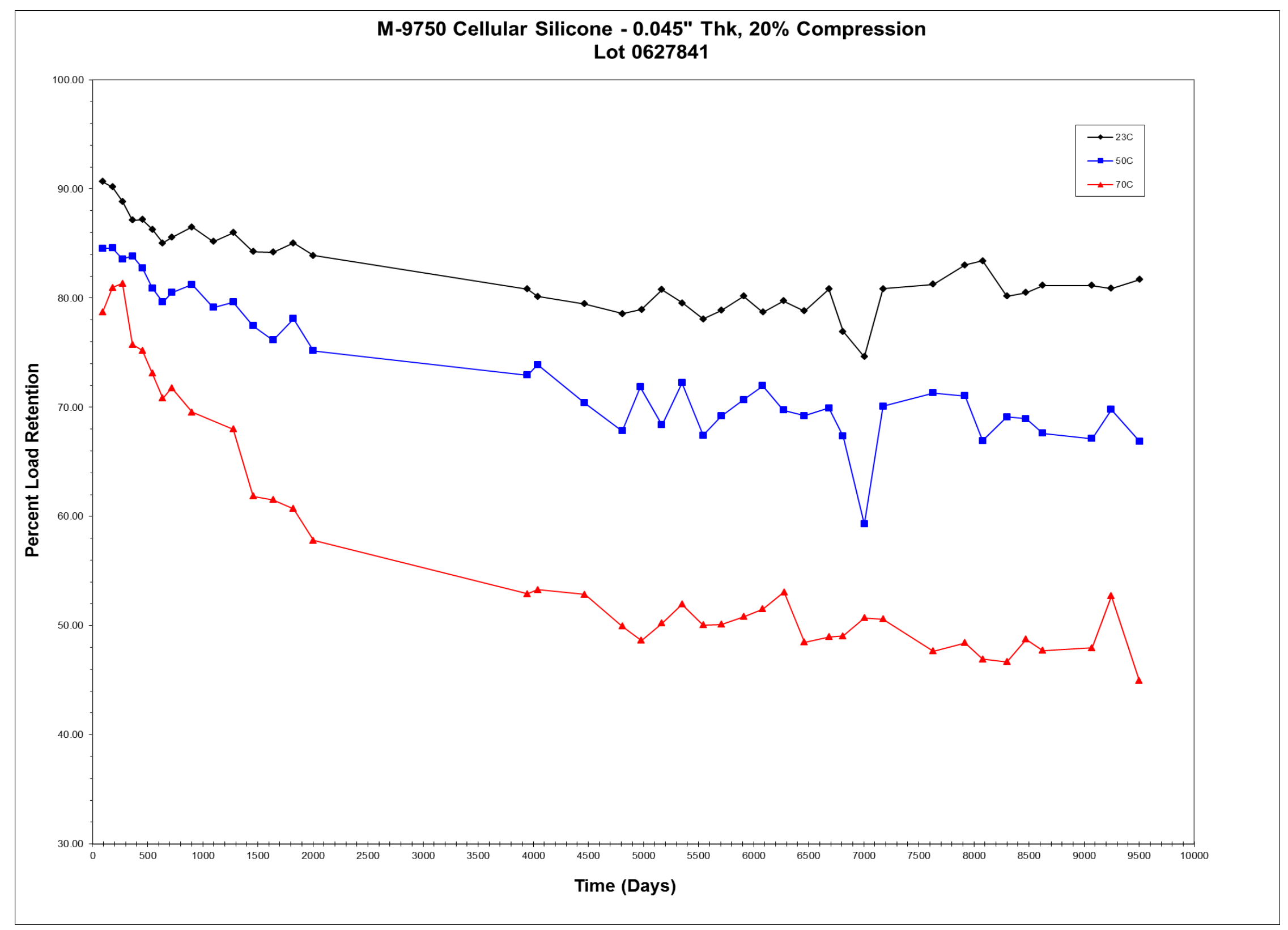




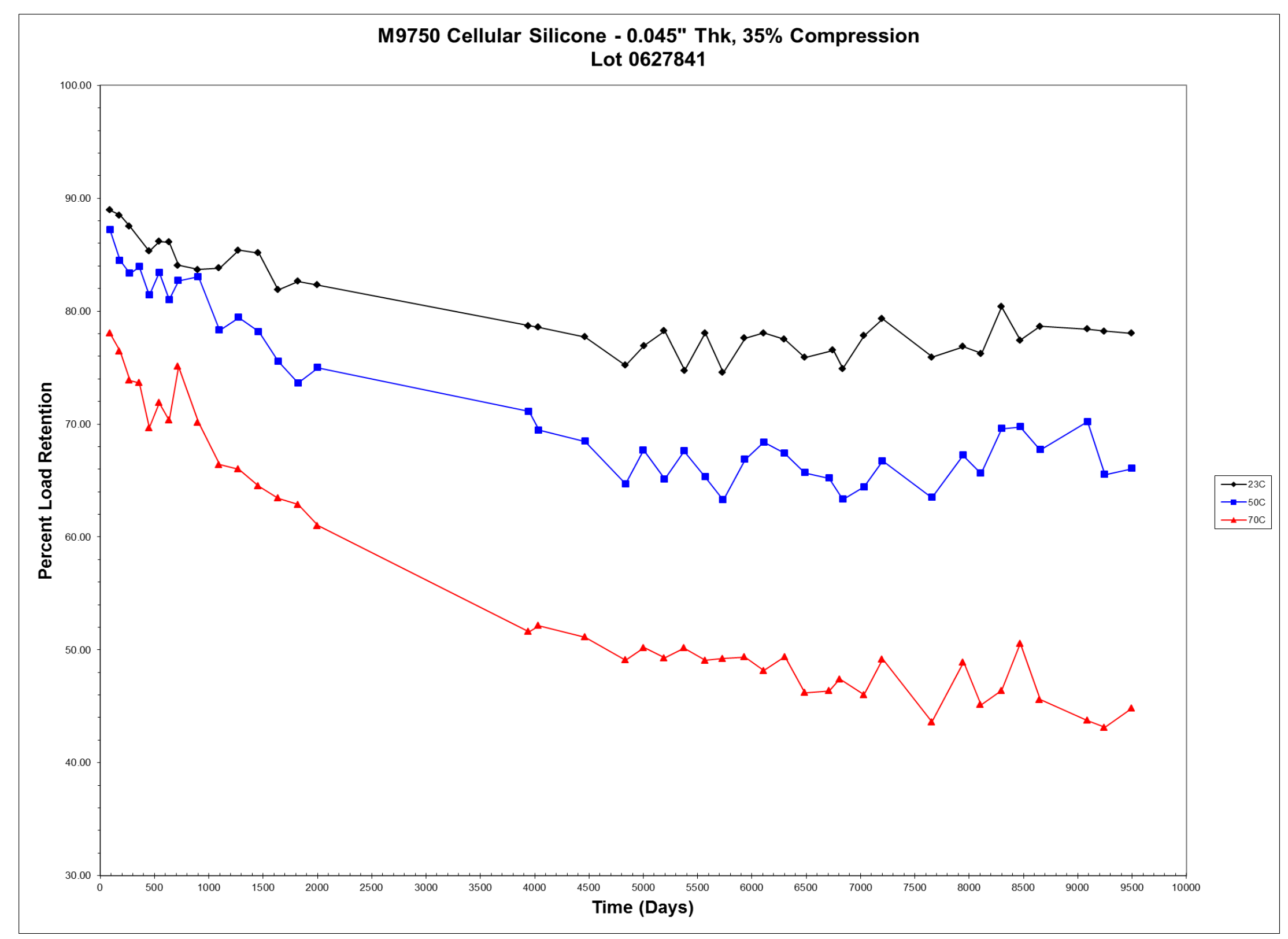




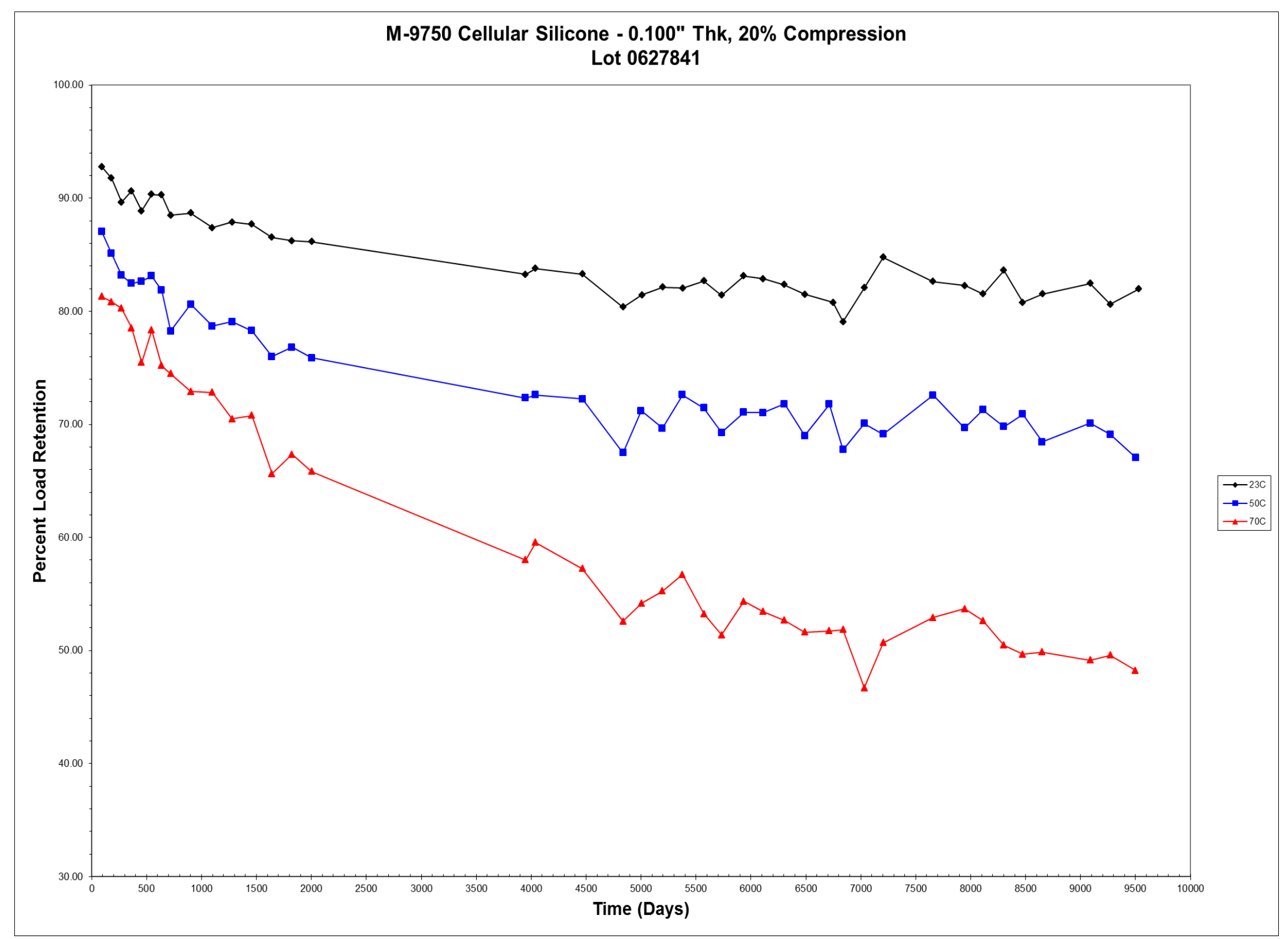




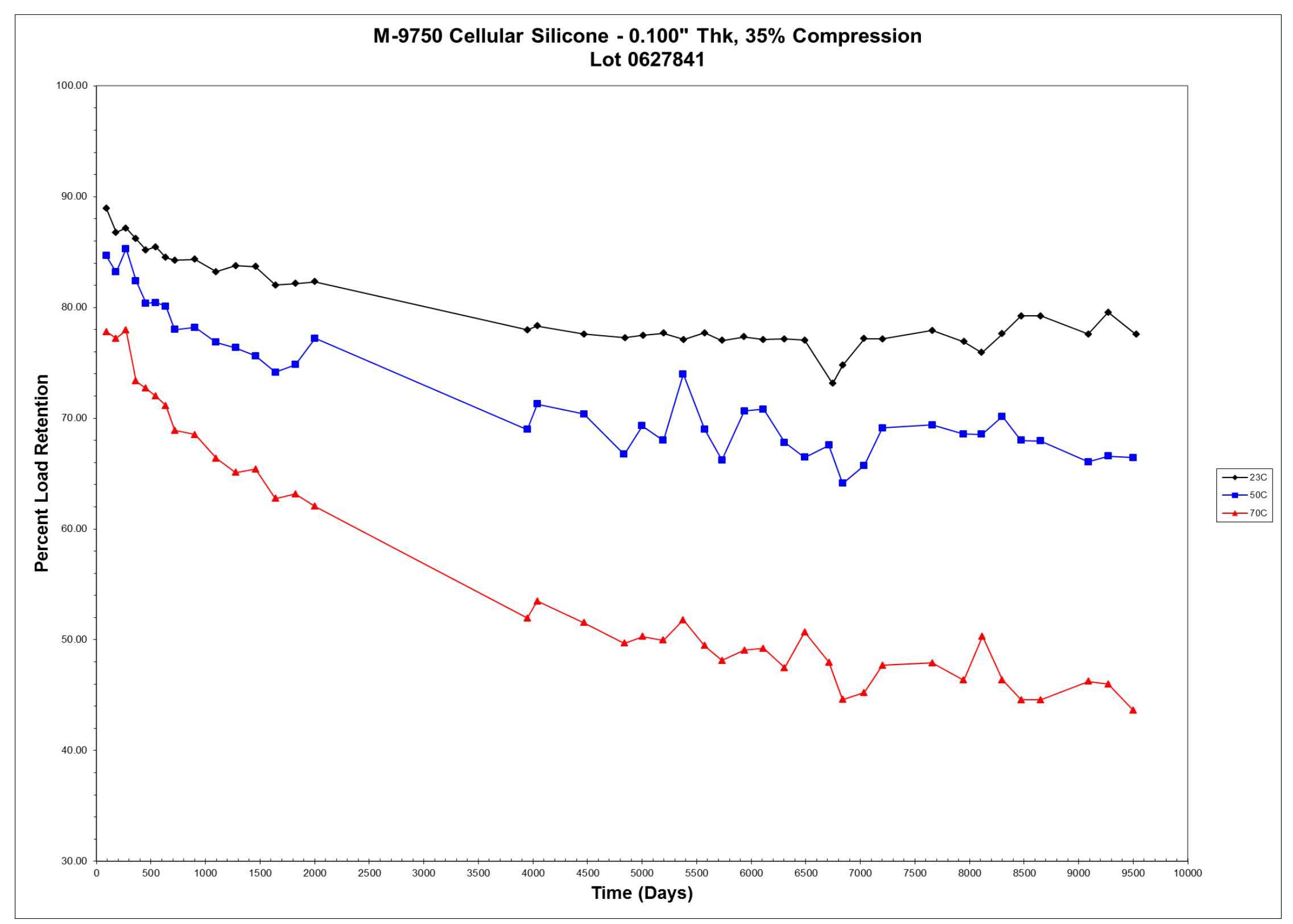




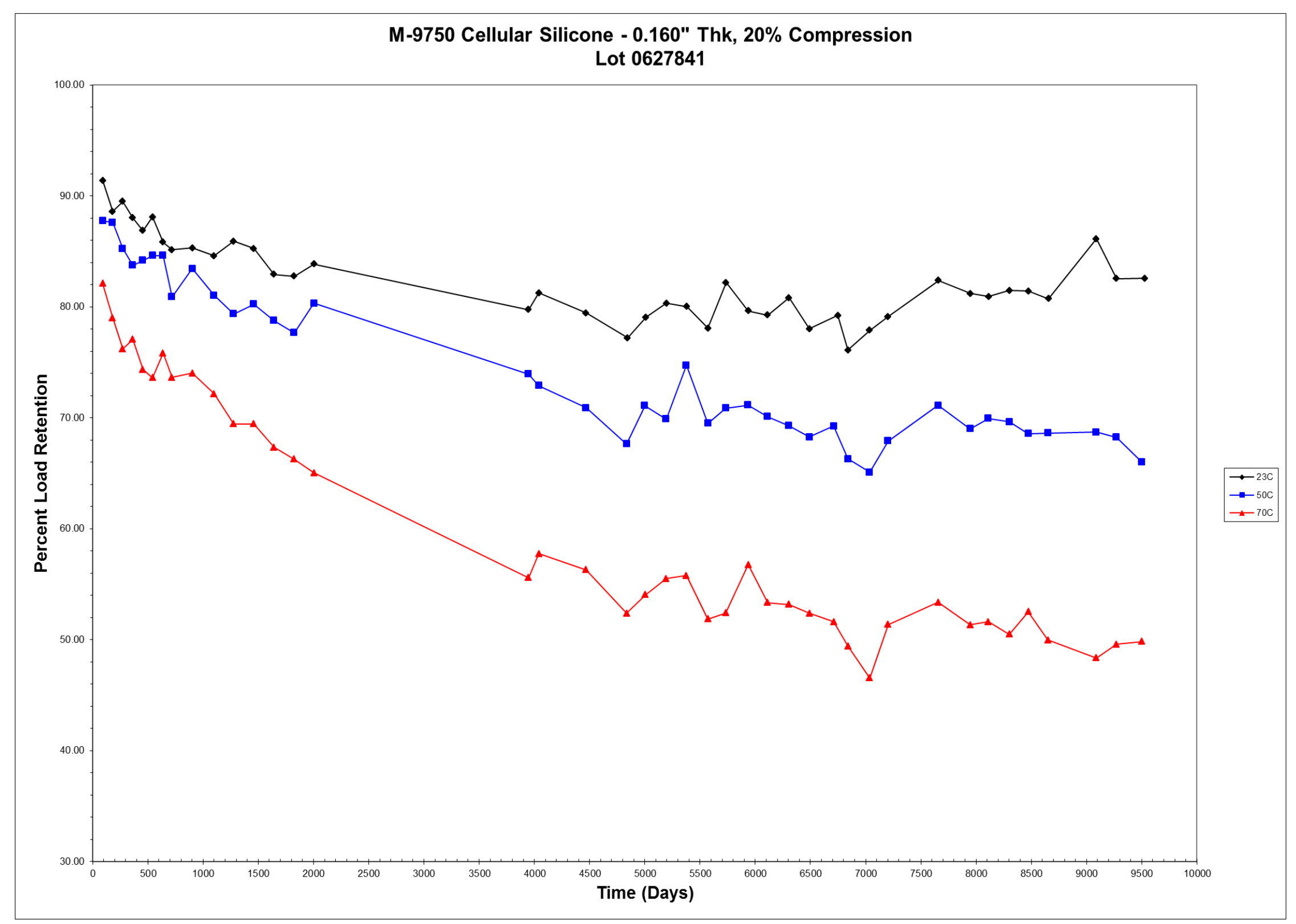




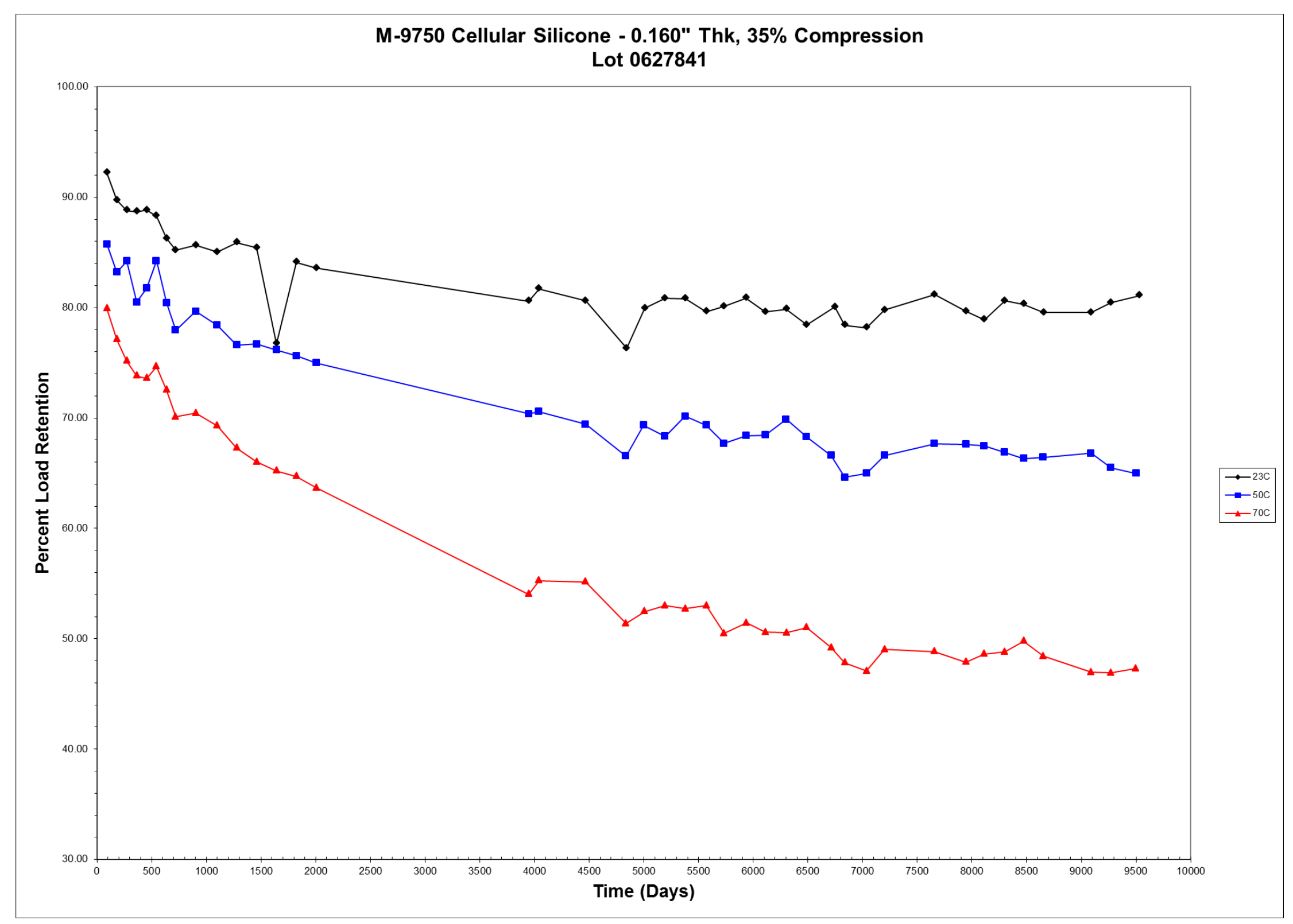




\section{Appendix B}

\section{M-97 at 0.7 Weight Percent Vinyl Charts}


M-97 at $0.7 \mathrm{wt} \%$ Vinyl, Lot 0416821

$0.045 "$ Thick, $0.53 \mathrm{~g} / \mathrm{cc}$ and $20 \%$ Compression

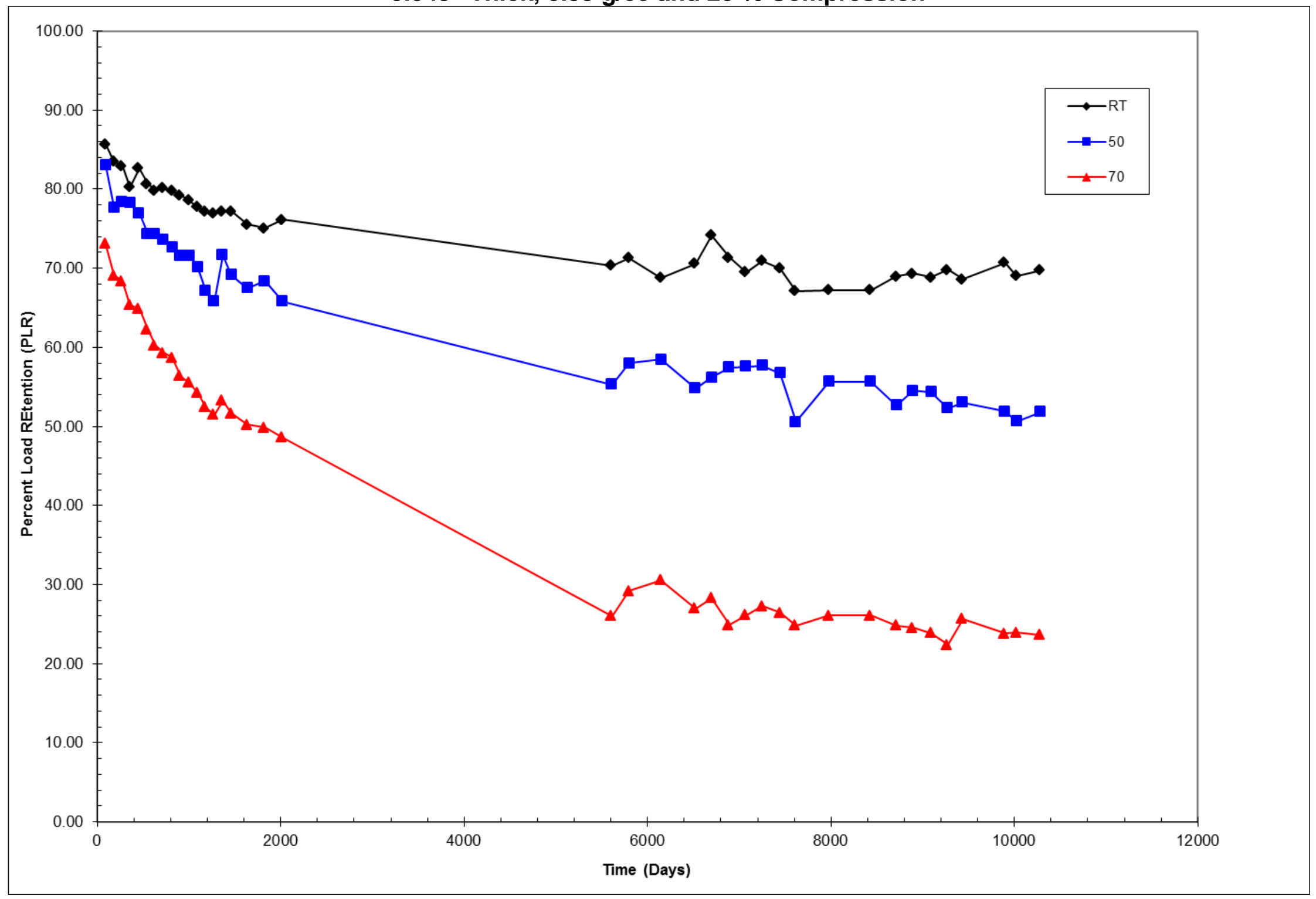


M-97 at $0.7 \mathrm{wt} \%$ Vinyl, Lot 0416821

0.045 " Thick, $0.53 \mathrm{~g} / \mathrm{cc}$ and $35 \%$ Compression

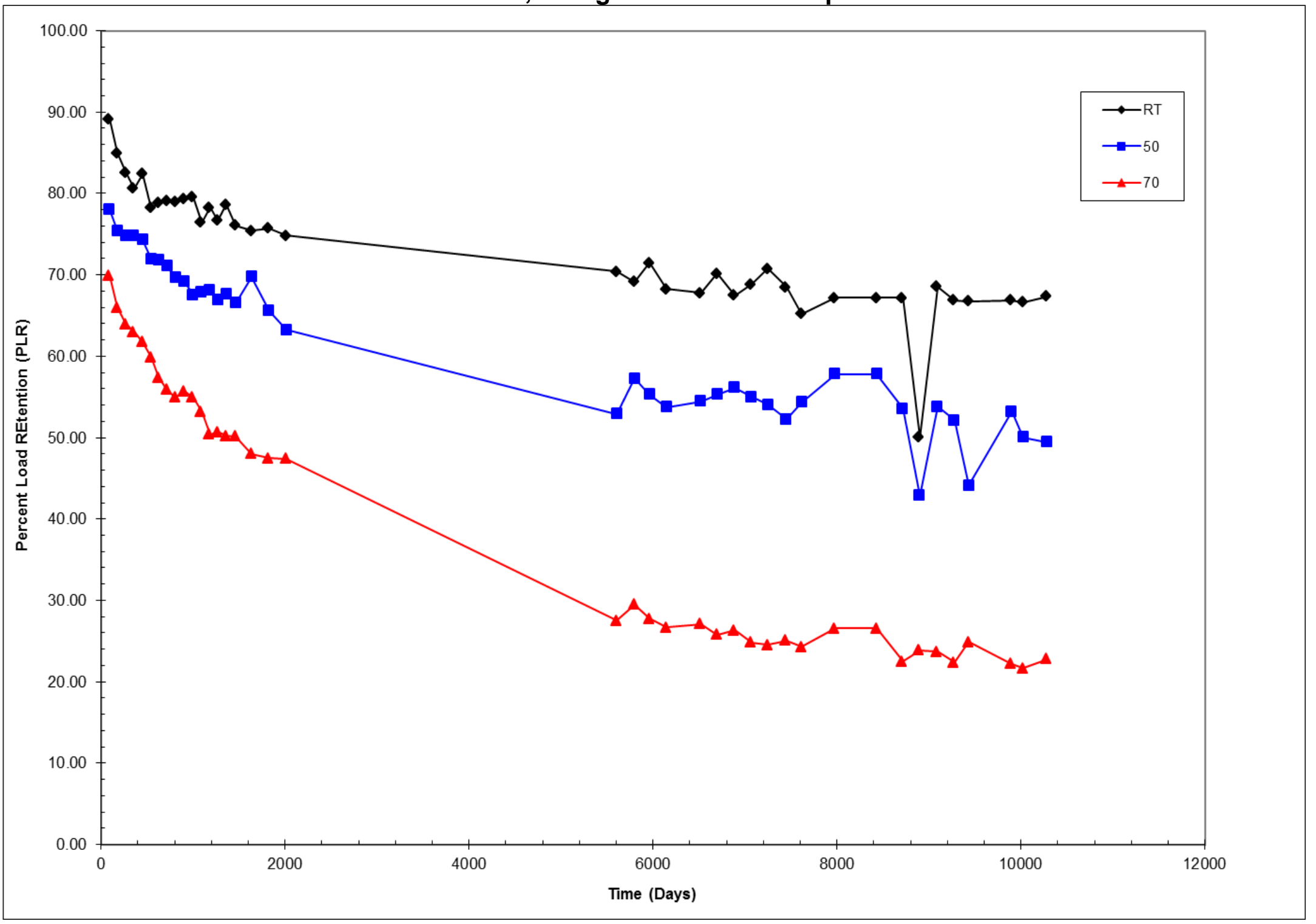


M-97 at $0.7 \mathrm{wt} \%$ Vinyl, Lot 0416821

$0.100 "$ Thick, $0.53 \mathrm{~g} / \mathrm{cc}$ and $20 \%$ Compression

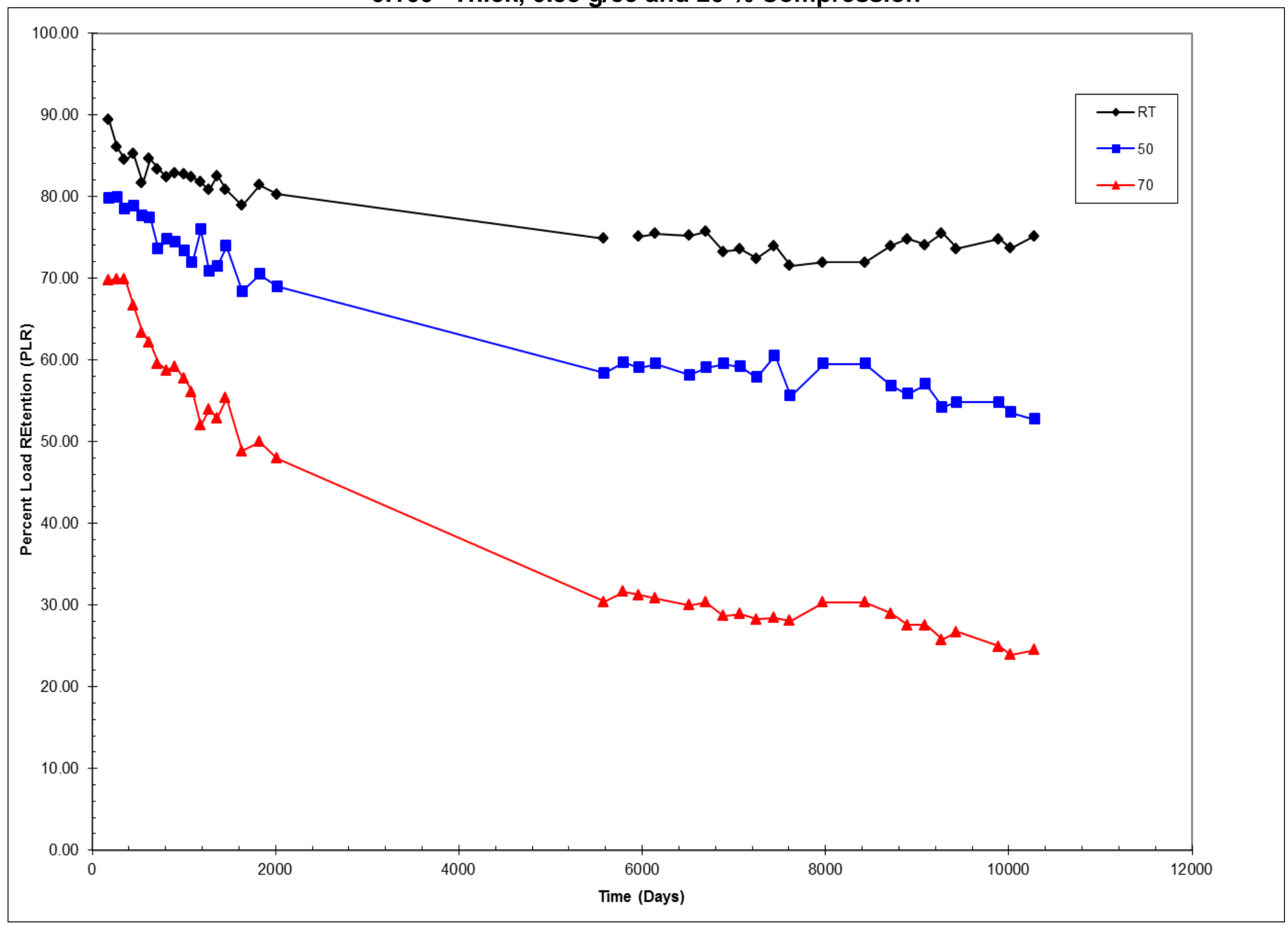


M-97 at 0.7 wt\% Vinyl, Lot 0416821

$0.100 "$ Thick, $0.53 \mathrm{~g} / \mathrm{cc}$ and $35 \%$ Compression

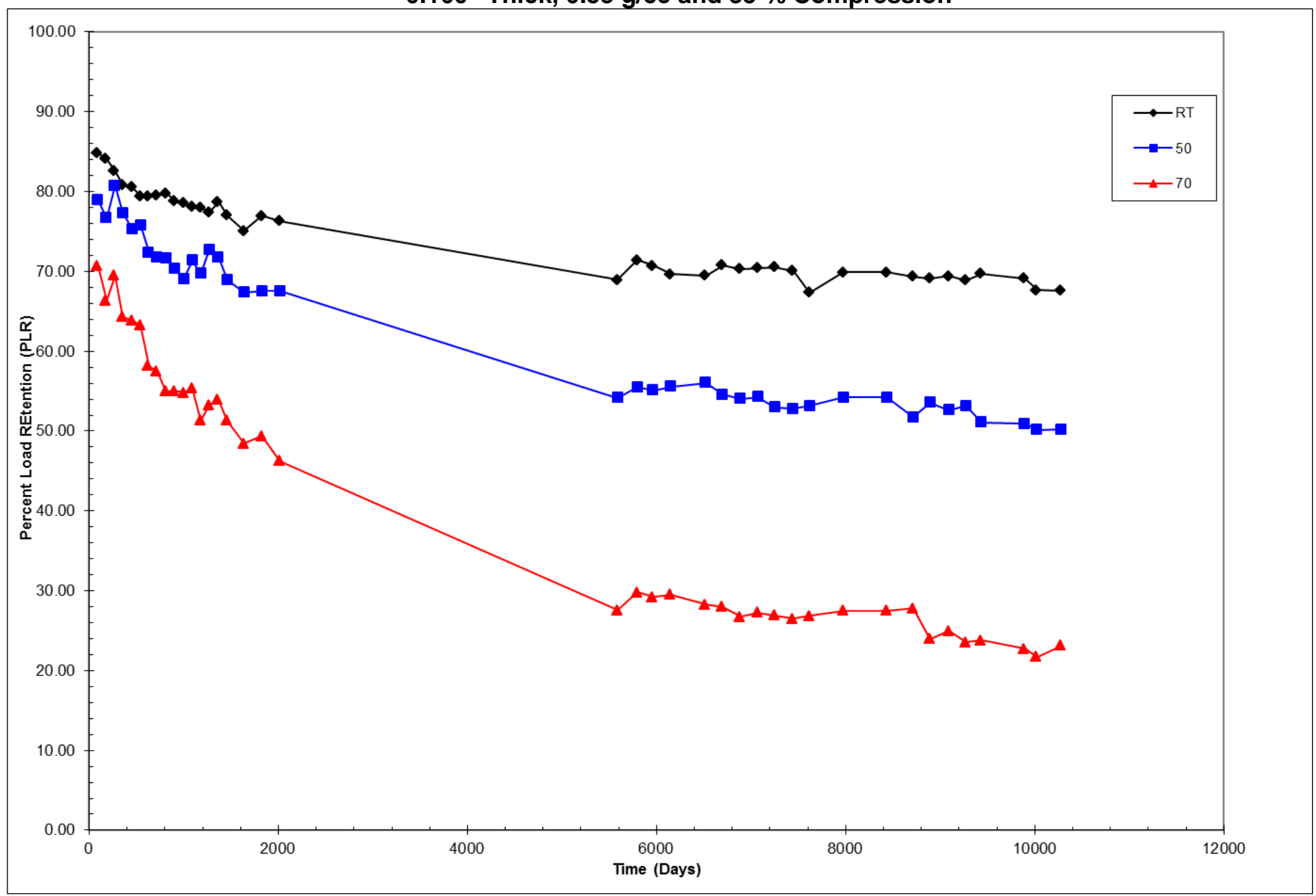


M-97 @ 0.7 wt\% Vinyl, Lot 0416821

0.160 " Thick, $0.53 \mathrm{~g} / \mathrm{cc}$ and $20 \%$ Compression

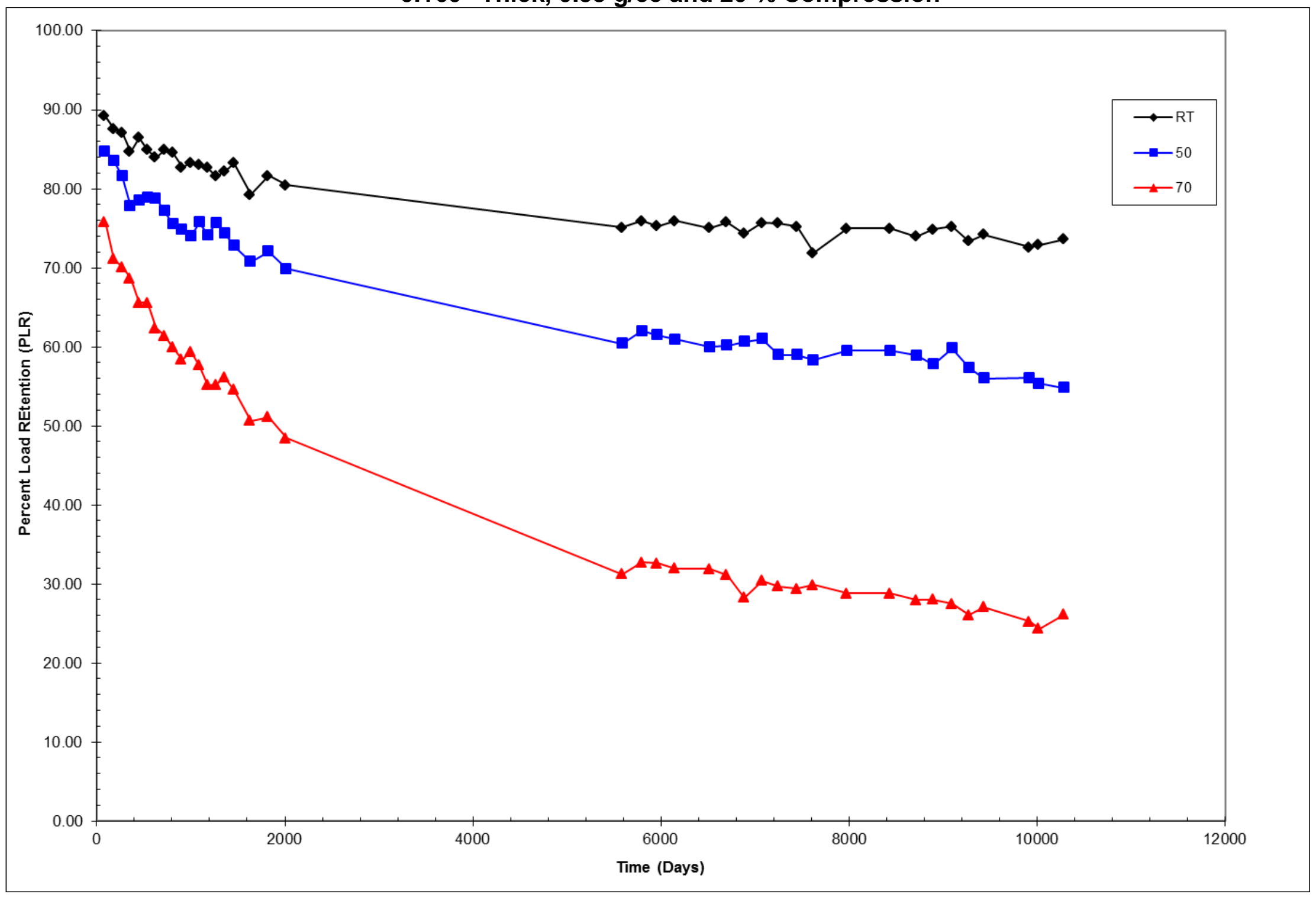


M-97 at $0.7 \mathrm{wt} \%$ Vinyl, Lot 0416821

0.160 " Thick, $0.53 \mathrm{~g} / \mathrm{cc}$ and $35 \%$ Compression

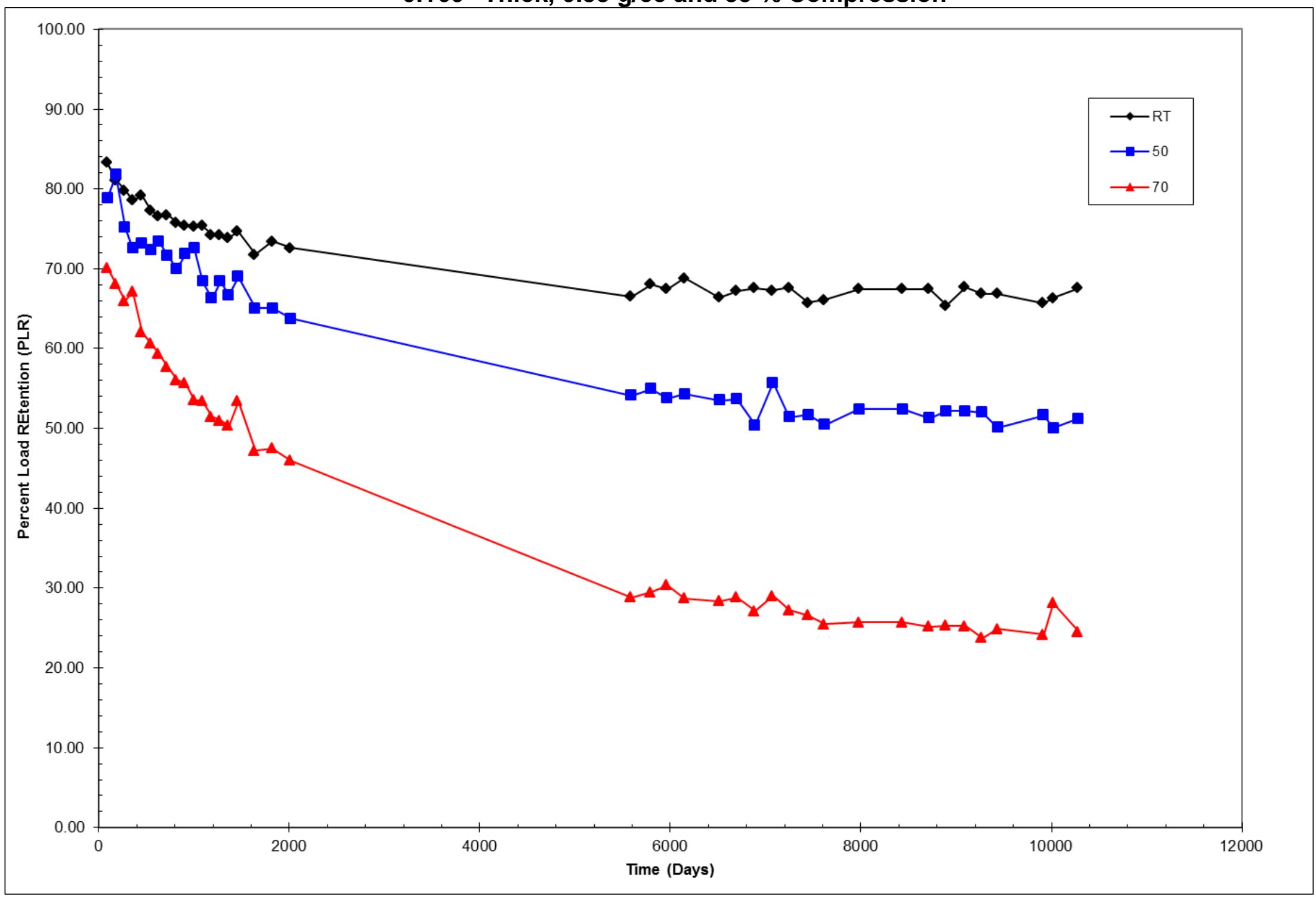




\section{Appendix C}

\section{M-9747 and M-9777 Charts}




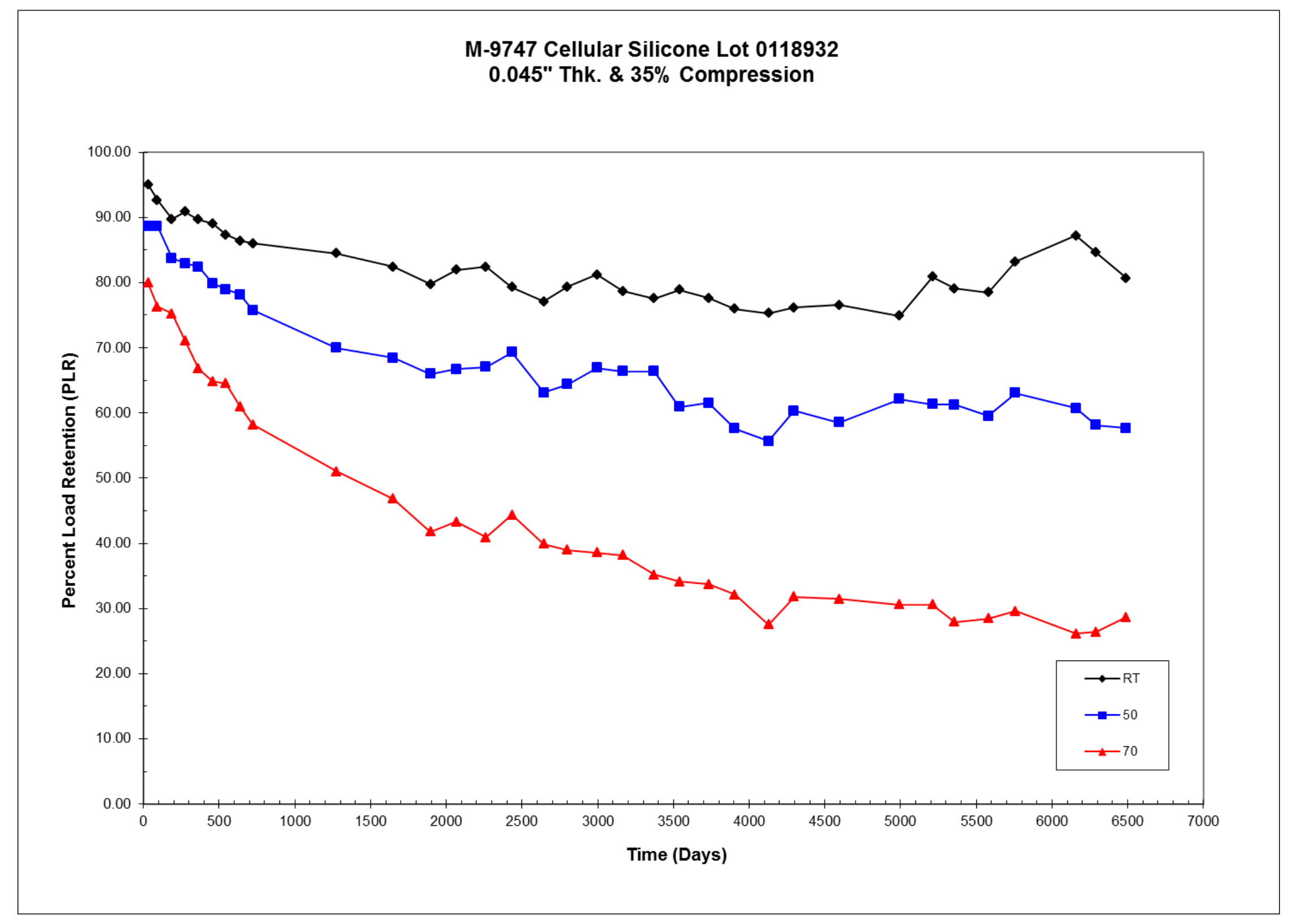




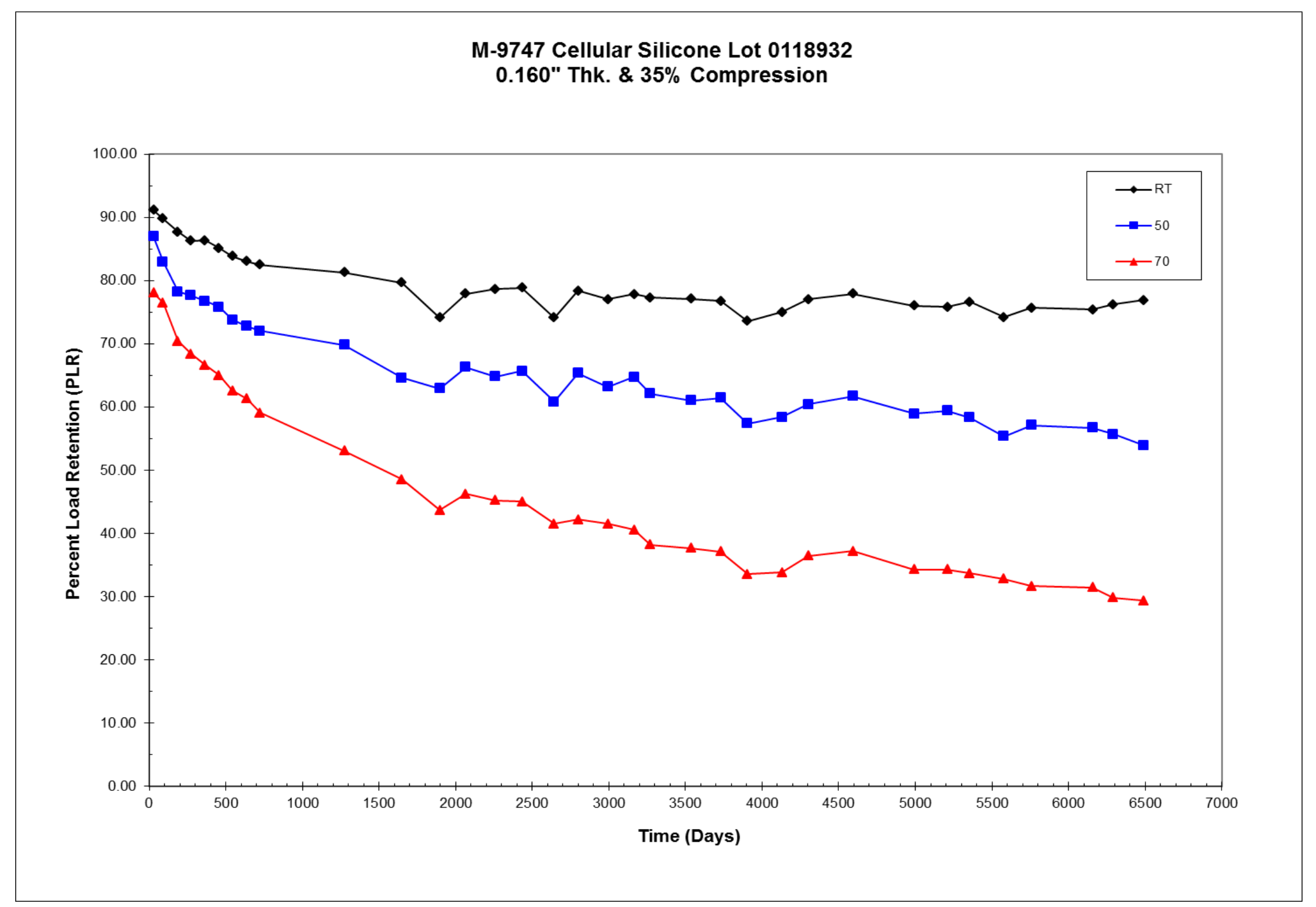




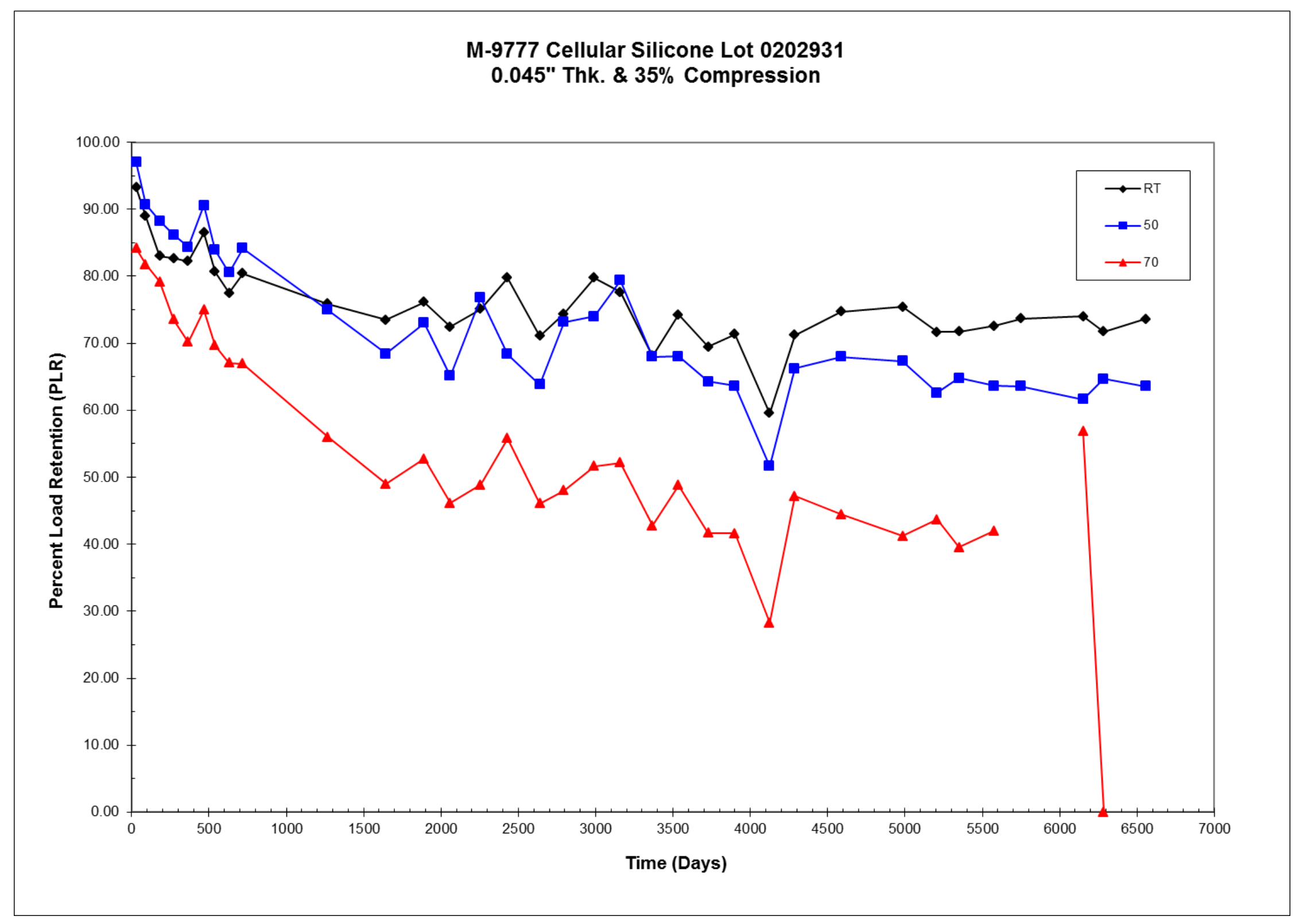




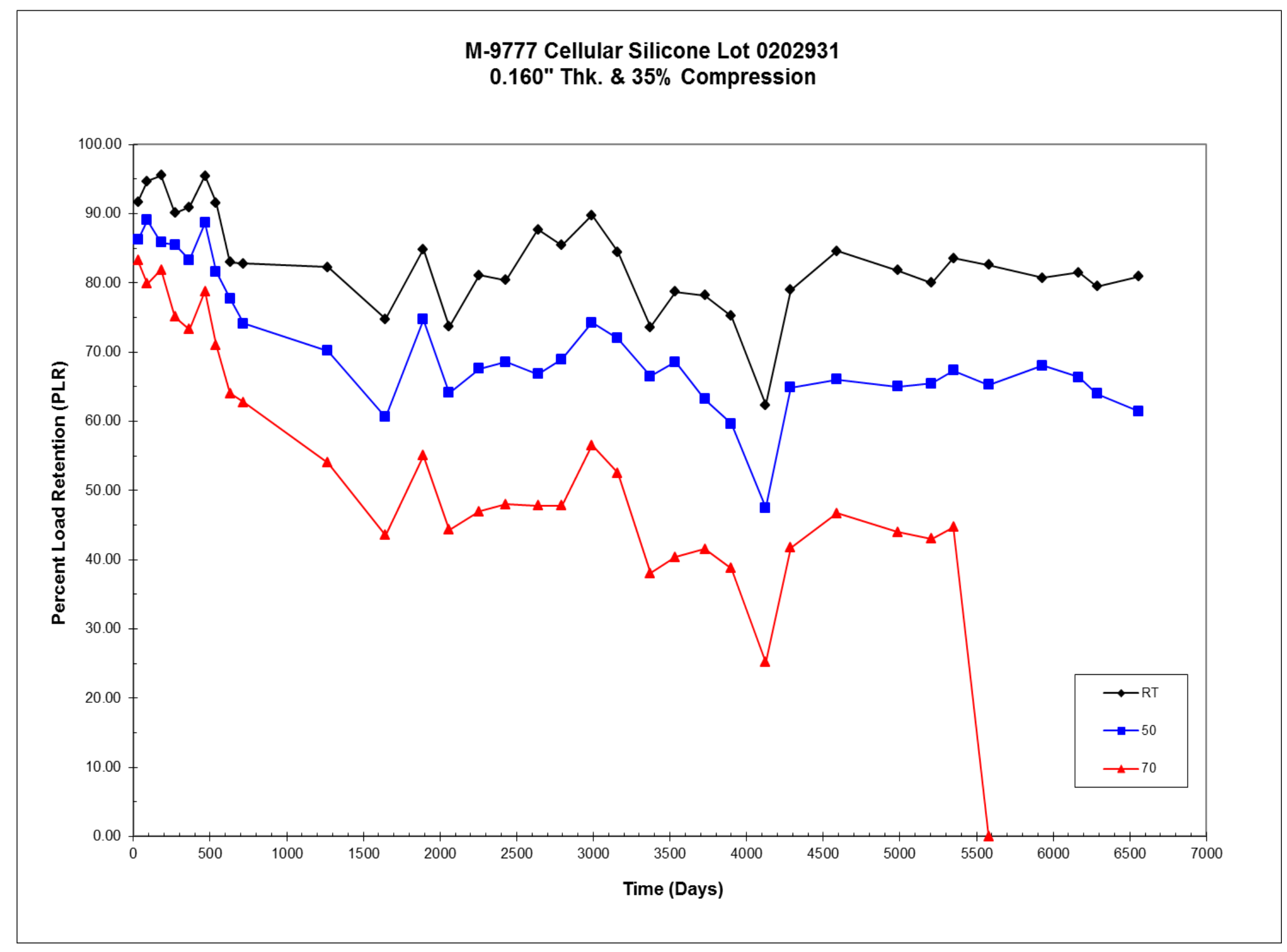


Appendix D

SE-54C Charts 


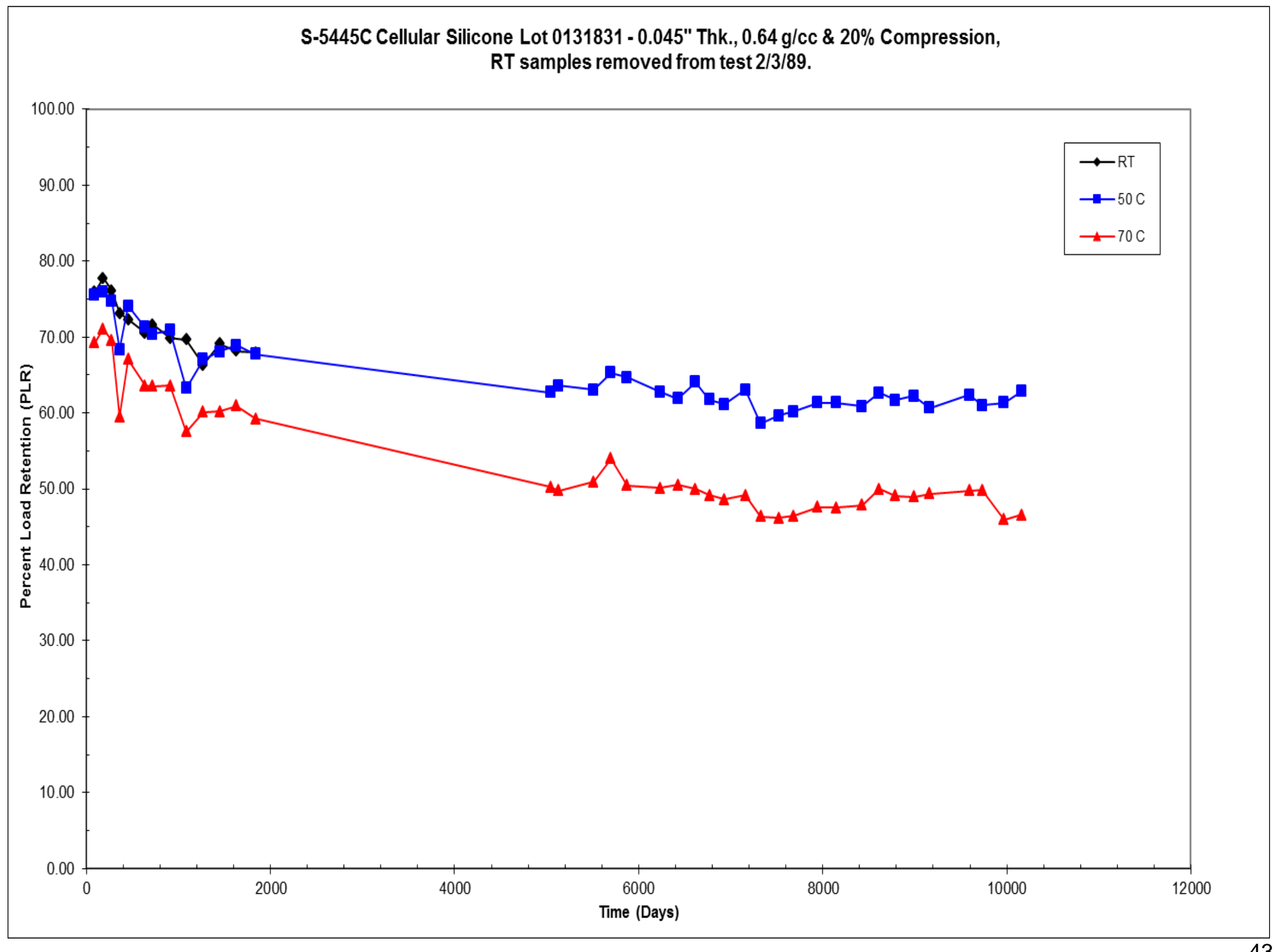




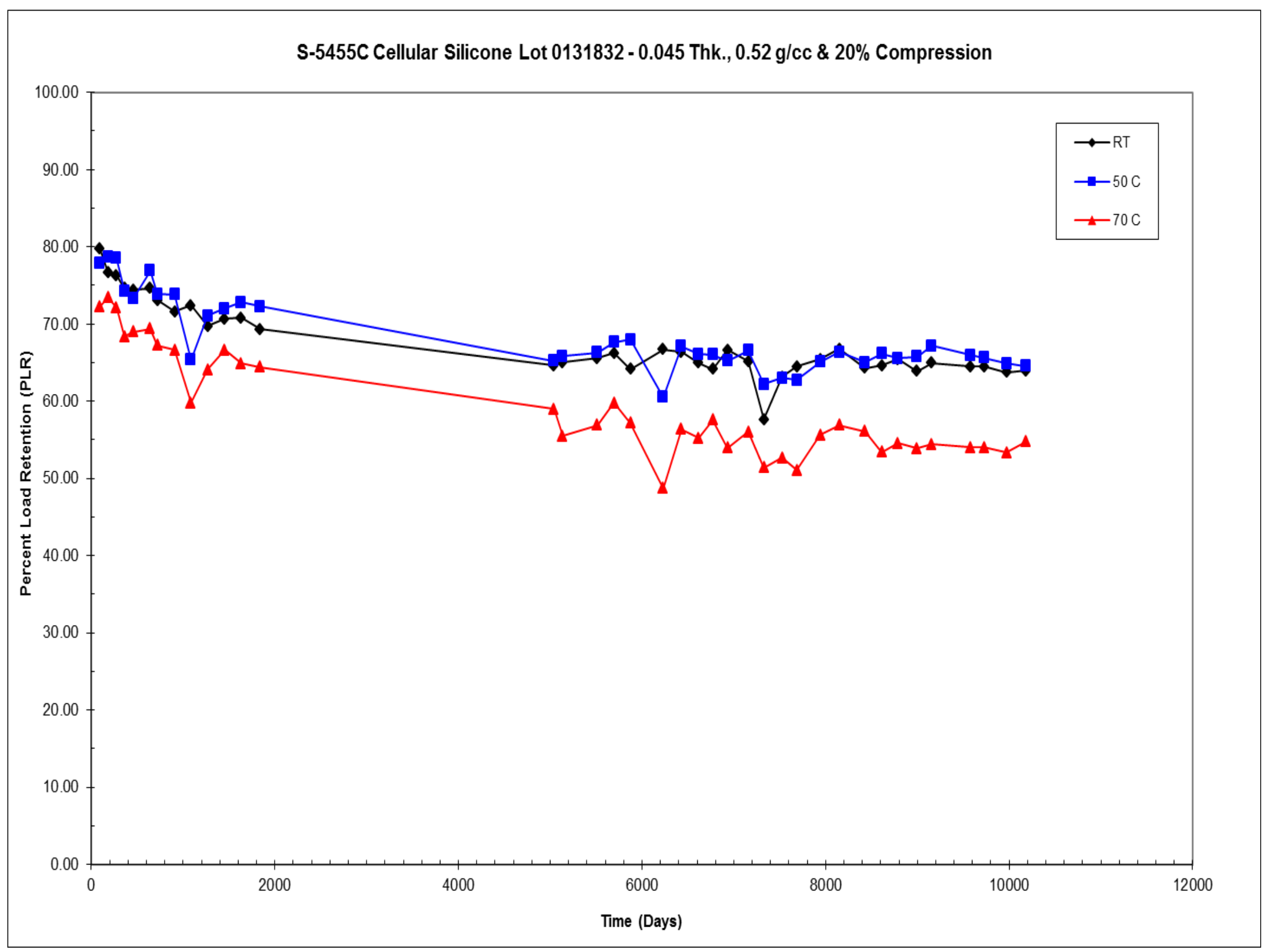




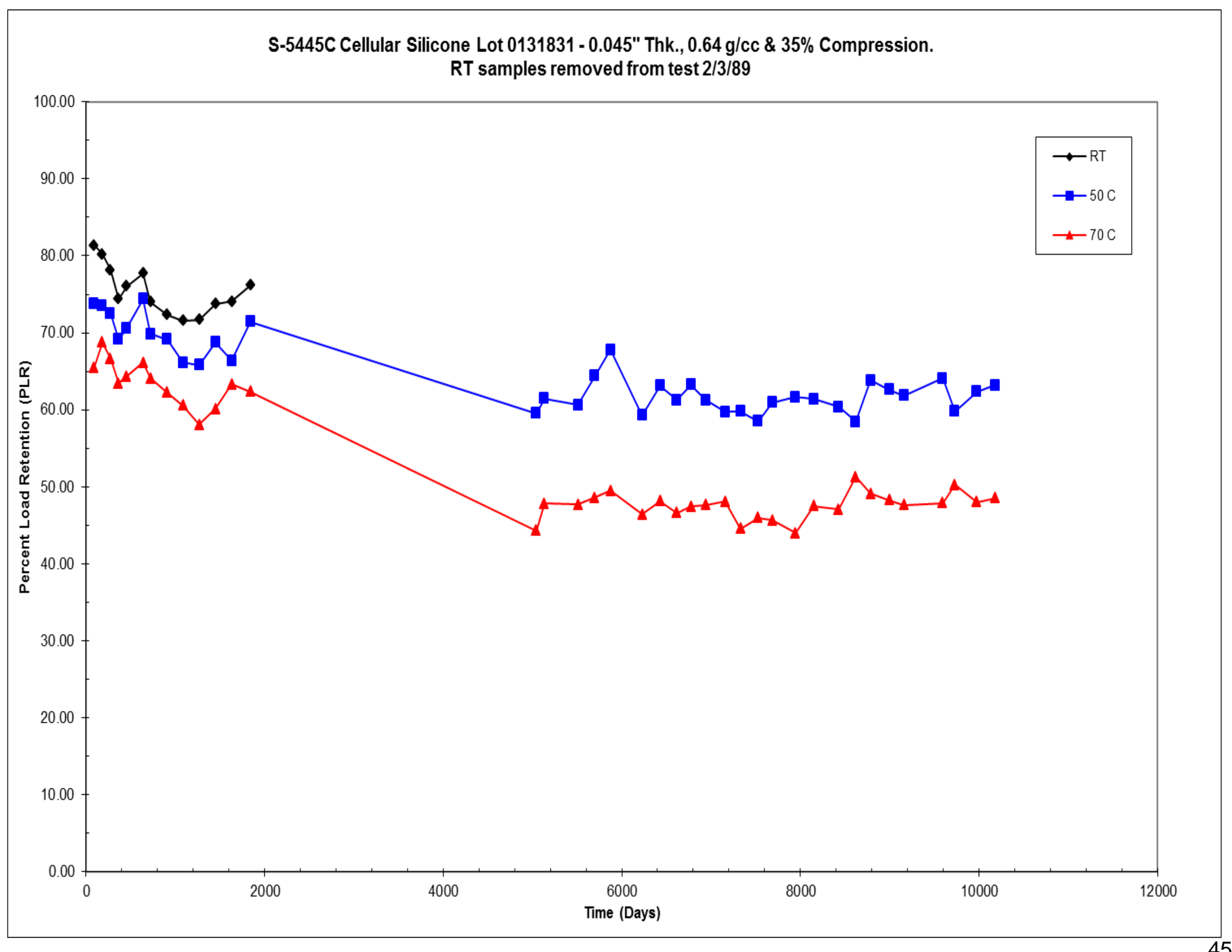




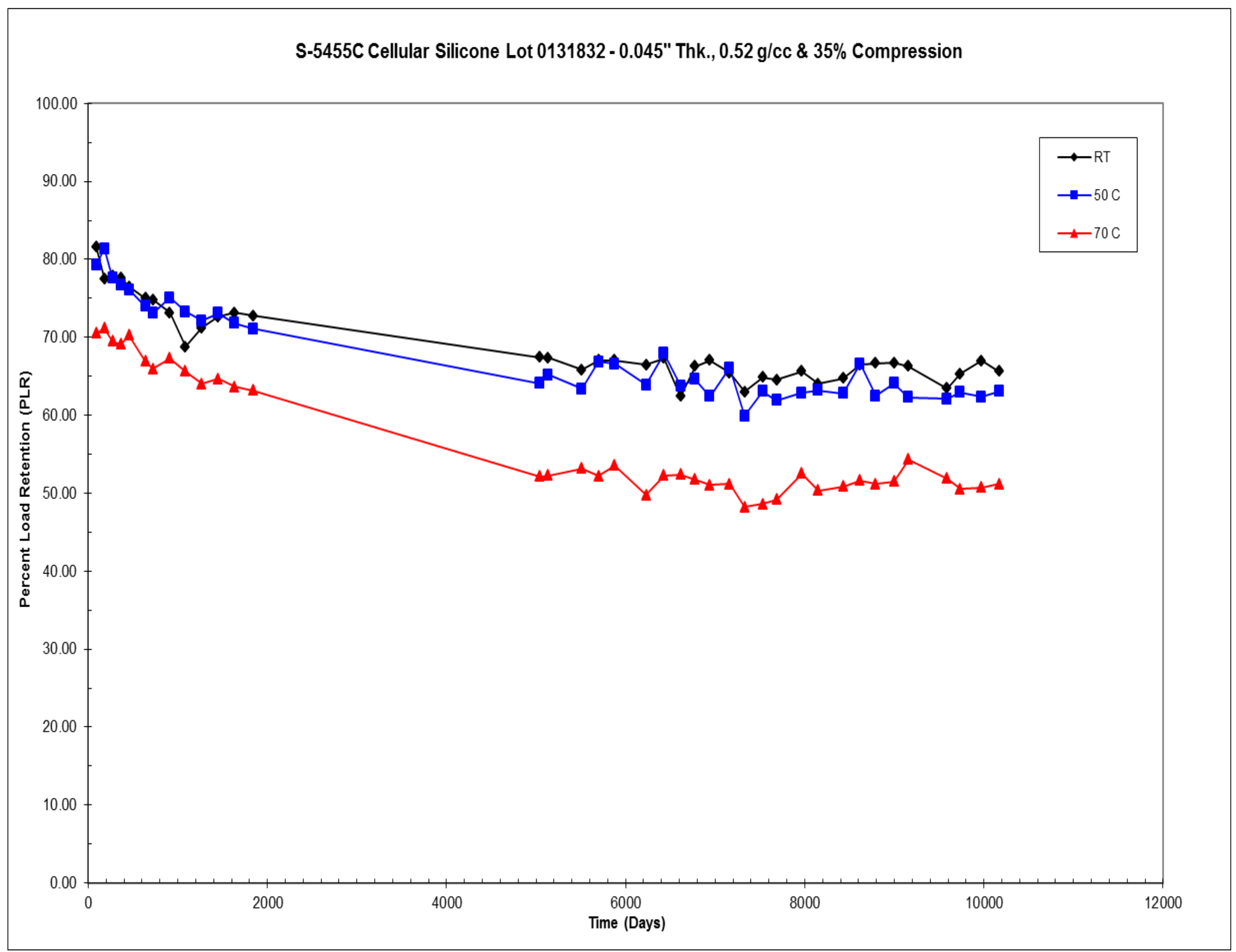




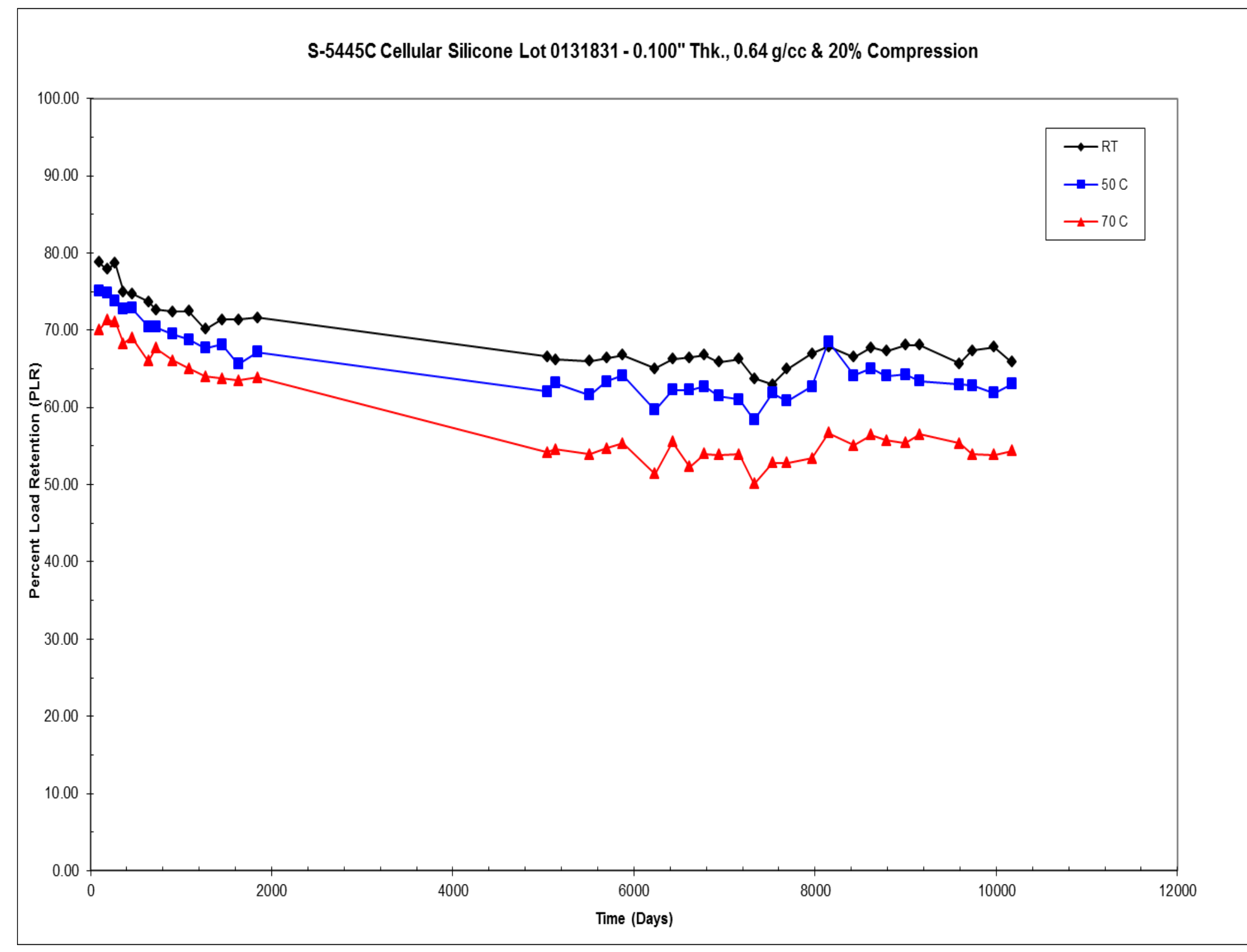




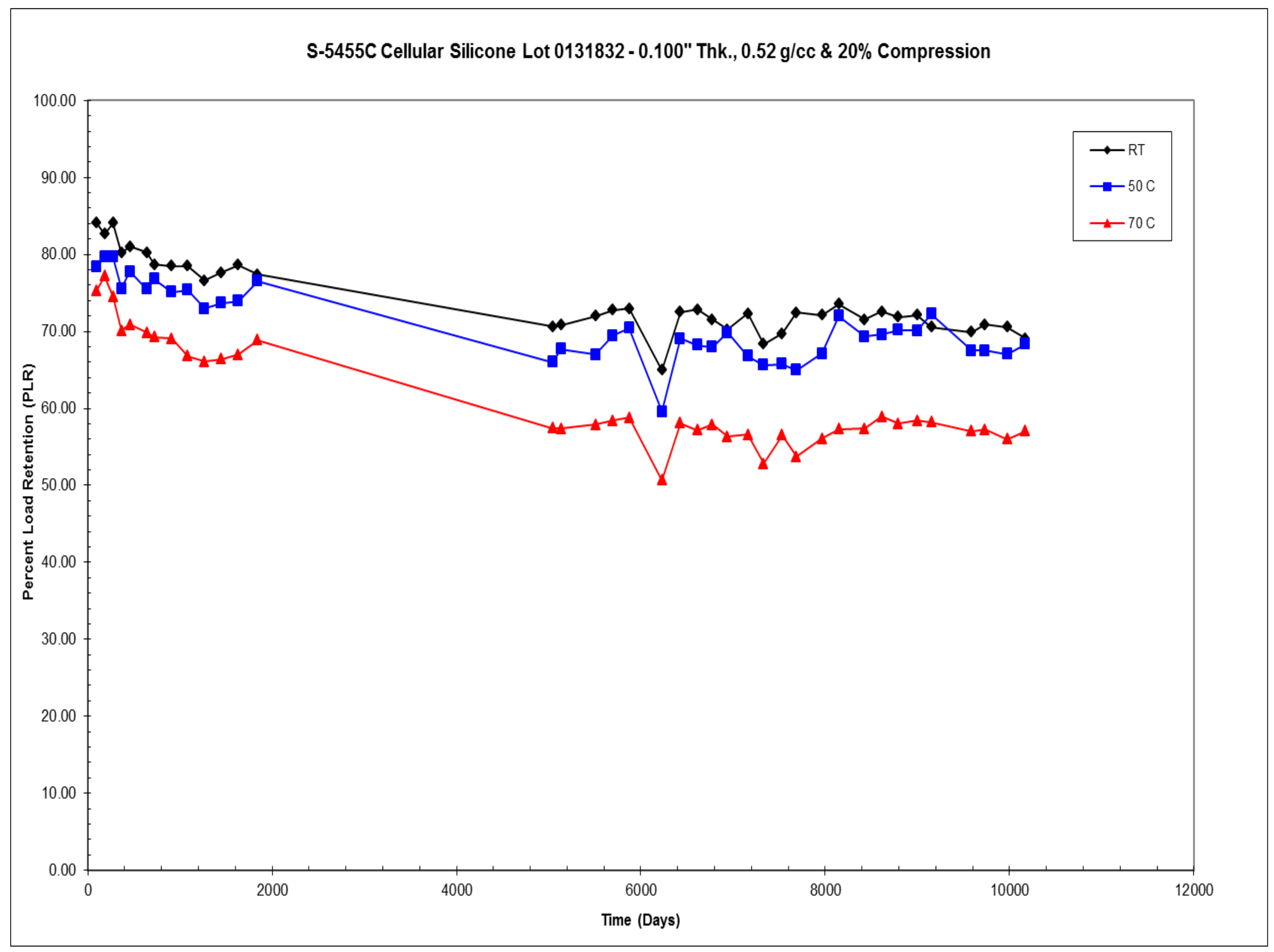




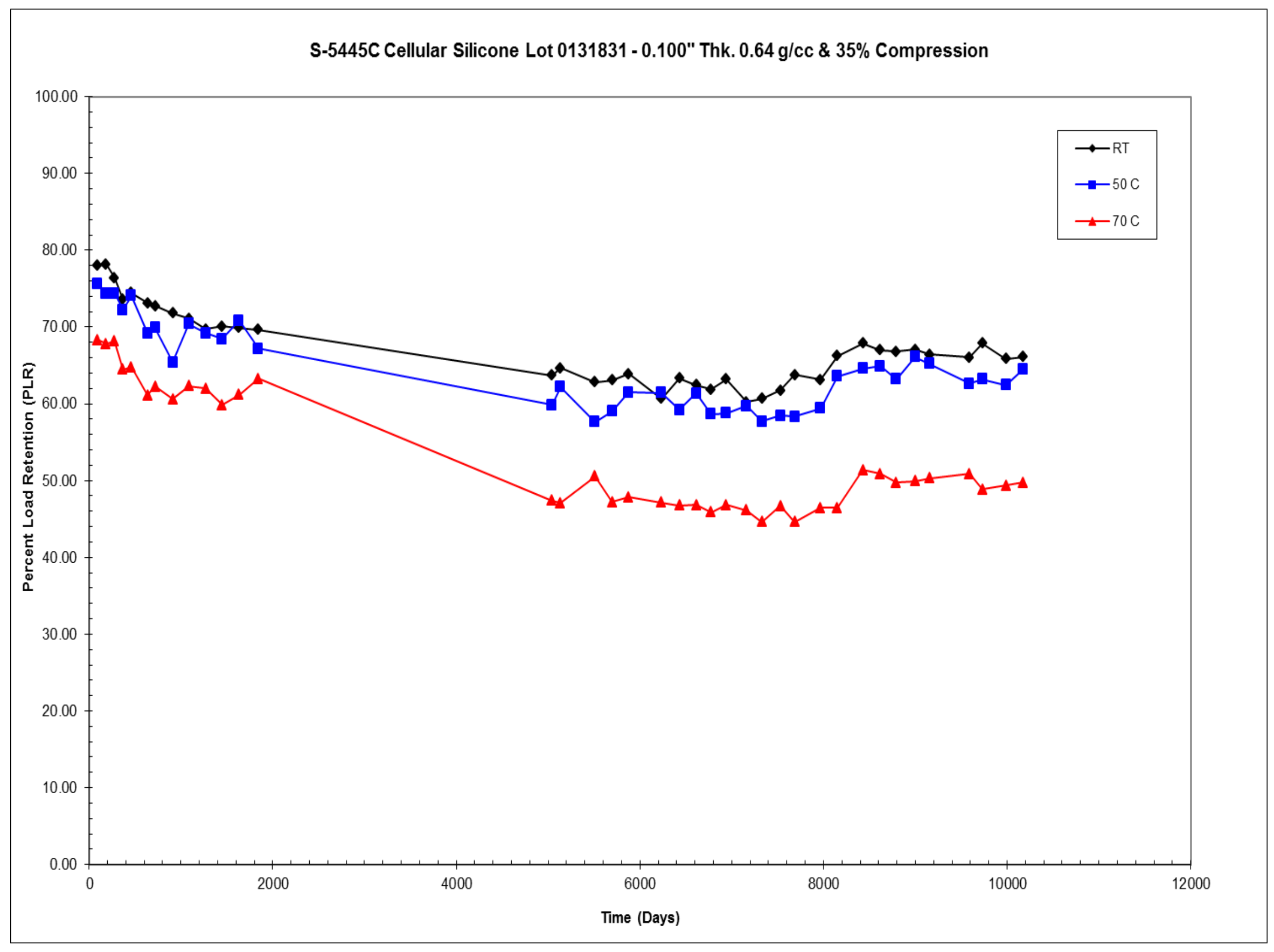




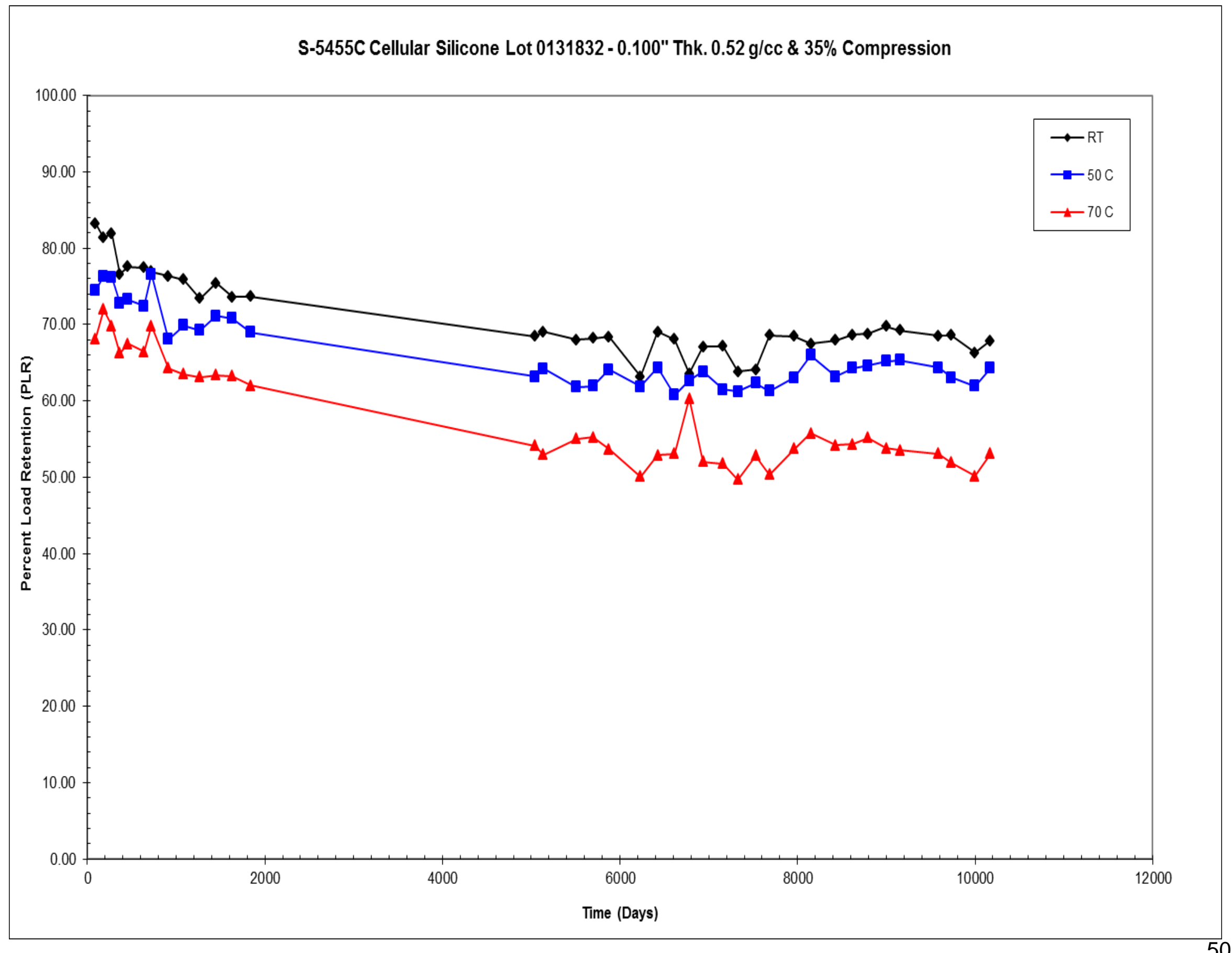




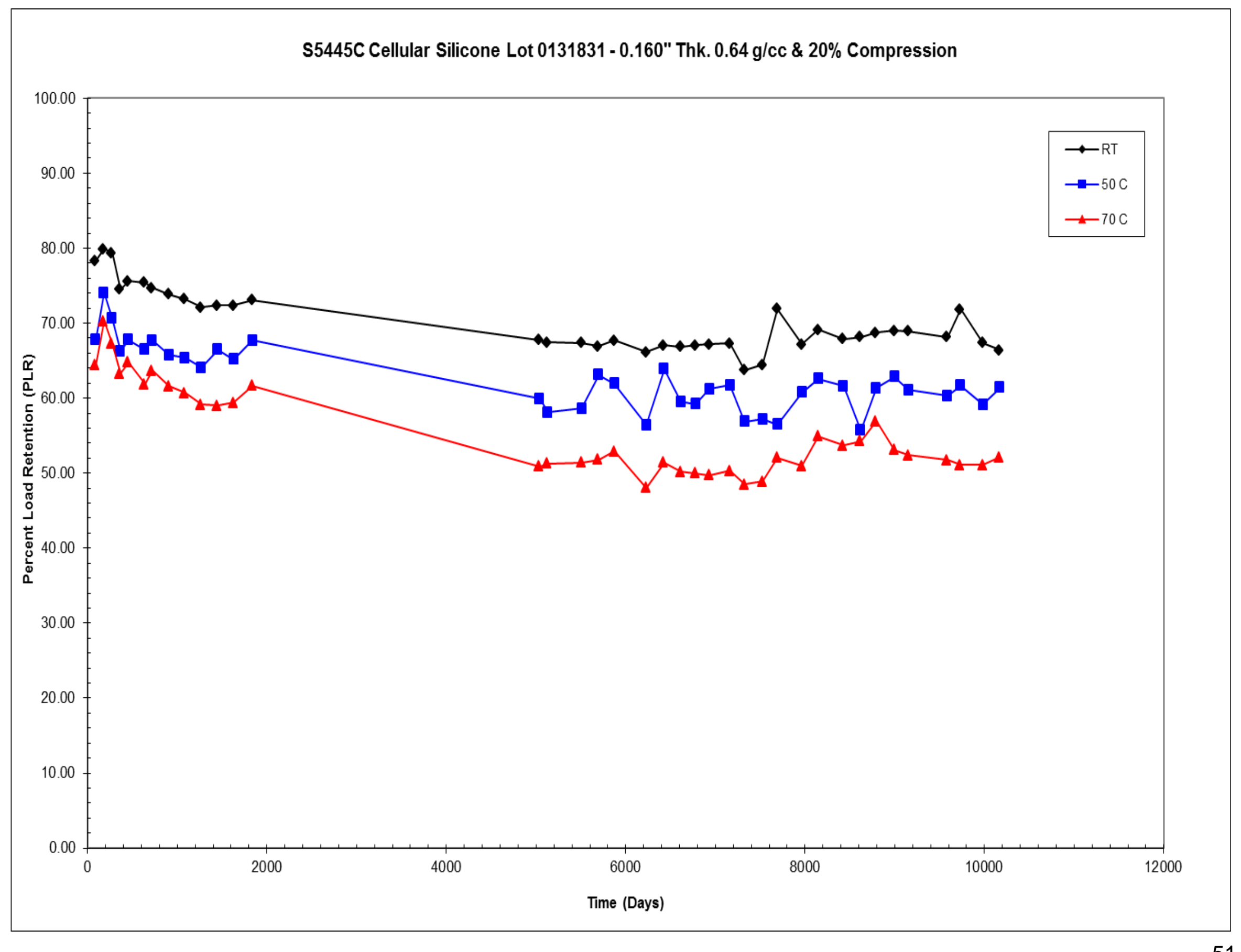




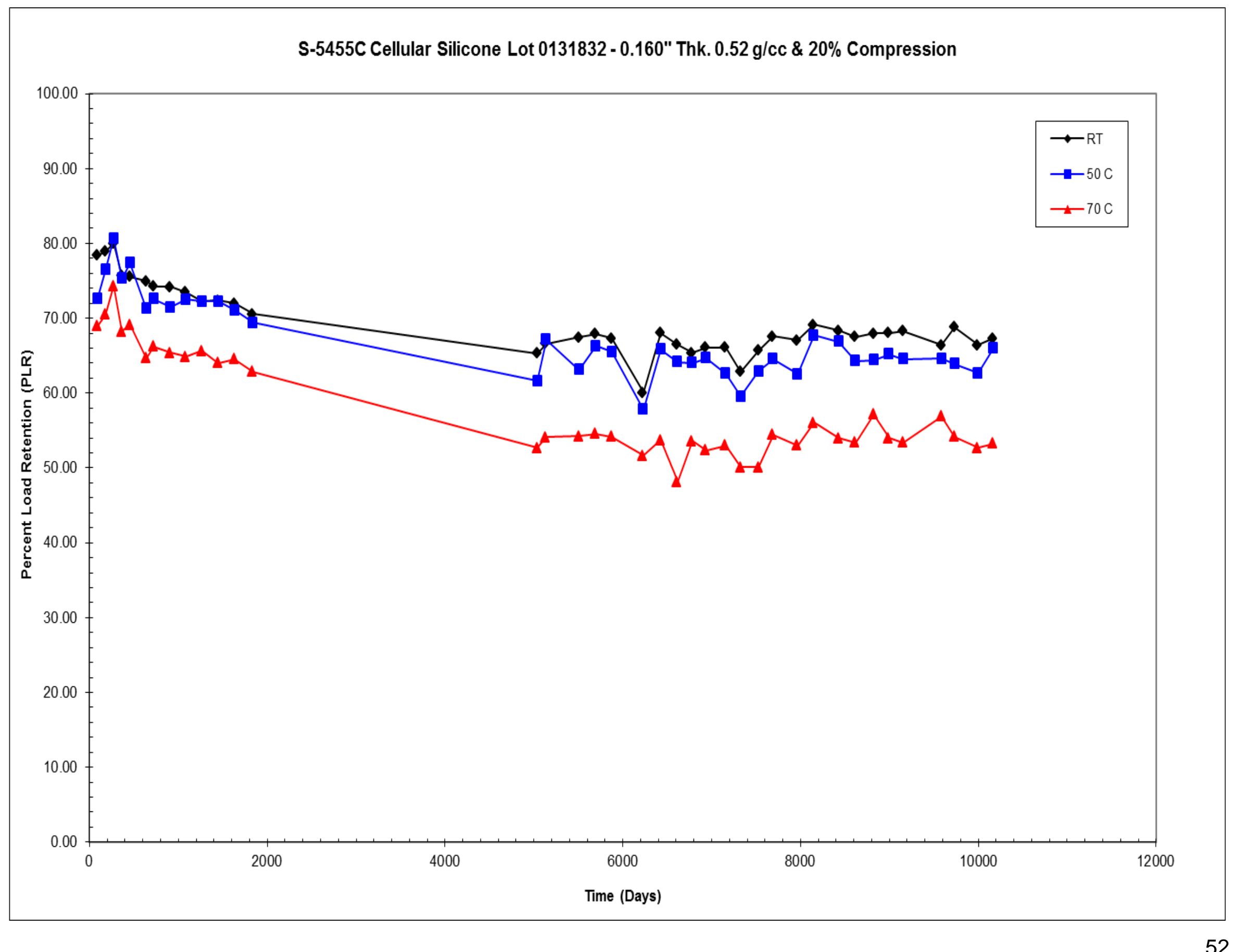




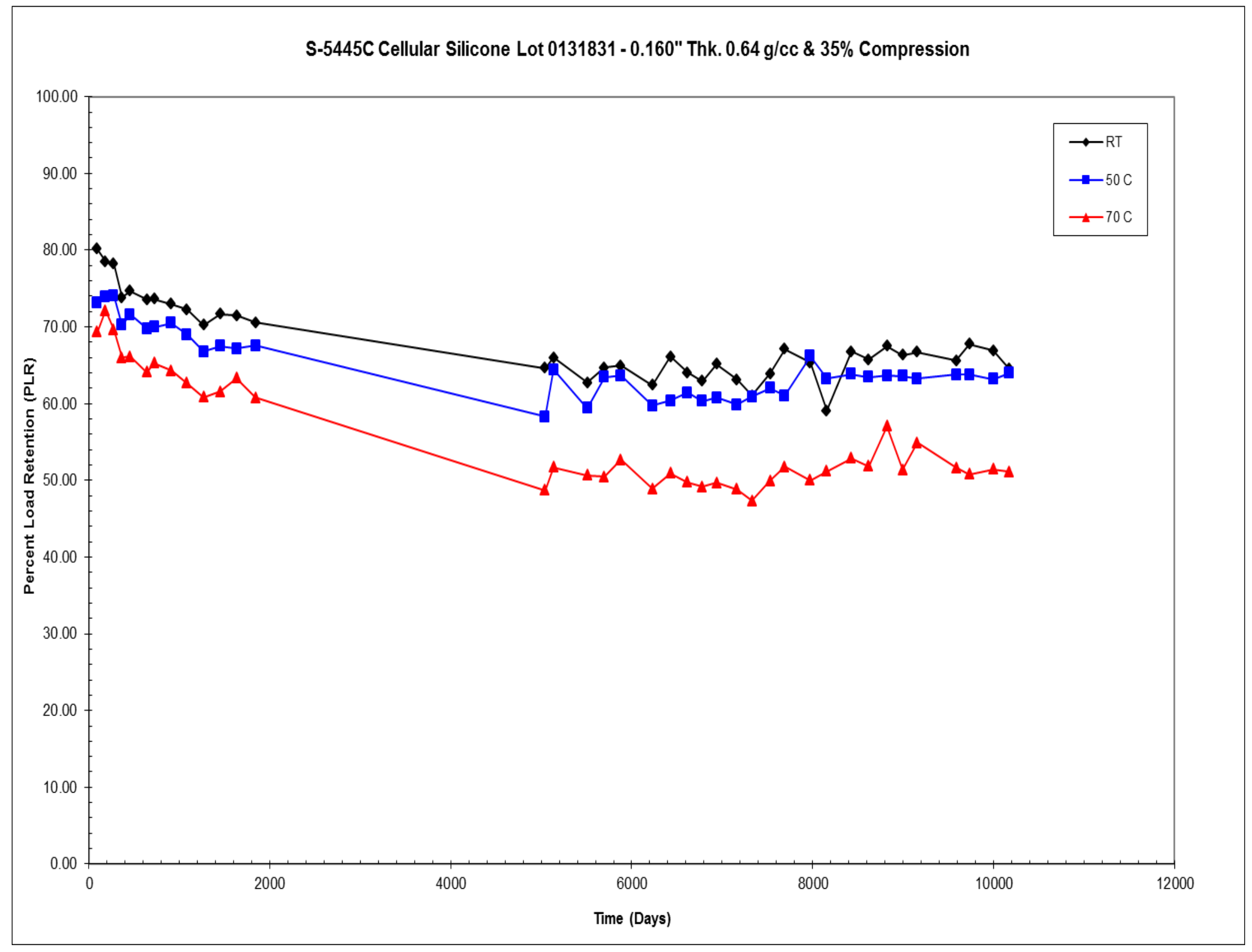




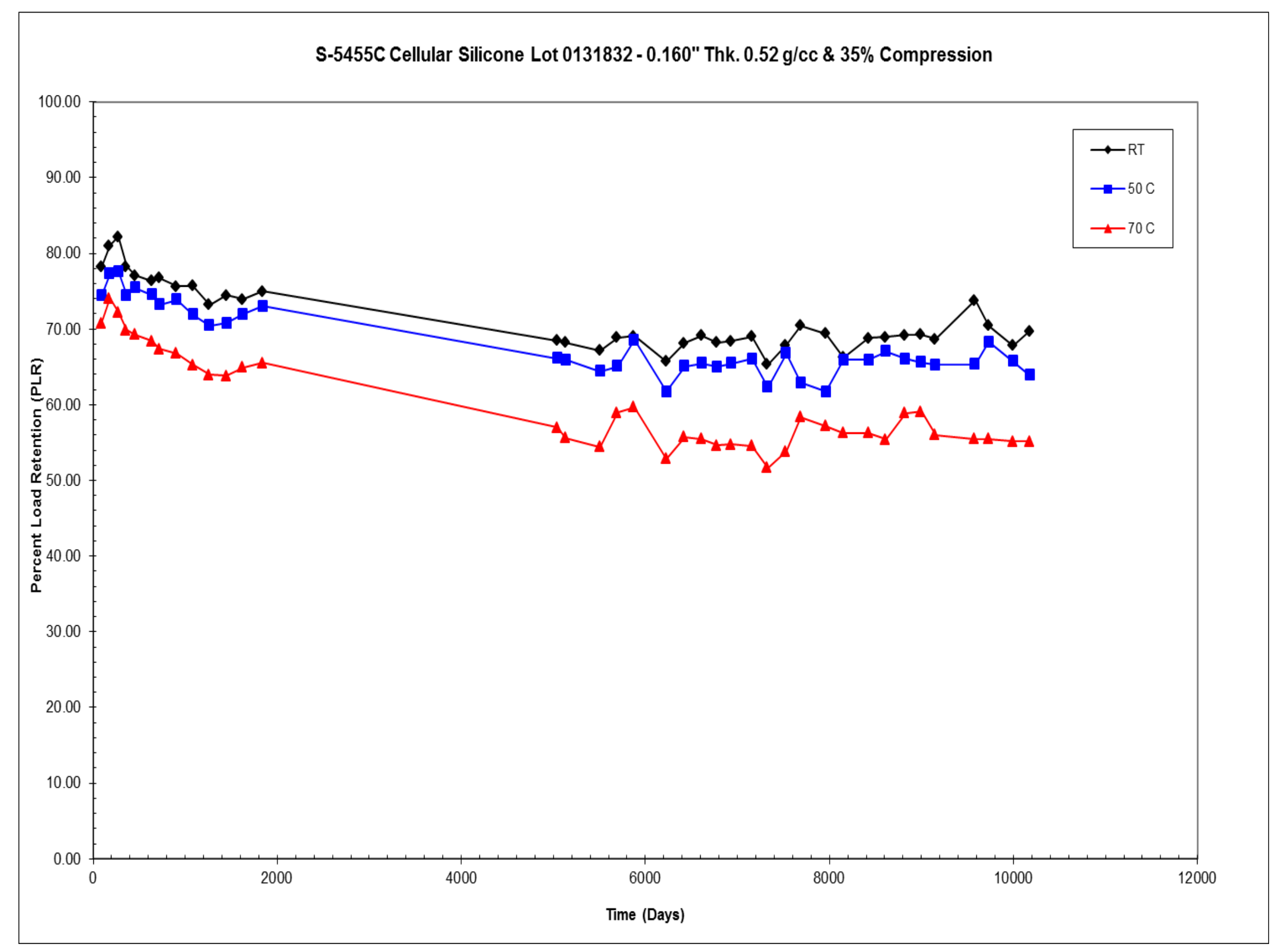




\section{Appendix E}

\section{SE-54 Reload Charts}




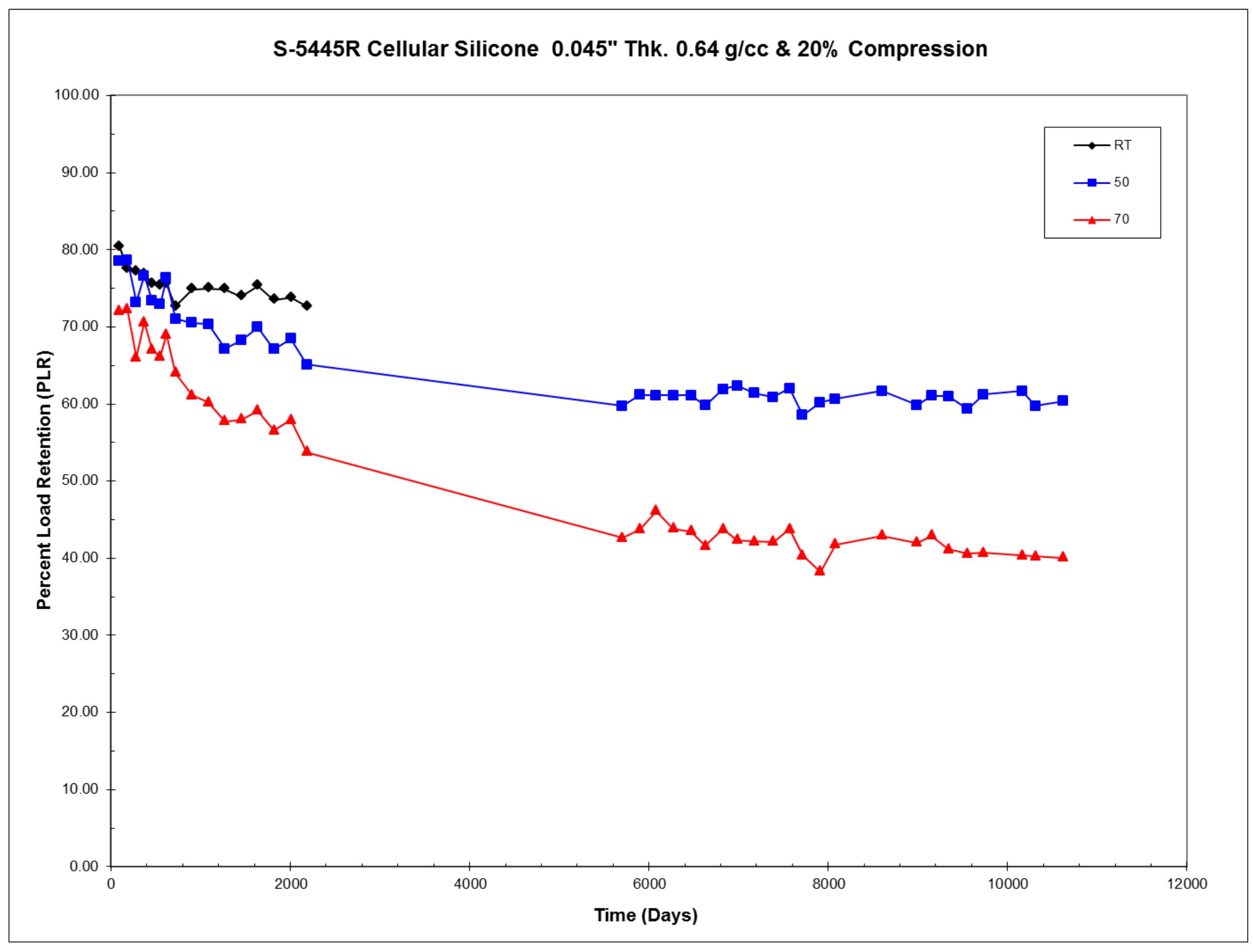




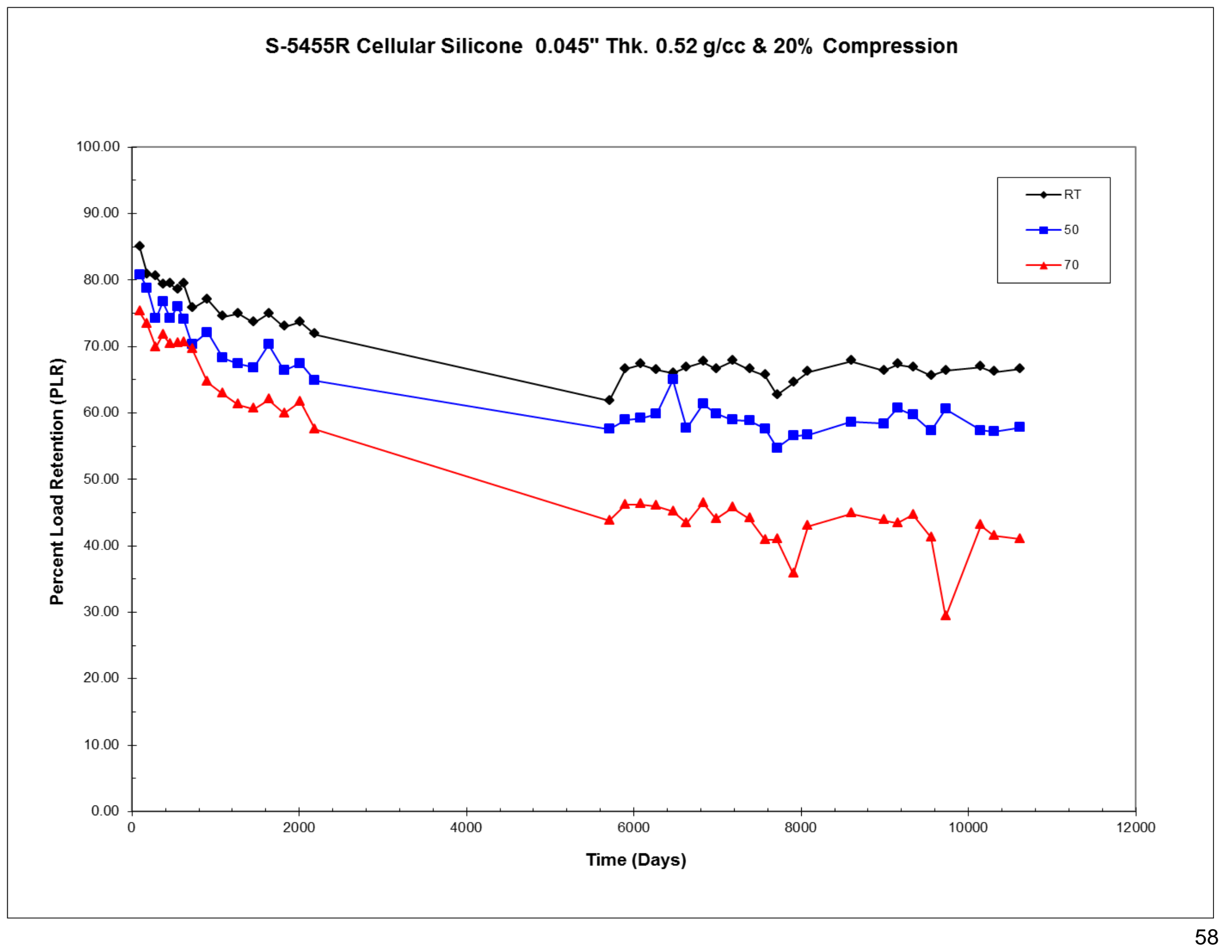




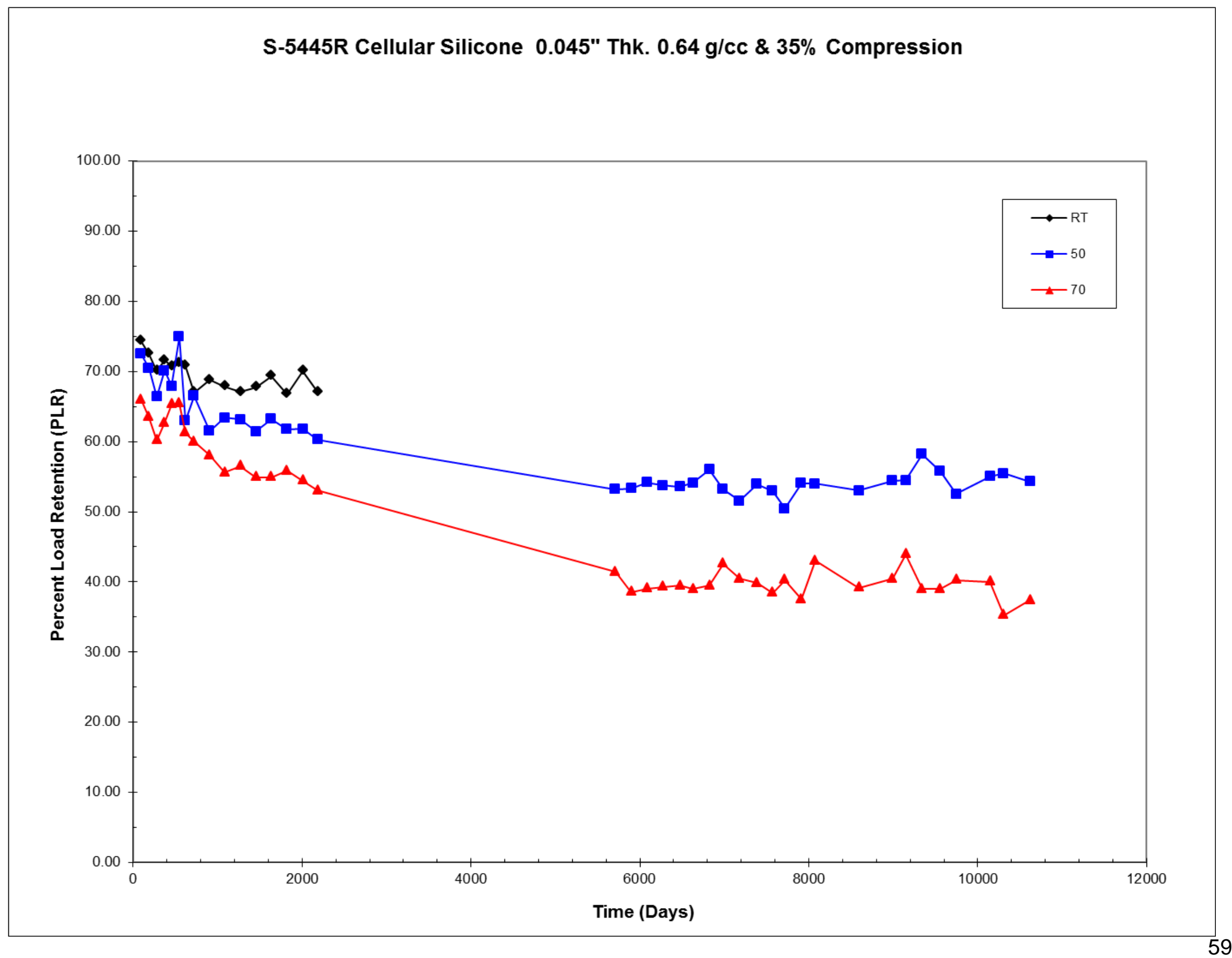




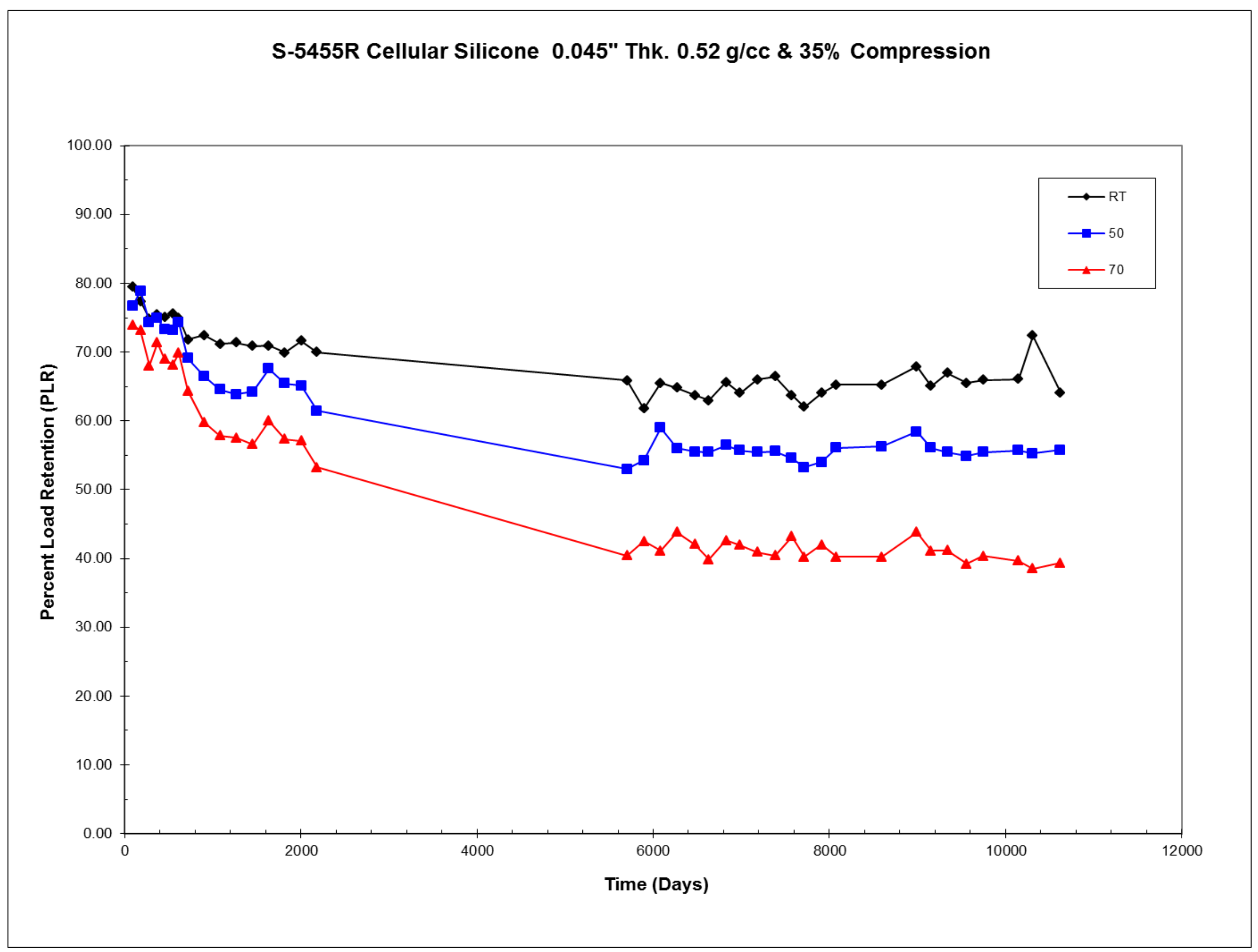




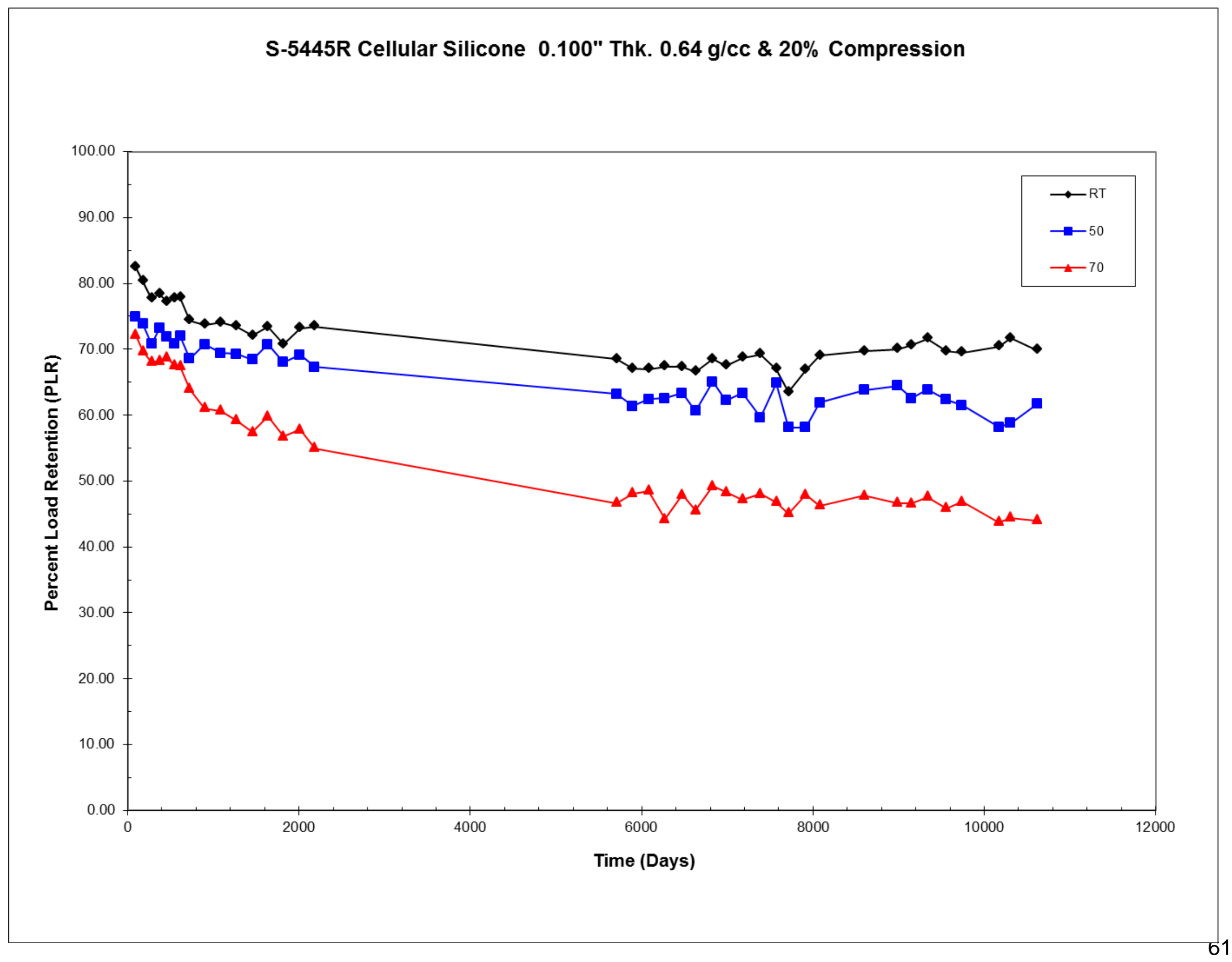




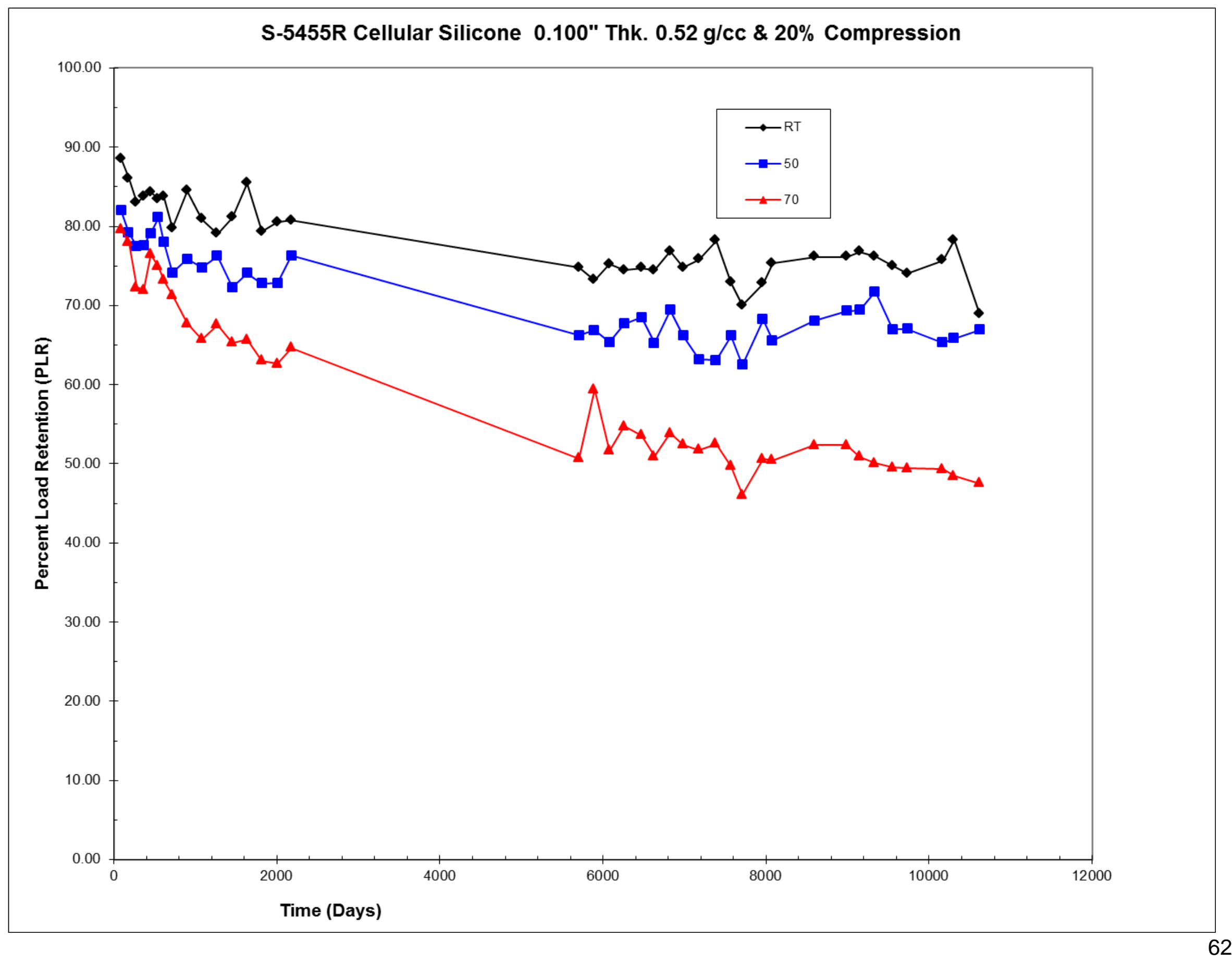




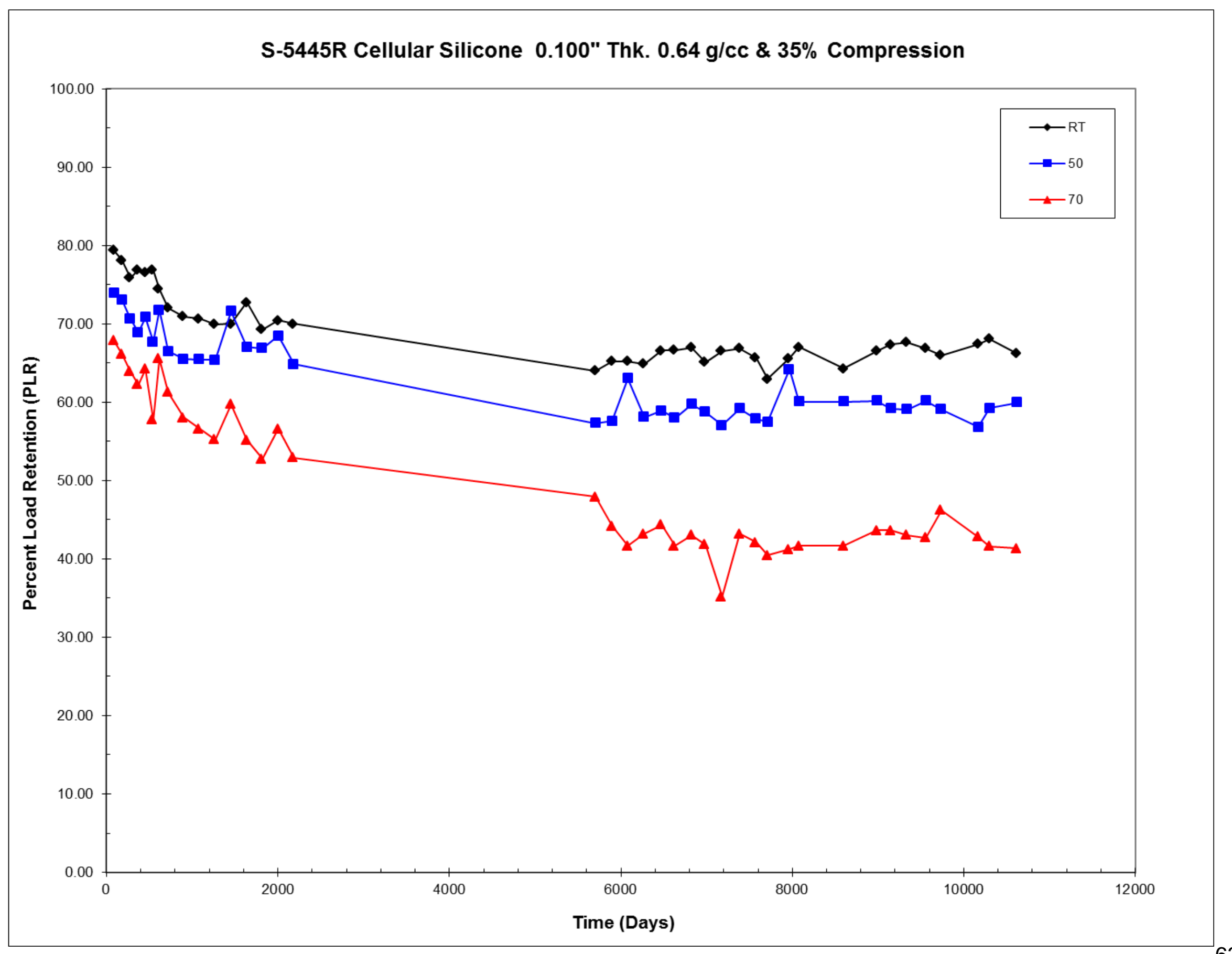




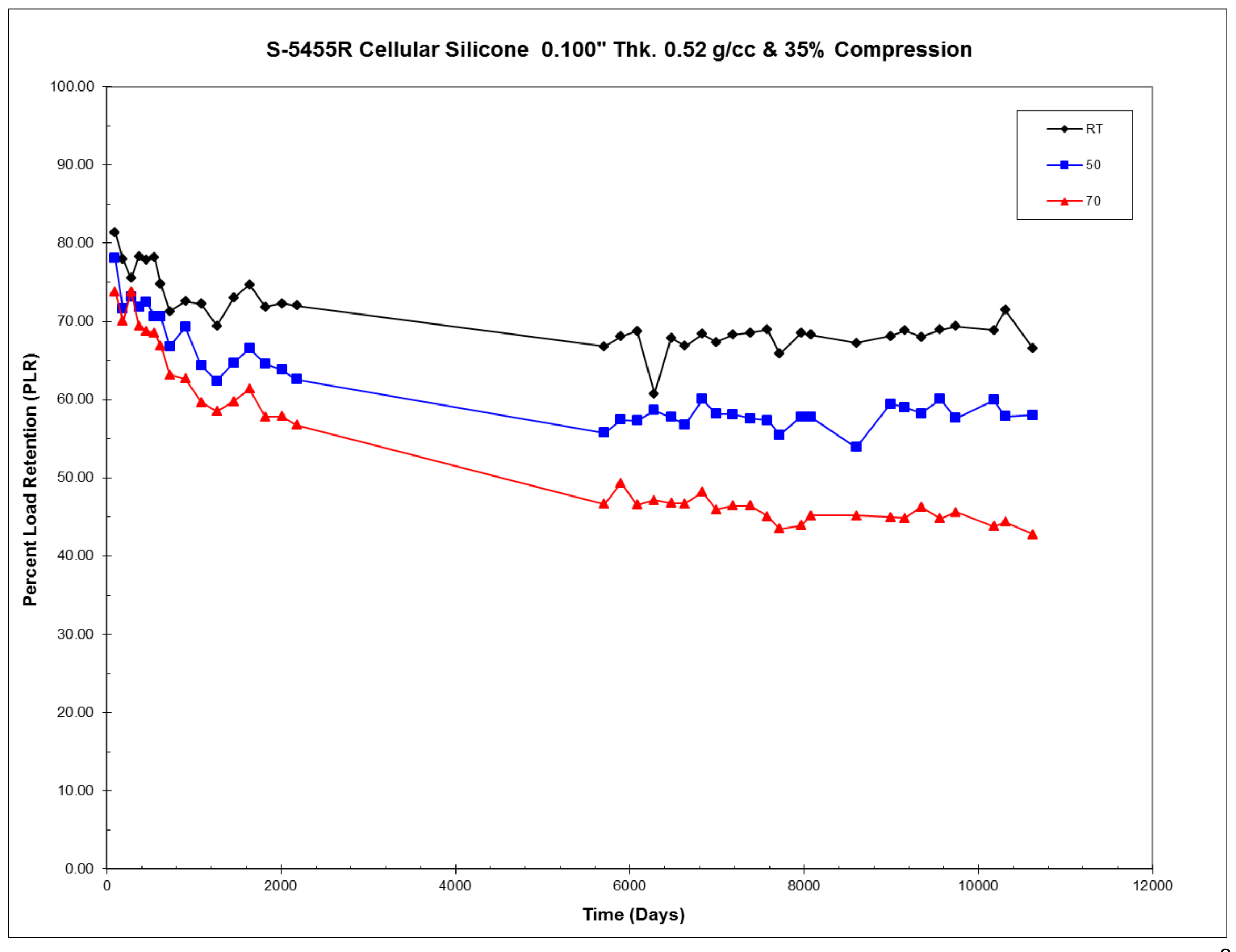




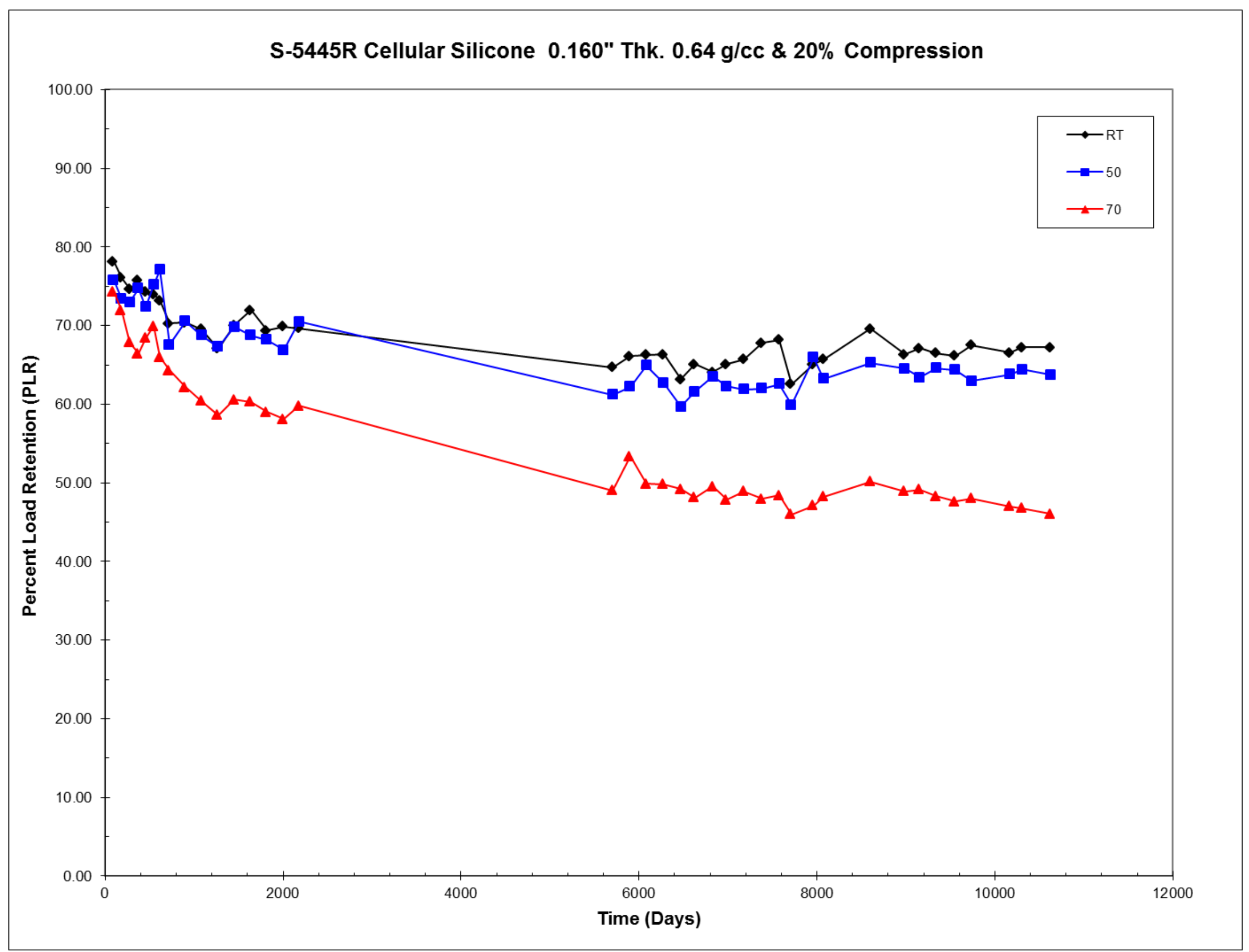




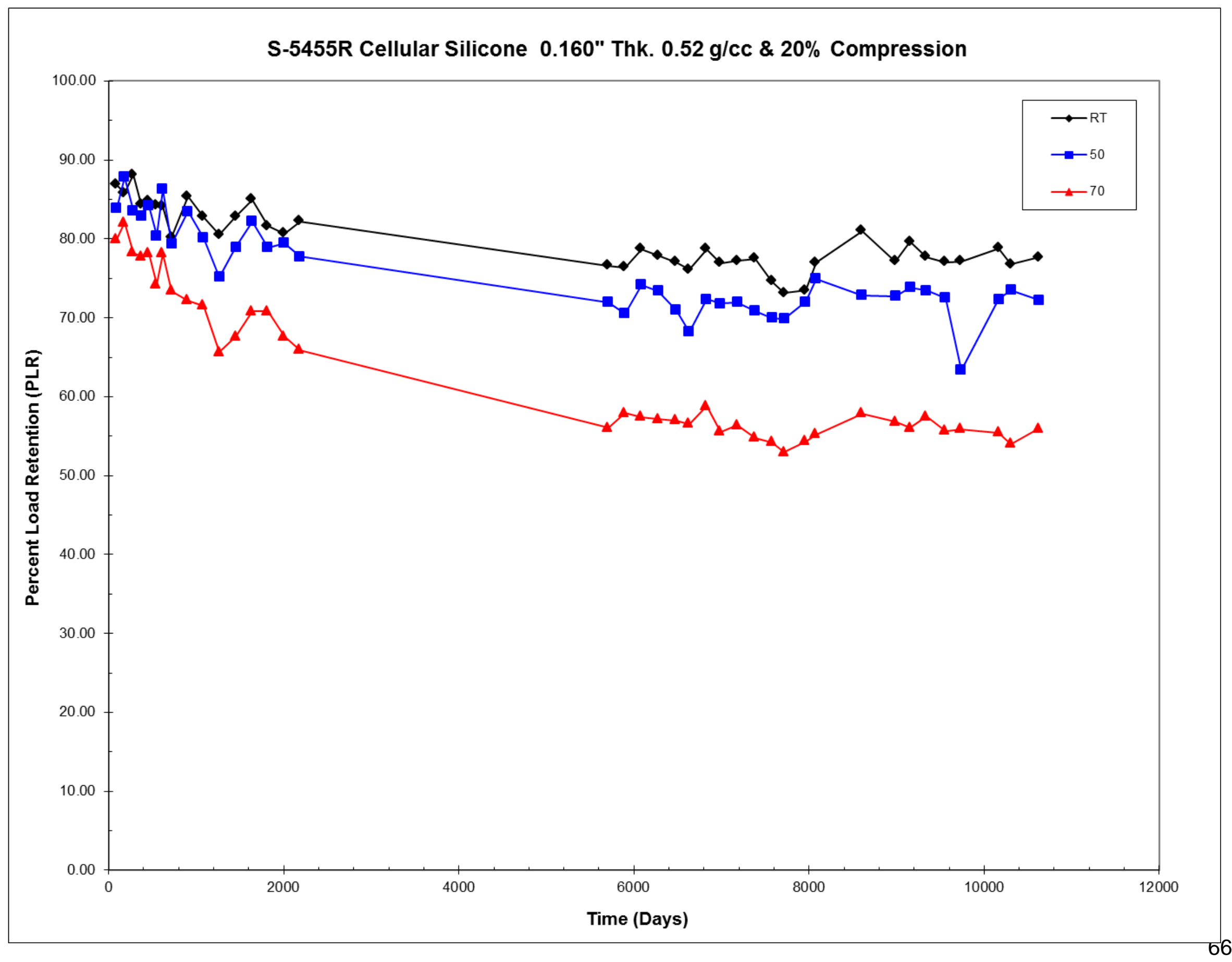




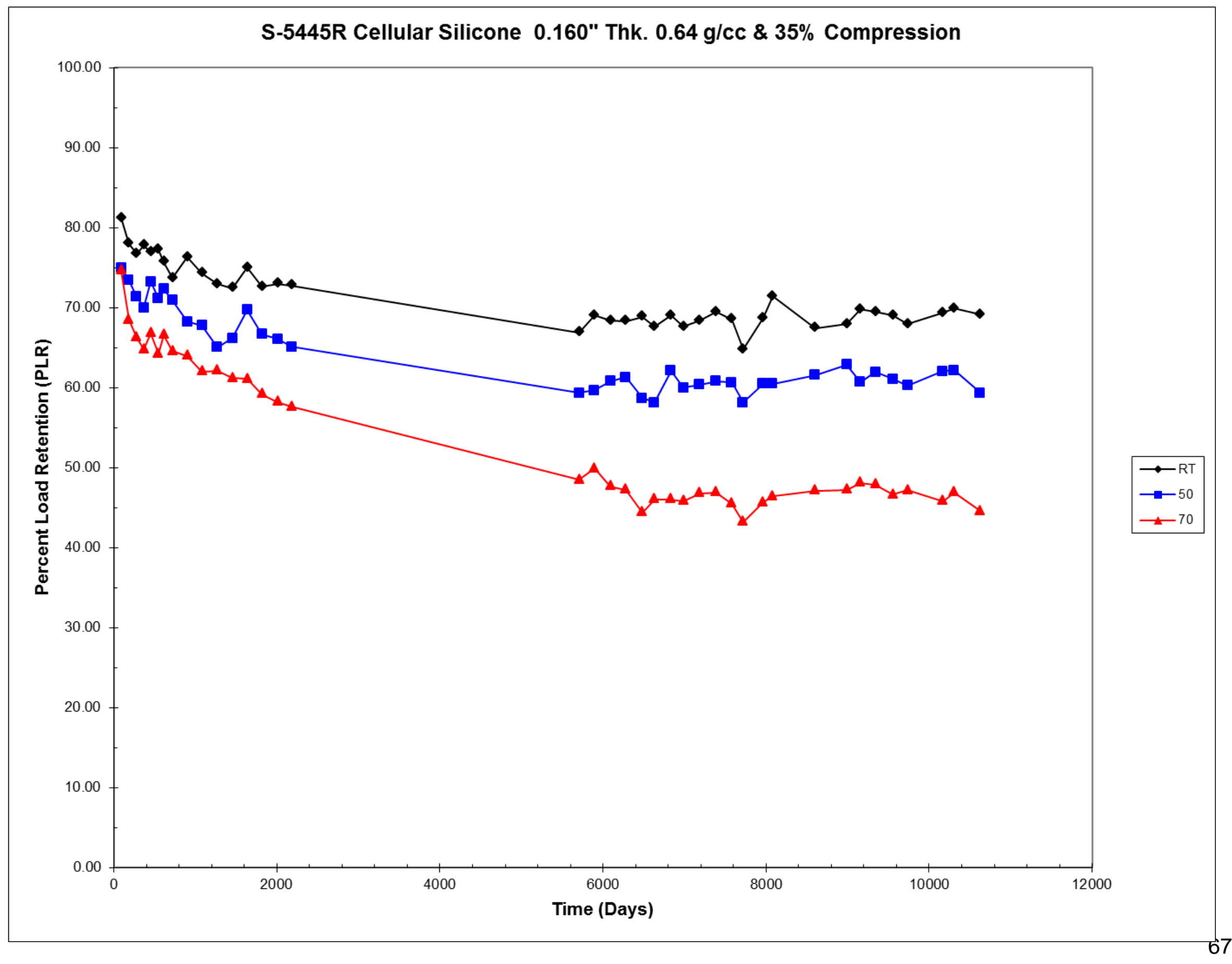




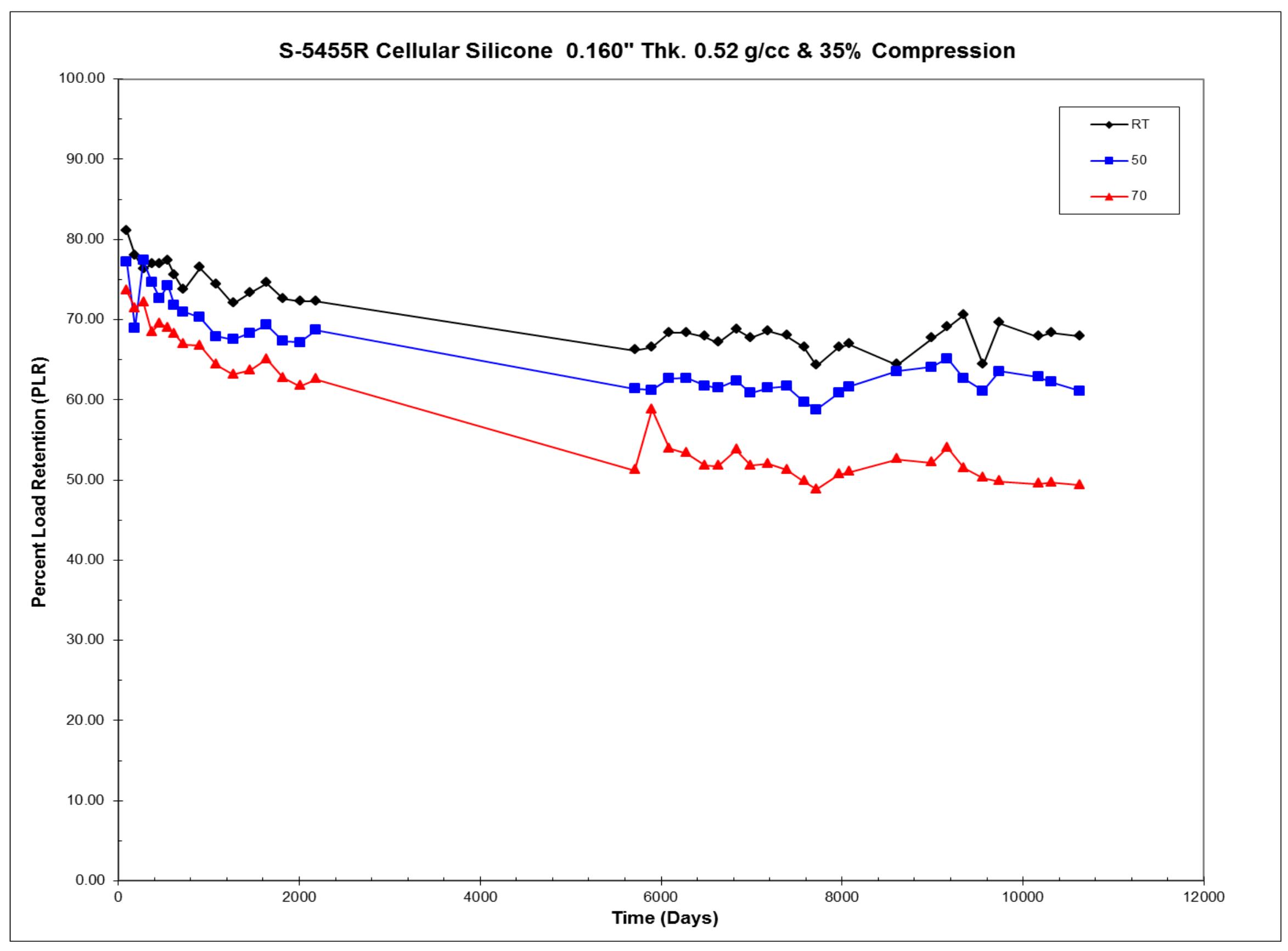




\section{Appendix F \\ S-5445 Compounded With "Fine Urea" Charts}




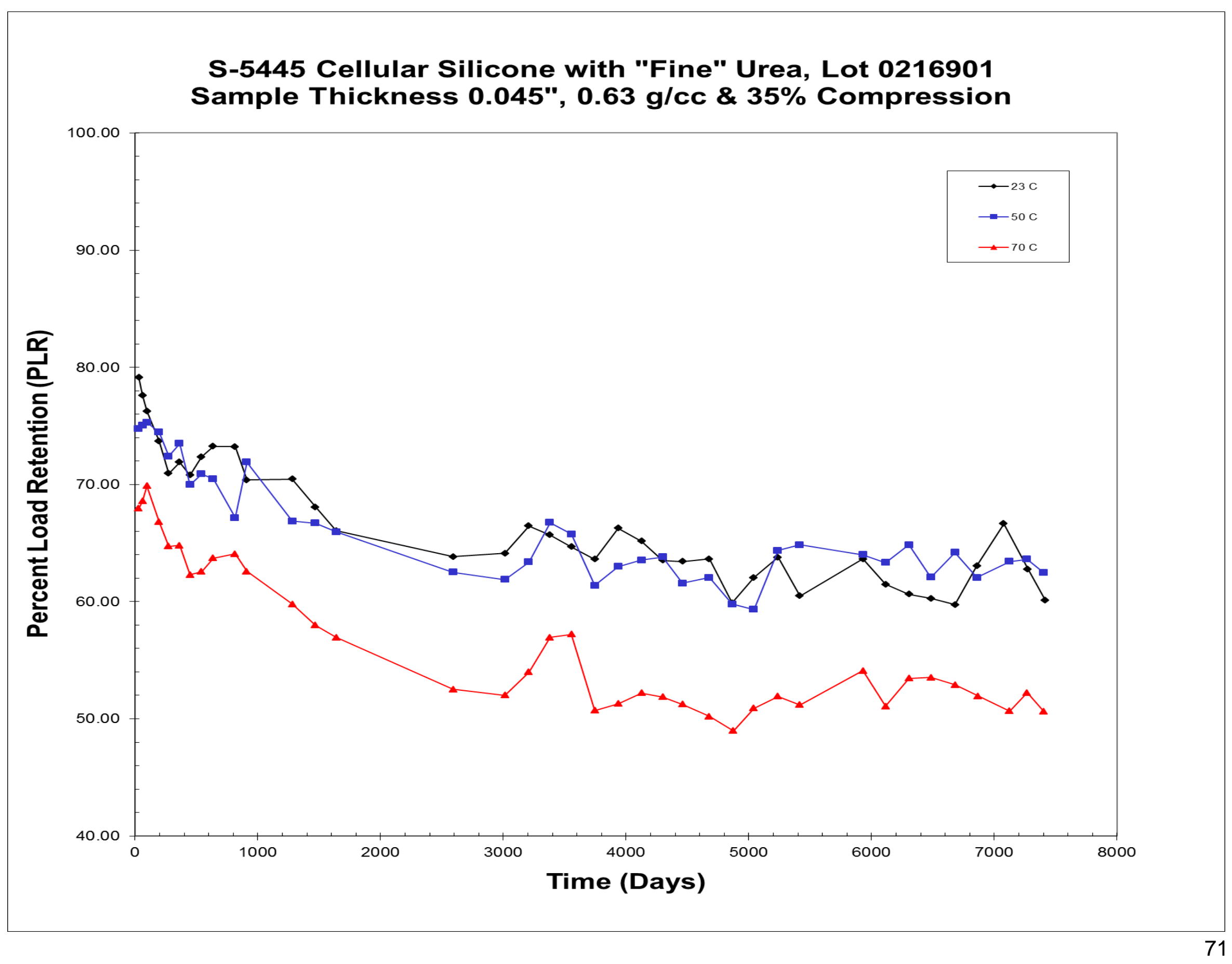




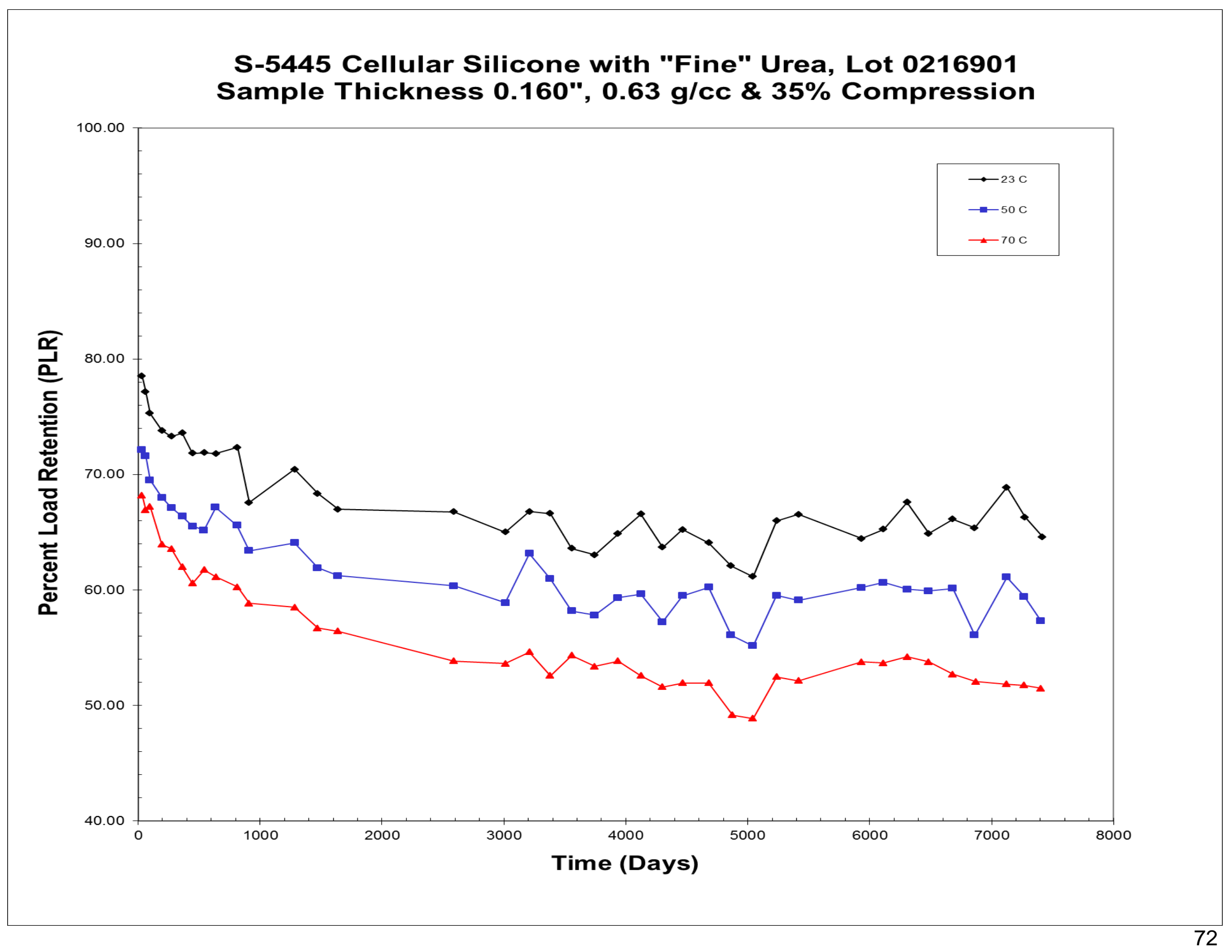


Appendix G

M-9760 Charts 


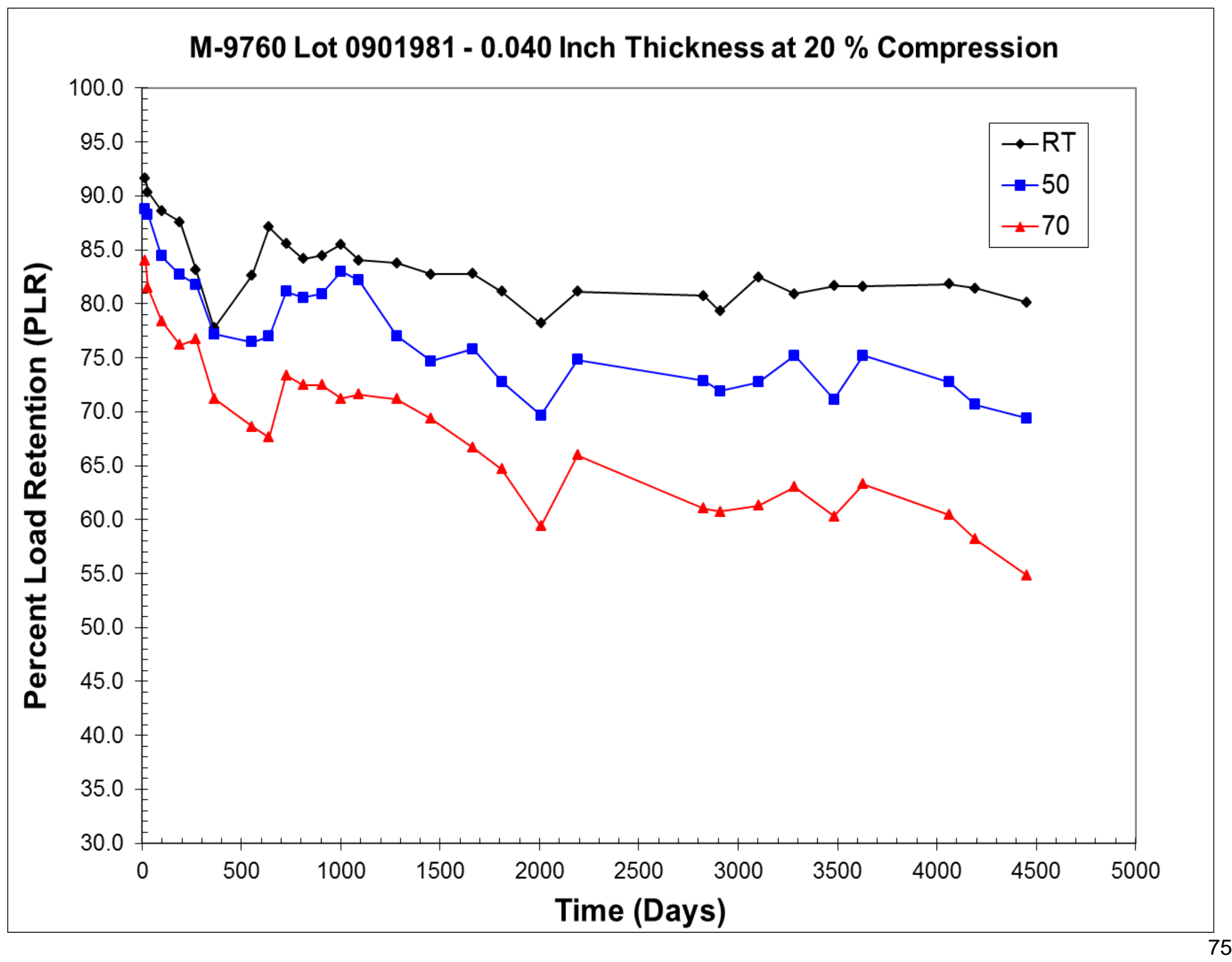




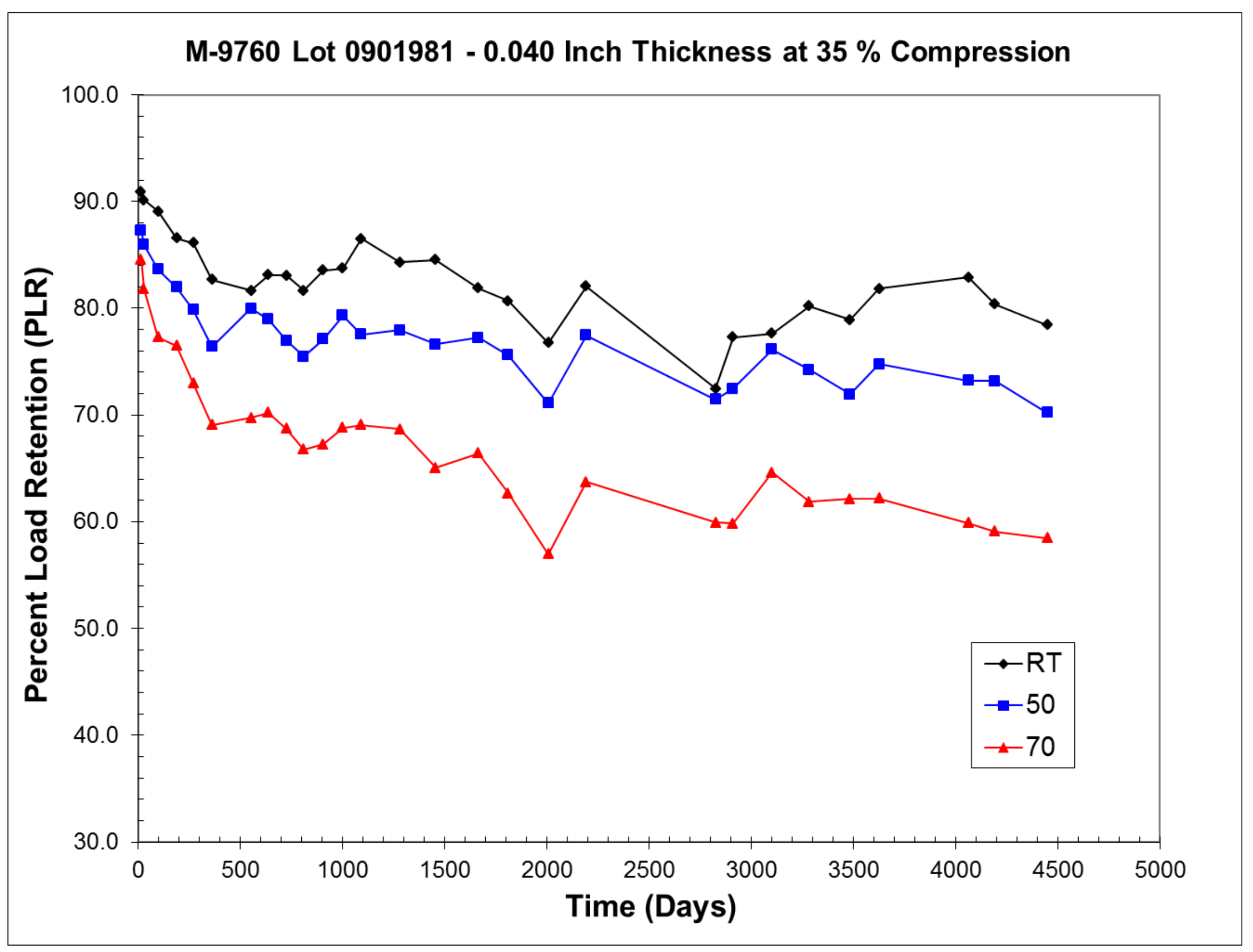




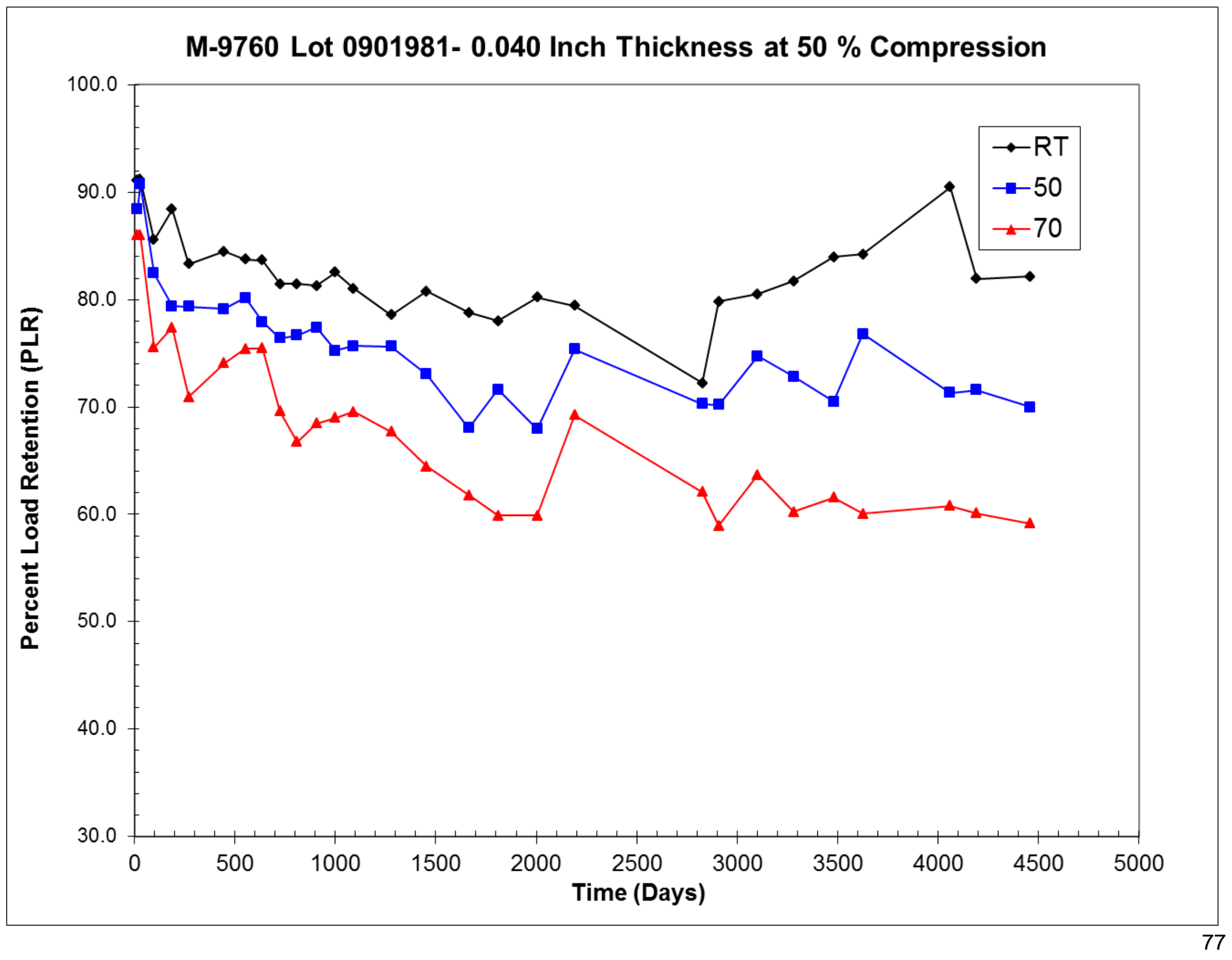




\section{Appendix H}

\section{M-9763 Charts}




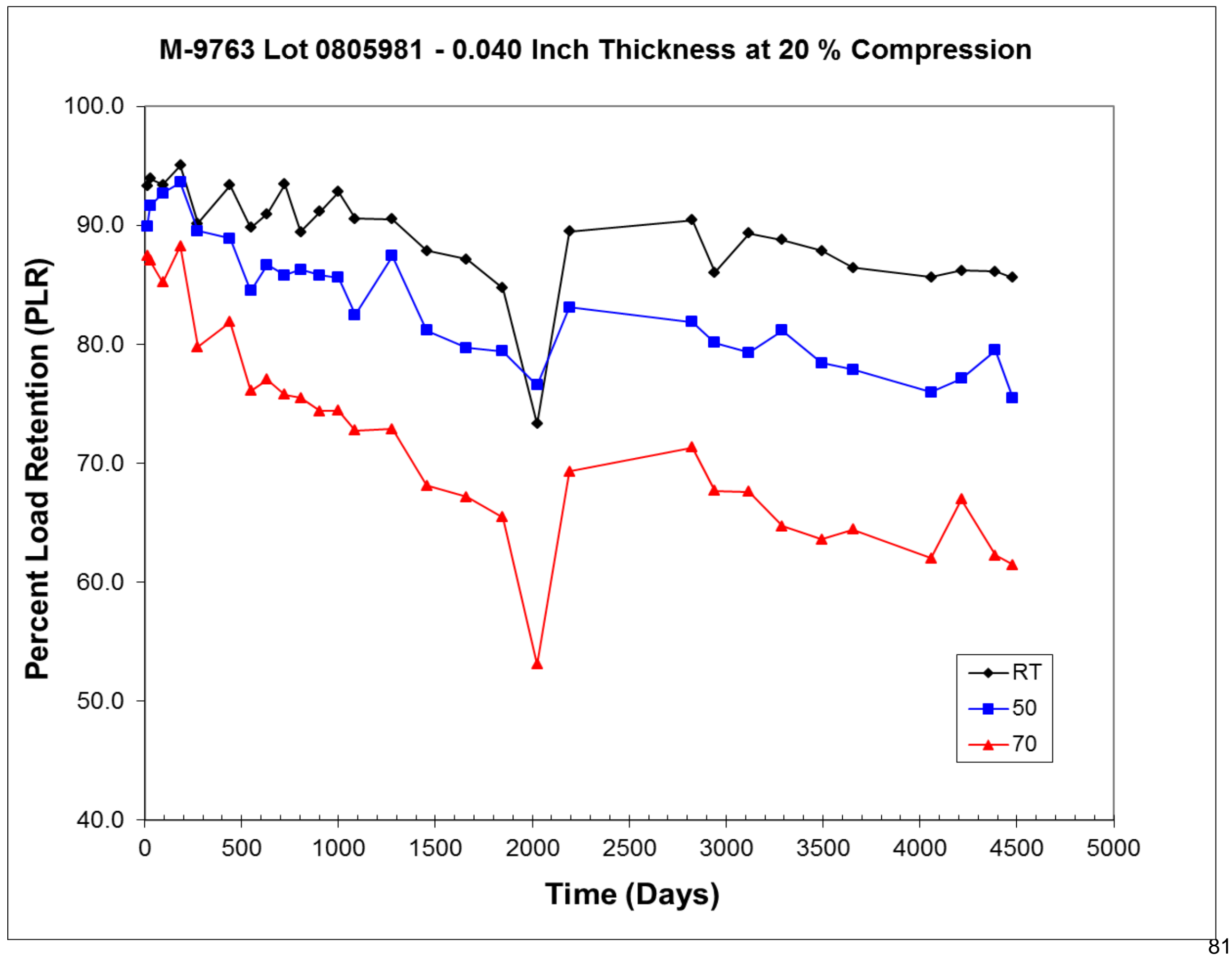




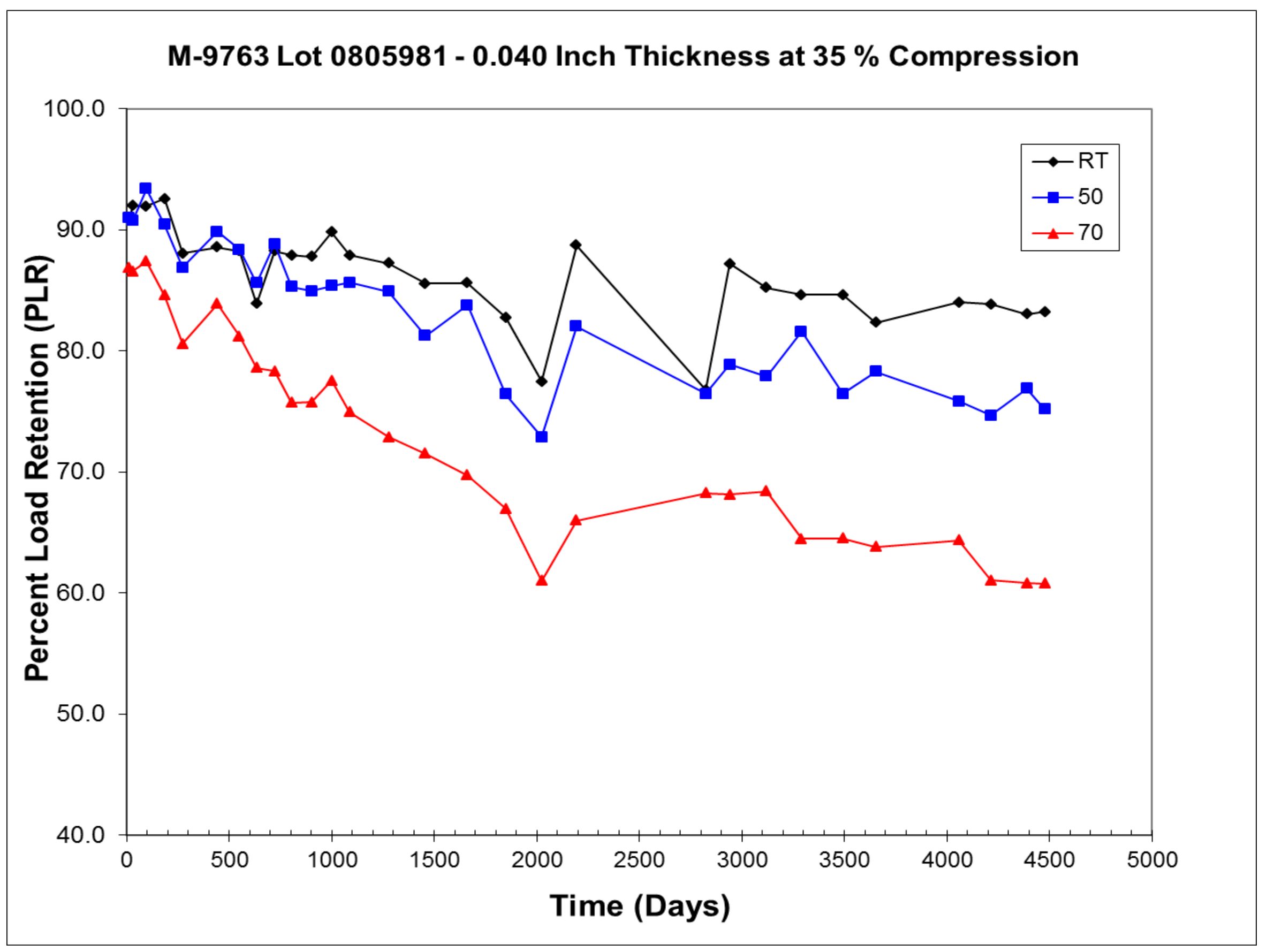




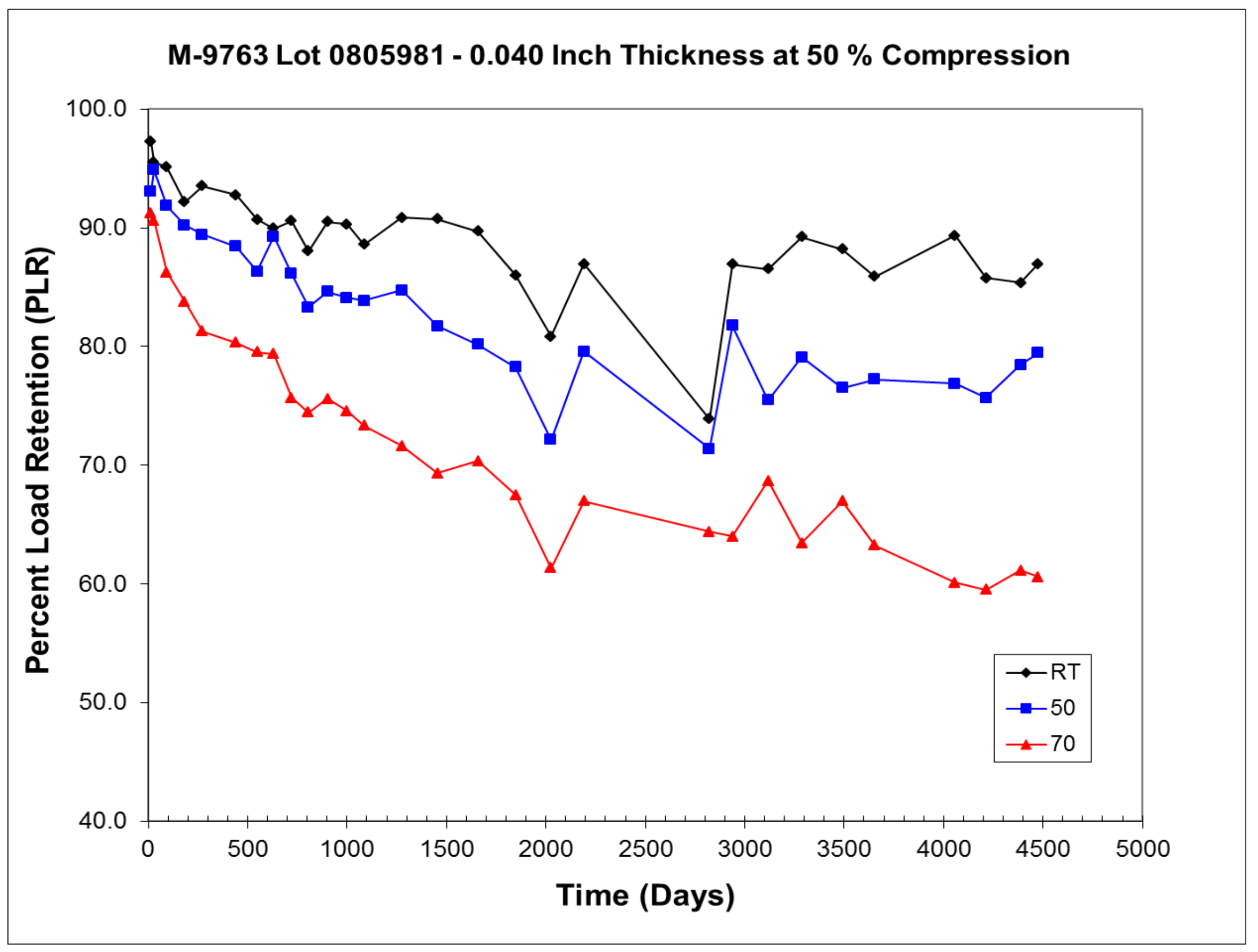




\section{Appendix I}

\section{M-9763 Standard Life Test Charts}




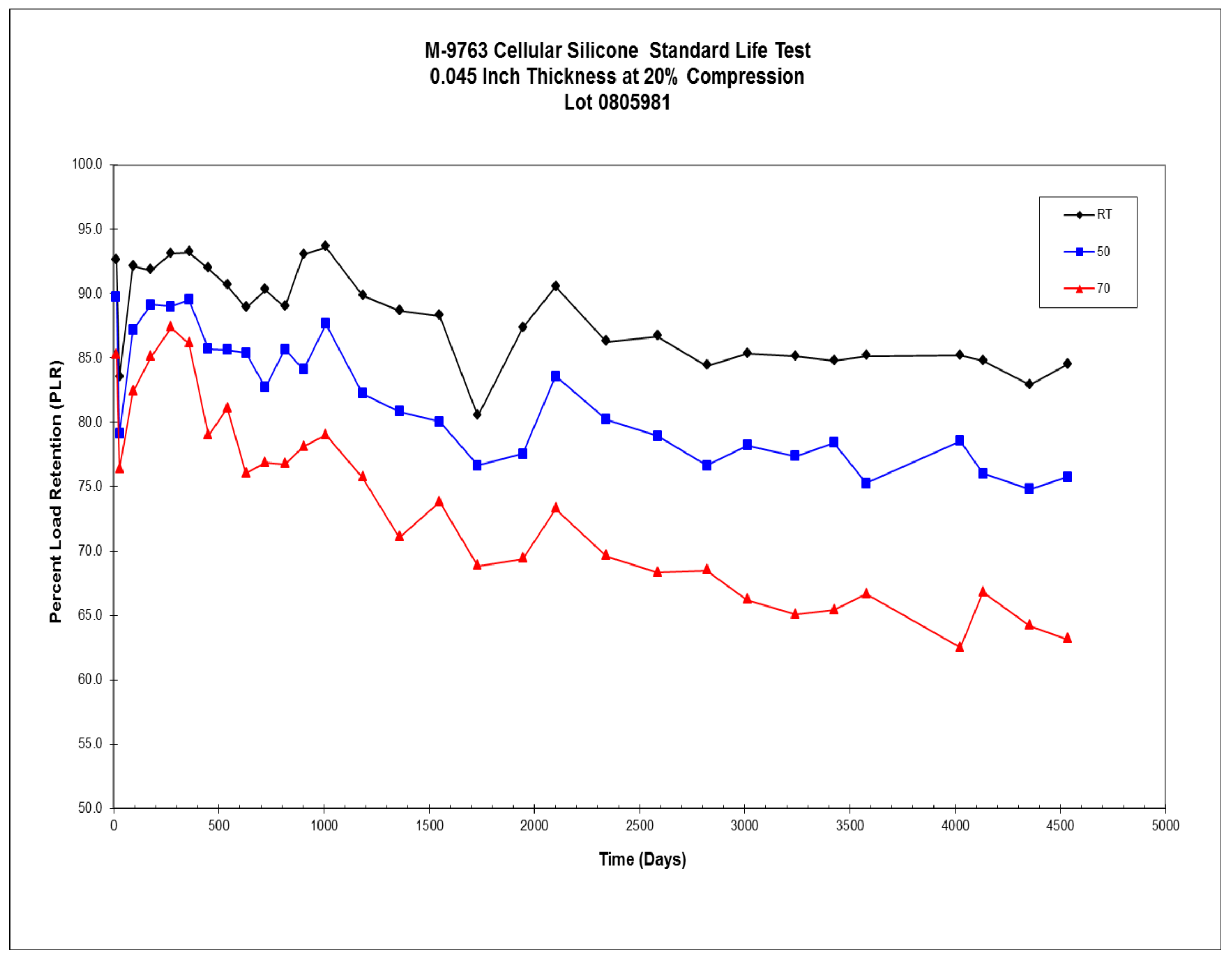




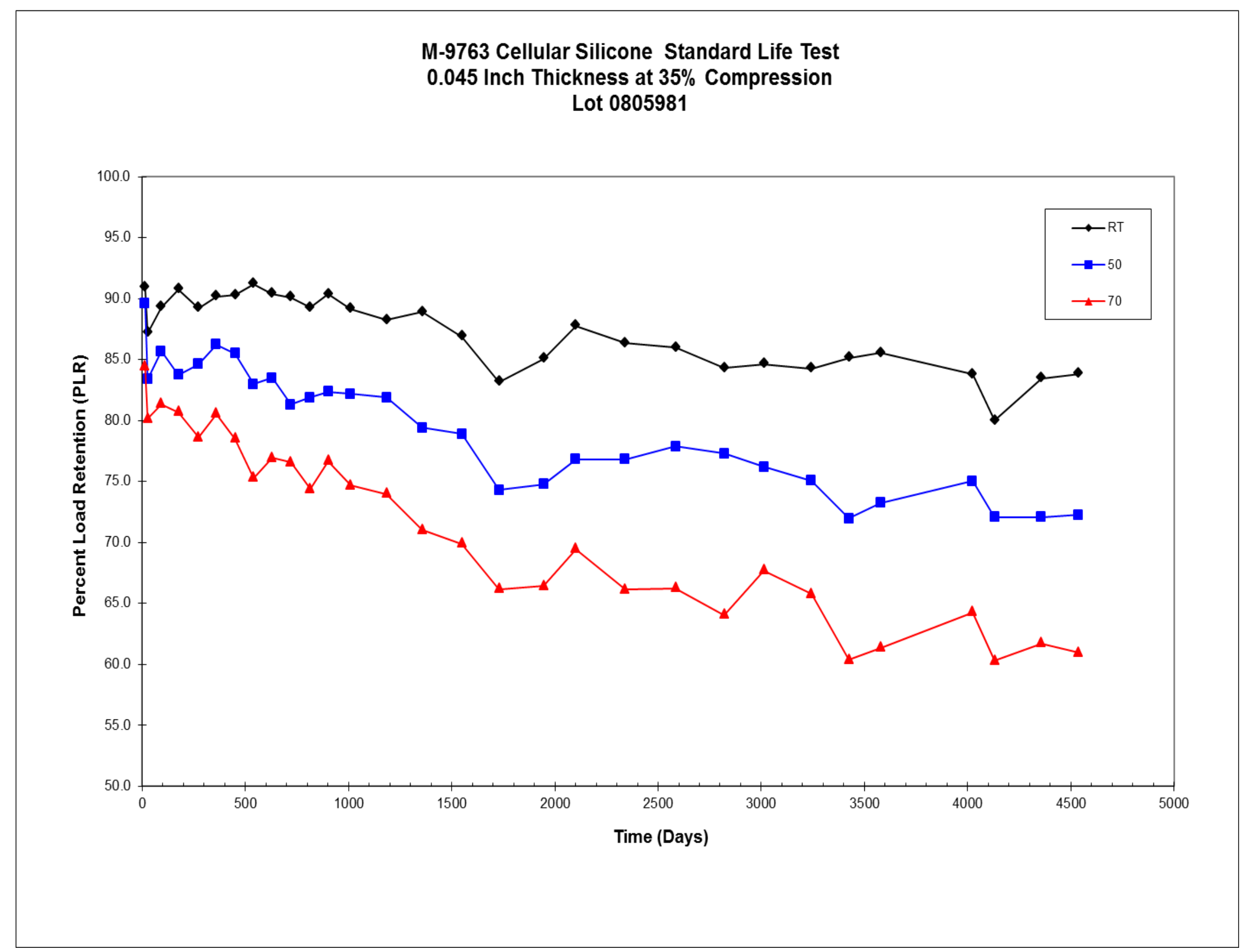




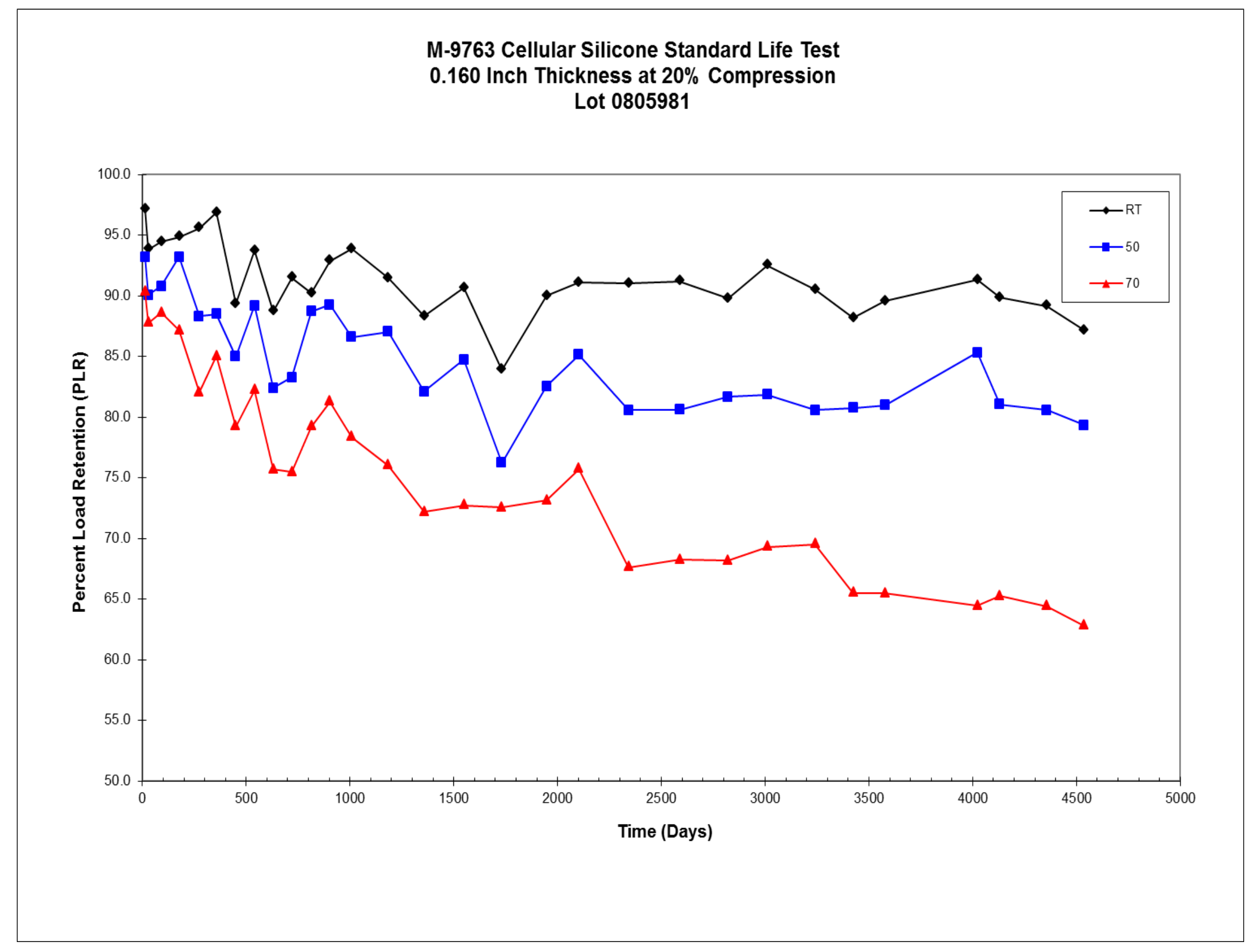




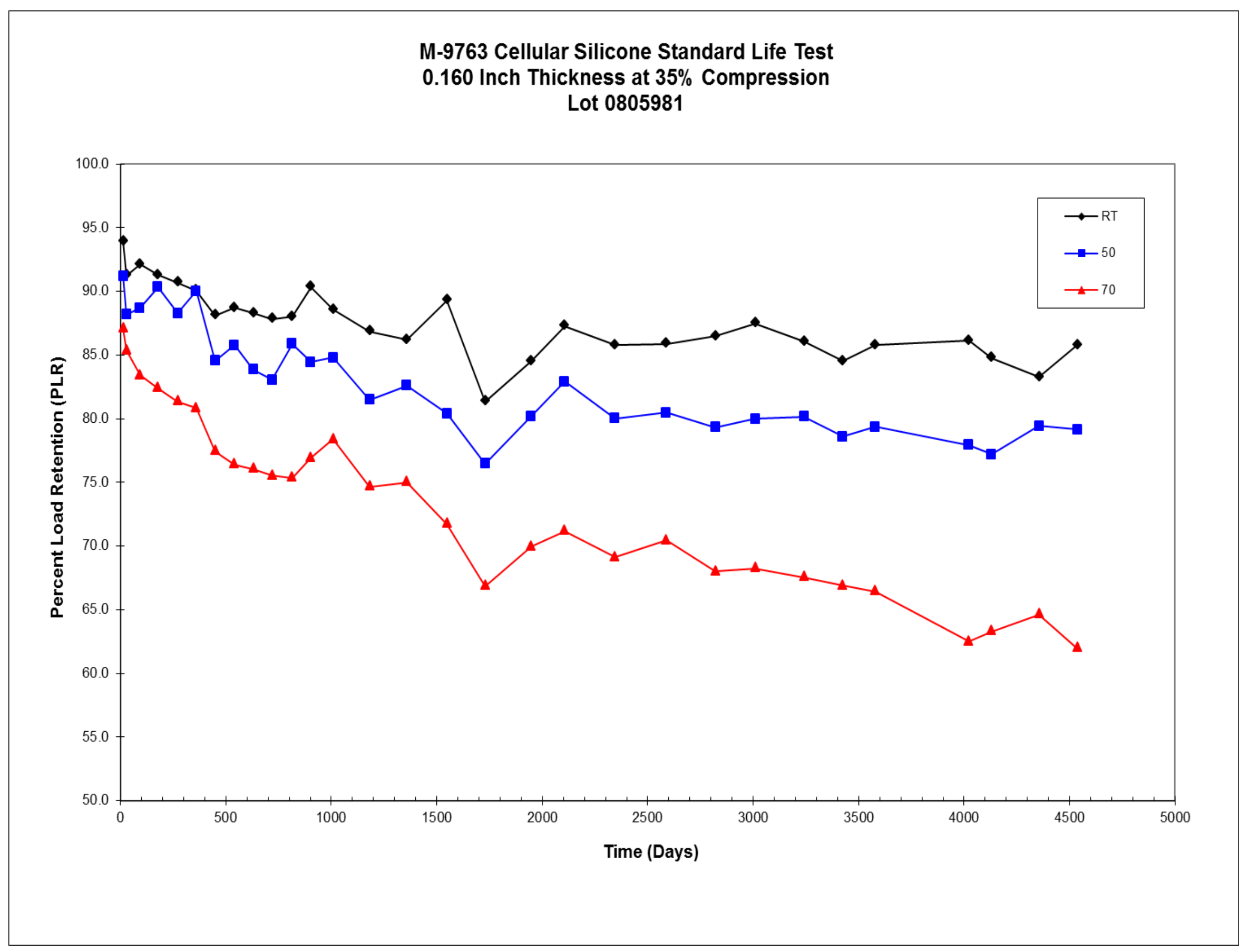

